\title{
The Development of Novel Aptamer Sensor Platforms for use in Biosensing
}

\author{
by
}

\author{
Tariq J. Francis
}

BSc. (Hon), Carleton University, 2009

A thesis submitted to the Faculty of Graduate and Postdoctoral Affairs in partial fulfillment of the requirements for the degree of

Master of Science

in

Chemistry

Carleton University

Ottawa, Ontario

(C) 2011, Tariq J. Francis 
Library and Archives

Canada

Published Heritage

Branch

395 Wellington Street

Ottawa ON K1A ON4

Canada
Bibliothèque et

Archives Canada

Direction du

Patrimoine de l'édition

395 , rue Wellington

Ottawa ON K1A ON4

Canada
Your file Votre référence

ISBN: 978-0-494-83198-4

Our file Notre référence

ISBN: $978-0-494-83198-4$

\section{NOTICE:}

The author has granted a nonexclusive license allowing Library and Archives Canada to reproduce, publish, archive, preserve, conserve, communicate to the public by telecommunication or on the Internet, loan, distribute and sell theses worldwide, for commercial or noncommercial purposes, in microform, paper, electronic and/or any other formats.

The author retains copyright ownership and moral rights in this thesis. Neither the thesis nor substantial extracts from it may be printed or otherwise reproduced without the author's permission.

\section{AVIS:}

L'auteur a accordé une licence non exclusive permettant à la Bibliothèque et Archives Canada de reproduire, publier, archiver, sauvegarder, conserver, transmettre au public par télécommunication ou par l'Internet, prêter, distribuer et vendre des thèses partout dans le monde, à des fins commerciales ou autres, sur support microforme, papier, électronique et/ou autres formats.

L'auteur conserve la propriété du droit d'auteur et des droits moraux qui protège cette thèse. $\mathrm{Ni}$ la thèse ni des extraits substantiels de celle-ci ne doivent être imprimés ou autrement reproduits sans son autorisation.
In compliance with the Canadian Privacy Act some supporting forms may have been removed from this thesis.

While these forms may be included in the document page count, their removal does not represent any loss of content from the thesis.
Conformément à la loi canadienne sur la protection de la vie privée, quelques formulaires secondaires ont èté enlevés de cette thèse.

Bien que ces formulaires aient inclus dans la pagination, il n'y aura aucun contenu manquant. 


\begin{abstract}
Aptamers are short, synthetic oligonucleotides that are able to bind specifically and with high affinity to a variety of targets. This property can be exploited for the development of sensor platforms. This work will describe the current results in the development of two such sensor platforms. These platforms are based upon the immobilization of aptamers on a gold surface via the gold-thiol interaction. The first of these platforms is an electrochemical aptasensor system. These results will include the development of an inorganic complex and its conjugation to single-stranded DNA (ssDNA). The immobilization of the modified ssDNA onto a gold electrode surface and its electrochemical characterization will also be discussed. The second platform that will be discussed is an optical sensor platform which utilizes changes in surface plasmon resonance as a means of detection. These results will include immobilization of the ssDNA onto the gold-coated fibre, as well as detection results from the target molecule. Together, these platforms will demonstrate progress toward the design of point-of-care diagnostics.
\end{abstract}




\section{Acknowledgments}

First and foremost I have to thank my parents for their continued support. Without them I would not be where I am today. I also want to thank Bruce Allen for his continued help and support in all avenues of my life. Azim Keshavjee has been a constant source of wisdom, guidance and music for the past 11 years and his friendship over the course of this degree has been nothing short of amazing.

A big thank you to Maria DeRosa for her support throughout my degree - she was an incredible source of information and support. It was and is greatly appreciated. Thank you too Jeff Smith and Matt Huebsch for their help with all things Mass Spectrometry. I learned a massive amount of information in a short space of time largely thanks to their input of time and patience. Going with the theme of thanking people named Jeff I want to give a huge thank you to Jeff Manthorpe and Monica Gill who, together, helped me save my cobalt project from an early demise. Their organic expertise proved invaluable and their time and patience was greatly appreciated. I would finally like to thank our collaborators on the Fibre project, Jacques Albert and Yanina Shevchenko. It was a pleasure working with you both. I'd also like to thank Dave Blair who has been a good friend and coworker for years now. His experience and input into our various projects has been invaluable. Finally, I'd like to give a big thank you to Bob Burk for inspiration and support throughout my undergraduate and graduate careers.

I'd also like to thank my second family in the DeRosa lab for their friendship both inside and outside of the lab - and amazing baking abilities. I'd mention everyone's 
names but this list of acknowledgements would be a thesis in itself. Mike B. and Amanda G. get special mentions - yourgh. I feel we should get some sort of a "I survived room 330" bumper sticker. Nabeel and Hanna are great friends who have been there for me throughout this degree - their support and friendship was and will always be greatly appreciated. Thank you to Jes and the rest of the Ellacott family for being supportive and encouraging regardless of the situation. A list of acknowledgements isn't complete without a thank you to Manchester United.

Finally, I'd like to dedicate this thesis to the memory of my grandfather, John W. Patterson. 


\section{Table of Contents}

The Development of Novel Aptamer Sensor Platforms ........................................................ i

Abstract ................................................................................................................................. ii

Acknowledgments ............................................................................................................................ iii

Table of Contents ................................................................................................................................

List of Figures ........................................................................................................................... vii

List of Tables .......................................................................................................................... xiii

List of Abbreviations ............................................................................................................ xiv

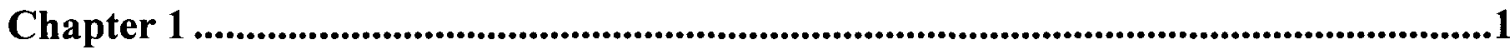

1.1 Aptamers

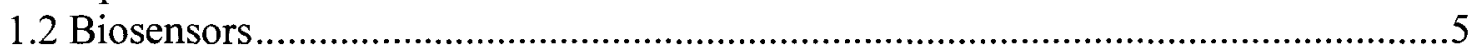

1.3 Electrochemical Aptamer Based Biosensors ..........................................................

1.4 Aptamer-Based Surface Plasmon Resonance Biosensors .......................................13

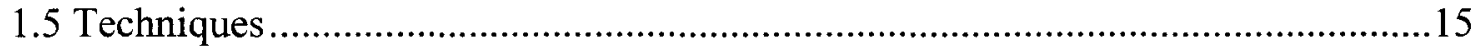

1.5.1 Oligonucleotide Synthesis .......................................................................

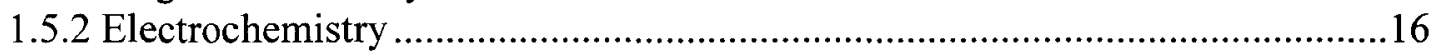

1.5.2.1 The Three Electrode System.............................................................

1.5.2.2 Cyclic Voltammetry ...................................................................................19

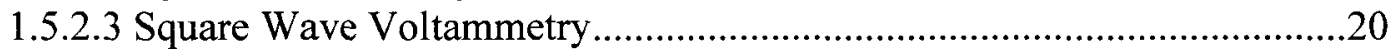

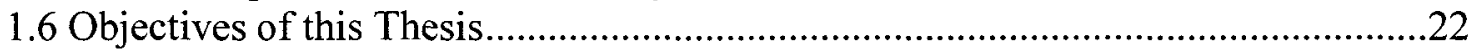

Chapter 2 ..........................................................................................................................23

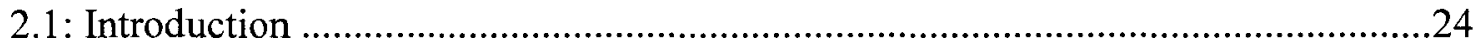

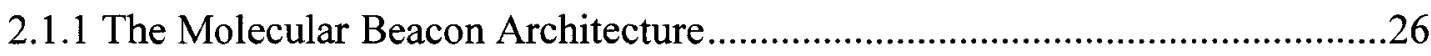

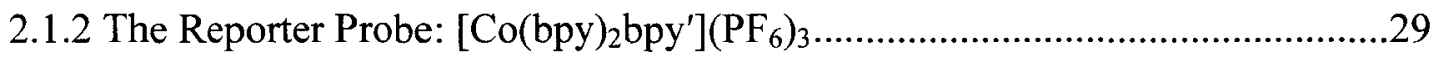

2.2 Experimental ..................................................................................................

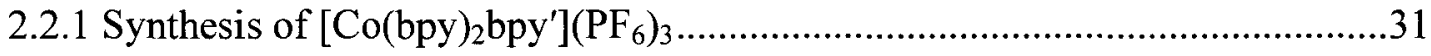

2.2.2 Oligonucleotide Synthesis .................................................................................

2.2.3 Conjugation of bpy' to DNA via EDC-NHS Chemistry, and purification ........34

2.2.3.1 Conjugation of bpy' to DNA using EDC-NHS Chemistry .........................34

2.2.3.2 Ethanol Precipitation ...................................................................................36

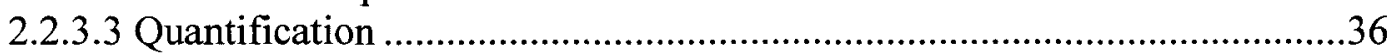

2.2.3.4 Purification by polyacrylamide gel electrophoresis (PAGE) ......................36

2.2.4 Conjugation of bpy' to DNA via TSTU-DIPEALDMAP Chemistry, and

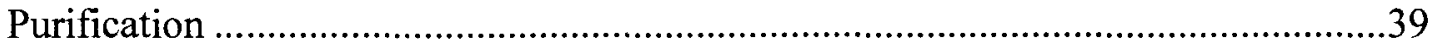

2.2.4.1 First attempt at DNA- bpy' conjugation: TSTUIDMAP.............................39

2.2.4.2 Second attempt at DNA-bpy' conjugation: TSTU\DIPEA ……...................41

2.2.4.3 High Performance Liquid Chromatography (HPLC) .................................42

2.2.5 Conjugation of $\left[\mathrm{Co}(\mathrm{bpy})_{2} \mathrm{bpy}^{\prime}\right]\left(\mathrm{PF}_{6}\right)_{3}$ to DNA via TSTU-DIPEA Chemistry...43

2.2.6 Coordination of $\left[\mathrm{Co}(\mathrm{bpy})_{2}\right]^{3+}$ to bpy' modified DNA.......................................45

2.2.7 Electrochemistry Procedures ..............................................................................46

2.2.7.1 Gold Electrode Cleaning Procedure ……..............................................46

2.2.7.2 Deposition procedure ................................................................................48

2.2.7.3 Electrochemistry of the modified electrodes ..............................................49

2.3 Results and Discussion .....................................................................................51

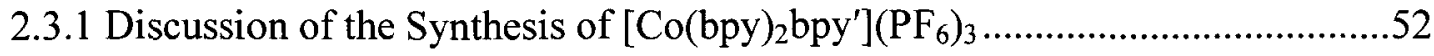


2.3.2 Discussion of conjugation of bpy' to DNA via EDC-NHS chemistry................55

2.3.3 Discussion of conjugation of bpy' to DNA via TSTU-DMAP chemistry .........64

2.3.4 Discussion of conjugation of $\mathrm{bpy}^{\prime}$ and $\left[\mathrm{Co}(\mathrm{bpy})_{2} \mathrm{bpy}^{\prime}\right]\left(\mathrm{PF}_{6}\right)_{3}$ to DNA via

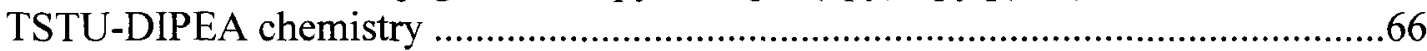

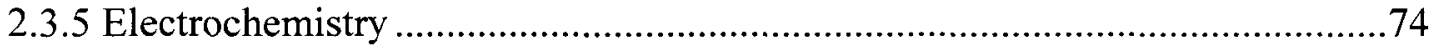

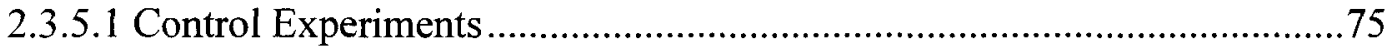

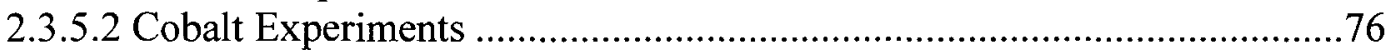

2.3.5.3 Validation of the results: Surface coverage analysis ..................................

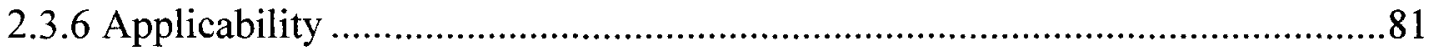

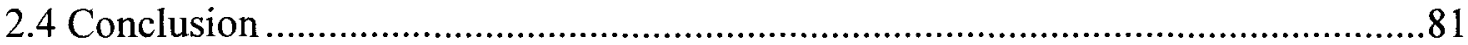

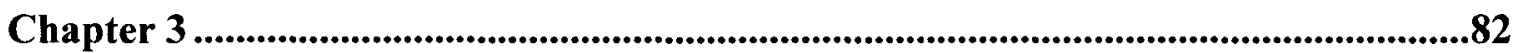

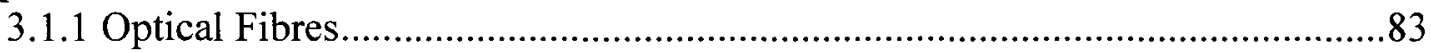

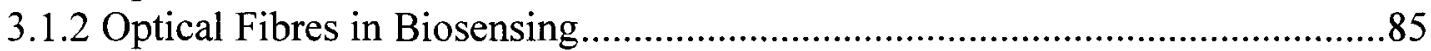

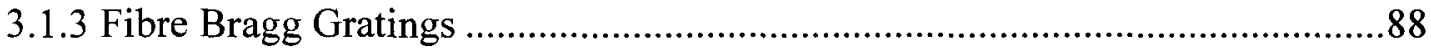

3.1.4 Sensor Platform and Project Goals ...............................................................99

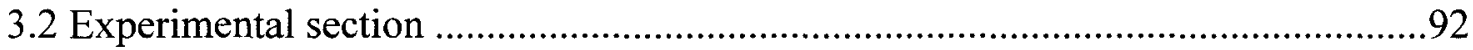

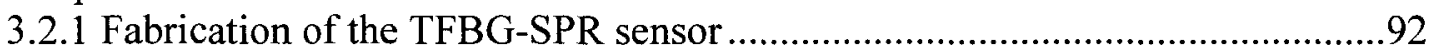

3.2.2 Experimental setup, optical configuration ......................................................93

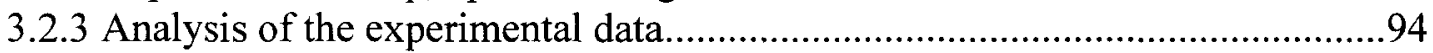

3.2.4 Aptamer sequences, buffers, serum, thrombin protein and water ......................95

3.2.5 Immobilization of the thrombin aptamer ......................................................96

3.2.6 Binding of the thrombin protein to the thrombin aptamer.................................97

3.2.7 Confocal microscope imaging ...................................................................97

3.2.8 Atomic Force Microscope (AFM) Imaging....................................................98

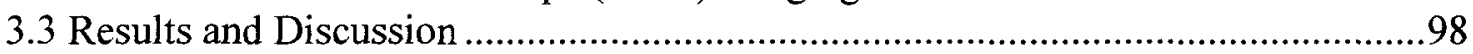

3.3.1 Monitoring of thrombin aptamer attachment to the surface .............................98

3.3.2 Confocal Microscopy: Verification of aptamer immobilization on the surface

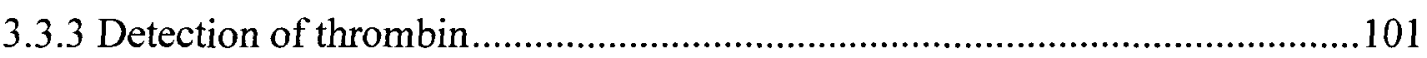

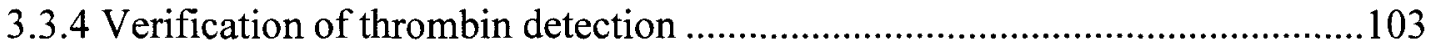

3.3.5 Limit of Detection, Discussion of Errors and Signal to Noise ratio ................104

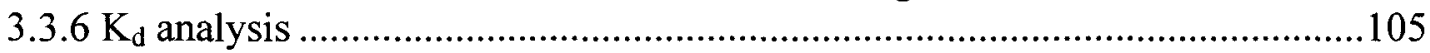

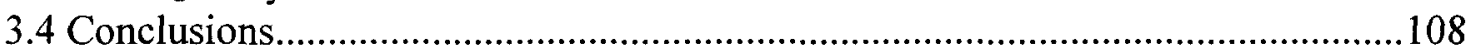

Appendix 1.0: DNA analysis via ESI-Mass Spectrometry ............................................109

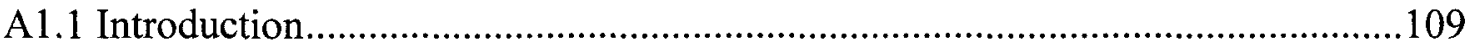

A1.1.1 Brief overview of the principles of ESI-MS ...........................................109

A1.1.2 Purpose of this investigation.................................................................110

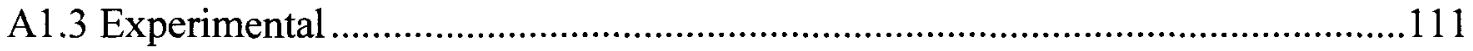

A1.3.1 Sample Preparation .............................................................................111

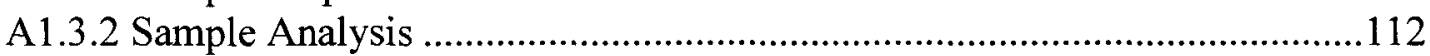

A1.4 Results and Discussion of Test Samples...........................................................113

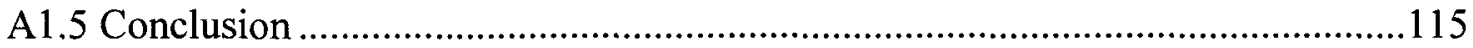

Appendix 2.0.............................................................................................................116

Appendix 3.0........................................................................................................................119

A3.1 Additional Dissociation constant data ..............................................................119

A3.2 Information about fitting model used to calculate $K_{d}$ constant.............................120 


\section{List of Figures}

Figure 1.1: Illustration of the SELEX process: A library of random oligonucleotides is mixed with a target; the binding sequences are separated from the nonbinders; the binders are separated from the target and amplified; the process is repeated [adapted from $\left.{ }^{6}\right]$....... 3

Figure 1.2: Different types of architectures for electrochemical aptamer biosensors. a) and b) show detection of cocaine and thrombin respectively; c) and d) show similar interactions with protein and small molecules in both single and double stranded cases.[adapted from ${ }^{33}$ ]

Figure 1.3: A schematic of a "signal off" electrochemical based aptasensor. Upon target binding the pathway for the redox probe becomes increasingly obstructed, thus limited electron transfer and thus reducing the signal.[adapted from ${ }^{36}$ ].....

Figure 1.4: Schematic of a signal on electrochemical based aptasensor. Upon target recognition the electrochemical probe is free to migrate to the surface of the electrode and thus generate a signal [Reprinted with permission from Xiao, Y.; Piorek, B. D.; Plaxco, K. W.; Heeger, A. J. A Reagentless Signal-On Architecture for Electronic, Aptamer-Based Sensors via Target-Induced Strand Displacement. J. Am. Chem. Soc. 2005, 127, 1799017991. Copyright 2005 American Chemical Society] $]^{38}$

Figure 1.5: A biosensor using the Kretschmann configuration: Total internal reflection of incident light occurs resulting in the generation of surface plasmons; the frequency of which can be used to detect an analyte passing over a modified gold surface.[adapted from ${ }^{41}$.

Figure 1.6: An example of a 3 electrode system illustrating the working electrode, auxiliary electrode and reference electrode [adapted from ${ }^{48}$ ]

Figure 1.7: Example of a cyclic voltammogram for the process $O+n e^{-} \rightleftharpoons R$ [adapted from $\left.{ }^{50}\right]$.

Figure 1.8: Example of a square wave voltammogram. "Forward" and "Reverse" are the response to the forward and backward components of the square wave.[adapted from ${ }^{51}$ ]

Figure 1.9: The driving signal behind a square wave voltammogram - the bold lines represent the potential waveform applied to the working electrode. The light lines indicate the 'staircase' onto which the square wave has been superimposed. Each cycle has a forward current sample (indicated by the solid dot) and a reverse current sample (indicated by the shaded dot). [adapted from ${ }^{46}$ ]

Figure 2.1: Structure of the reporter probe, $\left[\mathrm{Co}(\mathrm{bpy})_{2} \mathrm{bpy}^{\prime}\right]^{3+}$, including the modified bipyridine to allow for attachment to DNA. 
Figure 2.2: Molecular Beacon Architecture, the red dot represents the transducer; the red line represents the aptamer attached to the gold electrode, which is represented by the yellow bar.

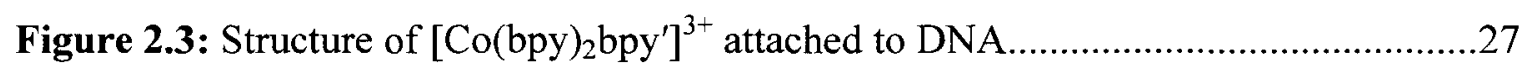

Figure 2.4: Gold-Thiol interaction - although ionic in appearance it is considered a type of covalent bond ${ }^{61}$ 27

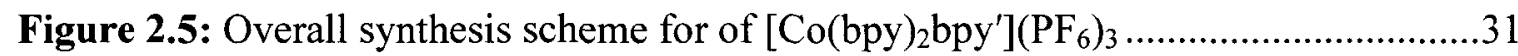

Figure 2.6: Overall Synthesis scheme for the conjugation of and 4-(3-carboxypropyl)-4'methyl-2,2'-bipyridine to DNA using EDC/NHS

Figure 2.7: Overall Synthesis scheme for the conjugation of and 4-(3-carboxypropyl)-4'methyl-2,2'-bipyridine to DNA using TSTU-DMAP chemistry

Figure 2.8: Overall Synthesis scheme for the conjugation of and 4-(3-carboxypropyl)-4'methyl-2,2'-bipyridine to DNA using TSTU-DIPEA chemistry....

Figure 2.9: Overall Synthesis scheme for the conjugation of and $\left[\mathrm{Co}(\mathrm{bpy})_{2} \mathrm{bpy}^{\prime}\right]\left(\mathrm{PF}_{6}\right)_{3}$ to DNA using TSTU-DIPEA chemistry

Figure 2.10: Overall Synthesis scheme for the conjugation of $\left[\mathrm{Co}(\mathrm{bpy})_{2} \mathrm{Cl}_{2}\right] \mathrm{Cl}$ to DNAbpy' $^{\prime}$

Figure 2.11: Cyclic Voltammogram of a clean gold electrode; conducted using the settings described in Table 2

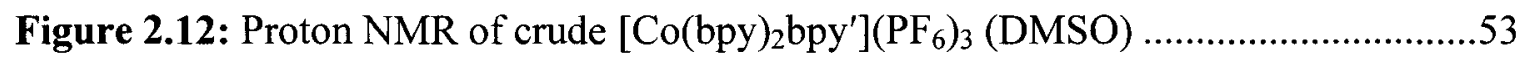

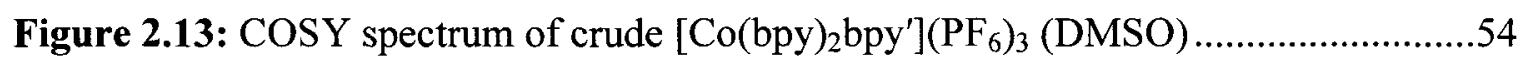

Figure 2.14: Summary of the peak assignment in bpy' ........................................55

Figure 2.15: PAGE image of DNA-bpy'. Each lane is an identical sample of EDC-NHS based DNA-bpy' coupling.

Figure 2.16: Deconvoluted electrospray mass spectrum of a) Band 1 and b) Band 2......57

Figure 2.16: Deconvoluted electrospray mass spectrum of c) Band 3 and d) Band 4.....58

Figure 2.17: UV Spectra of DNA recovered from gel bands 3 and 4 and reacted with $\left[\mathrm{Co}(\text { bpy })_{2} \mathrm{Cl}_{2}\right] \mathrm{Cl}$ : concentrated band 4 DNA (black trace), concentrated band 3 DNA (dark blue trace), diluted band 4 DNA (light blue trace) and diluted band 3 DNA (red trace) 
Figure 2.18: ESI MS of band 3 after reaction with $\left[\mathrm{Co}(\mathrm{bpy})_{2} \mathrm{Cl}_{2}\right] \mathrm{Cl}$

Figure 2.19: Mechanism of the Lossen Rearrangement observed in band 1. Figure adapted from ${ }^{75}$. The nucleophilic amino DNA attacks the carbonyl carbon of the NHS instead of the carbonyl carbon of the desired ligand.

Figure 2.20: Scheme adapted from Posthumus et al. ${ }^{76}$ illustrating the formation of the Oacyl urea and the shift to the $\mathrm{N}$-acyl form.

Figure 2.21: PAGE gel of the reaction product of the TSTU-DMAP conjugation attempt. Each lane consists of identical samples (left) and ESI-MS of the DNA extracted from the gel (right)

Figure 2.22: Image of the results of PAGE of the TSTU-DIPEA coupled reaction. Each lane consists of identical samples .66

Figure 2.23: a) ESI-MS of gel band 1 b) ESI-MS of gel band 2 and c) ESI-MS of crude reaction product.

Figure 2.24: ESI-MS of sequence 2 DNA-Cobalt conjugate; inset shows the DNA-cobalt conjugate at $5353 \mathrm{Da}$

Figure 2.25: HPLC chromatogram of Sequence 3 DNA-bpy' conjugate; left is the entire chromatogram and right is a zoom in of the peaks of interest 70

Figure 2.26: ESI-MS of HPLC purified DNA-bpy' conjugate 71

Figure 2.27: ESI-MS spectrum of the DNA-Cobalt conjugate from synthesis 2.2.5. The desired peak was observed at $5358 \mathrm{Da}$.

Figure 2.28: Square wave and cyclic voltammograms of a bare gold electrode (blue traces) and mercaptohexanol (red trace)

Figure 2.29: Comparison of gold electrodes with immobilized DNA-bpy' (red) and DNA-NH $\mathrm{N}_{2}$ (blue).

Figure 2.30: Cyclic voltammograms of DNA-bpy' (red) and $\mathrm{DNA}^{-\mathrm{NH}_{2}}$ (blue) containing electrodes after 1 hour of $\left[\mathrm{Co}(\mathrm{bpy})_{2} \mathrm{Cl}_{2}\right] \mathrm{Cl}$ deposition . .76

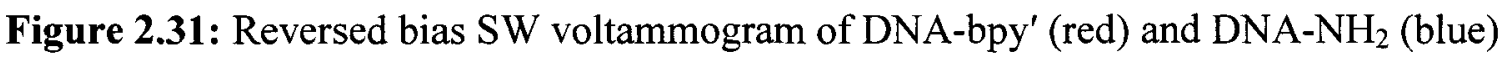
containing electrodes after 1 hour of $\left[\mathrm{Co}(\mathrm{bpy})_{2} \mathrm{Cl}_{2}\right] \mathrm{Cl}$ deposition

Figure 2.32: CV (left) and SW (right) of DNA-cobalt conjugate .78

Figure 2.33: CV's of Ruthenium Hexaammine using a DNA- $\mathrm{NH}_{2}$ modified electrode (left) and DNA-bpy'-Cobalt electrode (right)..... 
Figure 3.1: Cross sectional representation of an optical fibre

Figure 3.2: Excitation of surface plasma waves using optical waveguides; a) excitation of the surface plasma wave at the boundary of a metallic thin film and a dielectric layer, $b$ ) excitation of a surface plasma wave on a metallic thin film through a dielectric buffer layer [adapted from ${ }^{80}$ ]

Figure 3.3: Example of a Fibre Bragg grating [adapted from ${ }^{85}$ ] …................................8

Figure 3.4: Example of a Tilted Fibre Bragg Grating [adapted from ${ }^{85}$ ]

Figure 3.5: Schematic diagram of the tilted fibre Bragg grating sensor system. In this illustration the blue represents the target molecules (thrombin), the red represents the molecular recognition elements (15-mer DNA thrombin aptamer) on a gold coated fibre. Reprinted with permission from Shevchenko, Y.; Francis, T. J.; Blair, D. A. D.; Walsh, R.; DeRosa, M. C.; Albert, J. In Situ Biosensing with a Surface Plasmon Resonance Fiber Grating Aptasensor. Anal. Chem. 2011, ASAP. Copyright 2011 American Chemical Society

Figure 3.6: Schematic diagram of the sensor setup. Reprinted with permission from Shevchenko, Y.; Francis, T. J.; Blair, D. A. D.; Walsh, R.; DeRosa, M. C.; Albert, J. In Situ Biosensing with a Surface Plasmon Resonance Fiber Grating Aptasensor. Anal. Chem. 2011, ASAP. Copyright 2011 American Chemical Society

Figure 3.7: Transmission spectrum obtained with the SPR-TFBF sensor while immersed in a solution of thiolated thrombin aptamers. The red bracket indicate the SPR-coupled component of the spectra while the red arrow indicates the most sensitive SPR-coupled cladding resonance. Reprinted with permission from Shevchenko, Y.; Francis, T. J.; Blair, D. A. D.; Walsh, R.; DeRosa, M. C.; Albert, J. In Situ Biosensing with a Surface Plasmon Resonance Fiber Grating Aptasensor. Anal. Chem. 2011, ASAP. Copyright 2011 American Chemical Society

Figure 3.8: a) Change in SPR signal over the first 15 minutes of aptamer immobilization: purple trace - DNA buffer; blue trace - thrombin aptamer at $10 \mu \mathrm{M}$; black trace thrombin aptamer at $20 \mu \mathrm{M}$. b) relative change in SPR after 15 minutes of immobilization expressed as a bar graph for clarity. Reprinted with permission from Shevchenko, Y.; Francis, T. J.; Blair, D. A. D.; Walsh, R.; DeRosa, M. C.; Albert, J. In Situ Biosensing with a Surface Plasmon Resonance Fiber Grating Aptasensor. Anal. Chem. 2011, ASAP. Copyright 2011 American Chemical Society 
Figure 3.9: Confocal microscope image of an optical fibre immersed in a $45 \mu \mathrm{M}$ solution of $\mathrm{Cy} 3$ and thiol modified DNA for 20 hours. $11 \%$ laser strength, detector pinhole width $55 \mu \mathrm{m}, 63 \mathrm{X}$ magnification was applied (Left) and a confocal microscope image of a bare sensor immersed in a solution of free $\mathrm{Cy} 3$ dye (Right). Reprinted with permission from Shevchenko, Y.; Francis, T. J.; Blair, D. A. D.; Walsh, R.; DeRosa, M. C.; Albert, J. In Situ Biosensing with a Surface Plasmon Resonance Fiber Grating Aptasensor. Anal. Chem. 2011, ASAP. Copyright 2011 American Chemical Society

Figure 3.10: a) Change in SPR signal over the first 15 minutes of soaking in a variety of solutions: Protein Buffer (Light Blue); $5 \mu \mathrm{M}$ Bovine Serum Albumin (Green); $5 \mu \mathrm{M}$ Pepsin (Purple); $0.1 \mu \mathrm{M}$ thrombin (Red); $5 \mu \mathrm{M}$ thrombin (Black) b) Bar diagram comparing the results in SPR change over 100 minutes; included are the results of conducting the test in serum (blue bold bars). Reprinted with permission from Shevchenko, Y.; Francis, T. J.; Blair, D. A. D.; Walsh, R.; DeRosa, M. C.; Albert, J. In Situ Biosensing with a Surface Plasmon Resonance Fiber Grating Aptasensor. Anal. Chem. 2011, ASAP. Copyright 2011 American Chemical Society

Figure 3.11: 3D AFM image of the sensor's surface after soaking in the thiolated thrombin aptamer solution (Top left); 3D AFM images of the sensor's surface after attachment of thrombin (shown at different scales) (Top right, Bottom left and right). All measurements were conducted in tapping mode and measured in air on a dry sample. Reprinted with permission from Shevchenko, Y.; Francis, T. J.; Blair, D. A. D.; Walsh, R.; DeRosa, M. C.; Albert, J. In Situ Biosensing with a Surface Plasmon Resonance Fiber Grating Aptasensor. Anal. Chem. 2011, ASAP. Copyright 2011 American Chemical Society

Figure 3.12: SPR signal change during the "Ladder" test. Steps were as follows: 1. MilliQ water; 2. DNA buffer; 3. Thrombin Aptamer, concentration $20 \mu \mathrm{M} ; 4$. Thrombin, concentration $0.1 \mu \mathrm{M} ; 5$. Thrombin, concentration $0.5 \mu \mathrm{M} ; 6$. Thrombin, concentration 1 $\mu \mathrm{M}$; 7. Thrombin, concentration $5 \mu \mathrm{M}$; 8. Protein buffer; 9. Regeneration in $0.2 \mathrm{M}$ $\mathrm{Na}_{2} \mathrm{CO}_{3}$. The data was normalized to the maximum of the SPR signal and was fitted using Hill's equation by Yanina Shevchenko. ${ }^{99}$ Reprinted with permission from Shevchenko, Y.; Francis, T. J.; Blair, D. A. D.; Walsh, R.; DeRosa, M. C.; Albert, J. In Situ Biosensing with a Surface Plasmon Resonance Fiber Grating Aptasensor. Anal. Chem. 2011, ASAP. Copyright 2011 American Chemical Society

Figure A1.1: ESI-MS spectrum of the sequence TATAATTCGTTTTCGAATTATA collected using the syringe pump injection method

Figure A1.2: ESI-MS spectrum of the sequence $\mathrm{H}_{2} \mathrm{~N}-\left(\mathrm{CH}_{2}\right)_{6}-5^{\prime}$-ATG ATA GCA TCG GTC-3' collected using the C-18-fused silica column injection method.

Figure A2.1: ESI-MS spectrum of the product of the EDC-NHS quenching reaction ..116

Figure A2.2: ESI-MS spectrum of the product of EDC-NHS reaction using TSTUDIPEA conditions 
Figure A2.3: ESI-MS of the product of TSTU-DIPEA reaction using $3 \mathrm{NH}_{2}$-DNA (sequence 4)

Figure A2.4: ESI-MS Spectrum of crude $\left[\mathrm{Co}(\mathrm{bpy})_{2} \mathrm{bpy}^{\prime}\right]\left(\mathrm{PF}_{6}\right)_{3}$ 118

Figure A3.1: $K_{d}$ signal, raw data is shown along with smoothed data. Description of each step: 1. Protein Buffer; 2. Thrombin, concentration $0.00685 \mu \mathrm{M} ; 3$. Thrombin, concentration $0.0205 \mu \mathrm{M} ; 4$. Thrombin, concentration $0.0616 \mu \mathrm{M}$; 5. Thrombin, concentration $0.185 \mu \mathrm{M}$; 6. Thrombin, concentration $0.55 \mu \mathrm{M}$; 7. Thrombin, concentration $1.66 \mu \mathrm{M}$. Reprinted with permission from Shevchenko, Y.; Francis, T. J.; Blair, D. A. D.; Walsh, R.; DeRosa, M. C.; Albert, J. In Situ Biosensing with a Surface Plasmon Resonance Fiber Grating Aptasensor. Anal. Chem. 2011, ASAP. Copyright 2011 American Chemical Society 


\section{List of Tables}

Table 1: HPLC gradient used for collection of DNA-Conjugates................................43

Table 2: Electrochemistry settings for cleaning a gold electrode................................47

Table 3: Electrochemistry settings used for DNA experiments ................................49

Table 4: Electrochemistry settings used for Ruthenium Hexaammine experiments .........50

Table 5: Summary of all attempted conjugation pathways ........................................51

Table 6: Results of ICP MS Analysis ................................................................73 


\section{List of Abbreviations}

AFM - atomic force microscopy

ATP - Adenosine triphosphate

bpy $-2,2^{\prime}$-bipyridine

bpy' - 4-(3-carboxypropyl)-4'-methyl-2,2'-bipyridine

COSY - H-H correlation spectroscopy

$\mathrm{CPG}$ - Controlled pore glass

CV - Cyclic Voltammetry

Cy3, Cyanine 3 - 1-(e-carboxypentynyl)-14-ethyl-3,3,34,34-

tetramethylindocarbocyanine-5,54-disulfonate

DCM - dichloromethane

DEA - diethylamine

DIPEA - diisopropylethylamine

DMAP - Dimethylaminopyridine

DMF - dimethylformamide

DMSO - dimethylsulfoxide

DMT - dimethoxytrityl

DNA - deoxyribonucleic acid

ssDNA - single stranded deoxyribonucleic acid

EDC - 1-ethyl-3-(3-dimethylaminopropyl) carbodiimide hydrochloride

EDTA - ethylenediaminetetra-acetic acid disodium salt

ESI-MS - Electrospray ionization mass spectrometry

FBG - fibre Bragg grating

FRET - fluorescence resonance energy transfer 
HIV - Human immunodeficiency virus

HPLC - high performance liquid chromatography

$\operatorname{IgE}$ - immunoglobulin $\mathrm{E}$

$\mathrm{Kd}$ - Dissociation constant

LPFG - long-period fibre grating

LOD - Limit of Detection

MALDI-TOF-MS - Matrix assisted laser desorption/ionization time of flight mass spectrometry

MS - mass spectrometry

NHS - N-hydroxysuccinimide

NMR - nuclear magnetic resonance

OTA - Ochratoxin A

PAGE - polyacrylamide gel electrophoresis

PCR - polymerase chain reaction

Redox potential - reduction/oxidation potential

RNA - ribonucleic acid

SELEX - systematic evolution of ligands by exponential enrichment

SNR - Signal to noise ratio

SPR - surface plasmon resonance

SPW - surface plasma wave

SW - Square Wave Voltammetry

TBE buffer - TRIS/boric acid/EDTA buffer

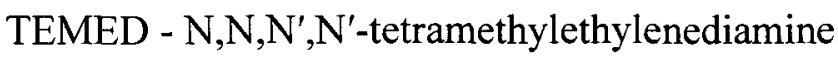


TFBG - tilted fibre Bragg grating

TM - transverse magnetic polarized light

TSTU - O-(N-Succinimidyl)-1,1,3,3-tetramethyluronium tetrafluoroborate 


\section{Chapter 1}

\section{Introduction}




\subsection{Aptamers}

The term aptamer is derived from the Latin aptus, meaning "to fit". are single-stranded synthetic RNA or DNA with the ability to bind to non-nucleic acid targets with a high affinity and specificity. ${ }^{1}$ They originate from an in vitro selection process known as SELEX (systematic evolution of ligands by exponential enrichment). ${ }^{2}$ This method was simultaneously developed by Tuerk and Gold ${ }^{3}$ and Ellington and Szostak $^{4}$, in 1990. SELEX is a process that begins with a random sequence - typically 30-40 nucleotides - flanked by constant sequences. This random sequence results in an oligonucleotide library that contains $10^{13}$ to $10^{15}$ unique sequences. ${ }^{5,6}$ These sequences are then exposed to the desired target. Sequences with an affinity bind to the target and those with no affinity, or a weak affinity, do not bind and are removed from the library. ${ }^{6}$ The binding sequences are then recovered and amplified using polymerase chain reaction (PCR). This process narrows down the aptamer candidates and thus enriches the library. The selection process is repeated approximately 7 to 15 times in order to create a sufficiently narrow pool of aptamer candidates. ${ }^{6}$ These candidates are then characterized for their binding affinity in order to determine their efficiency as aptamers. ${ }^{6}$ 


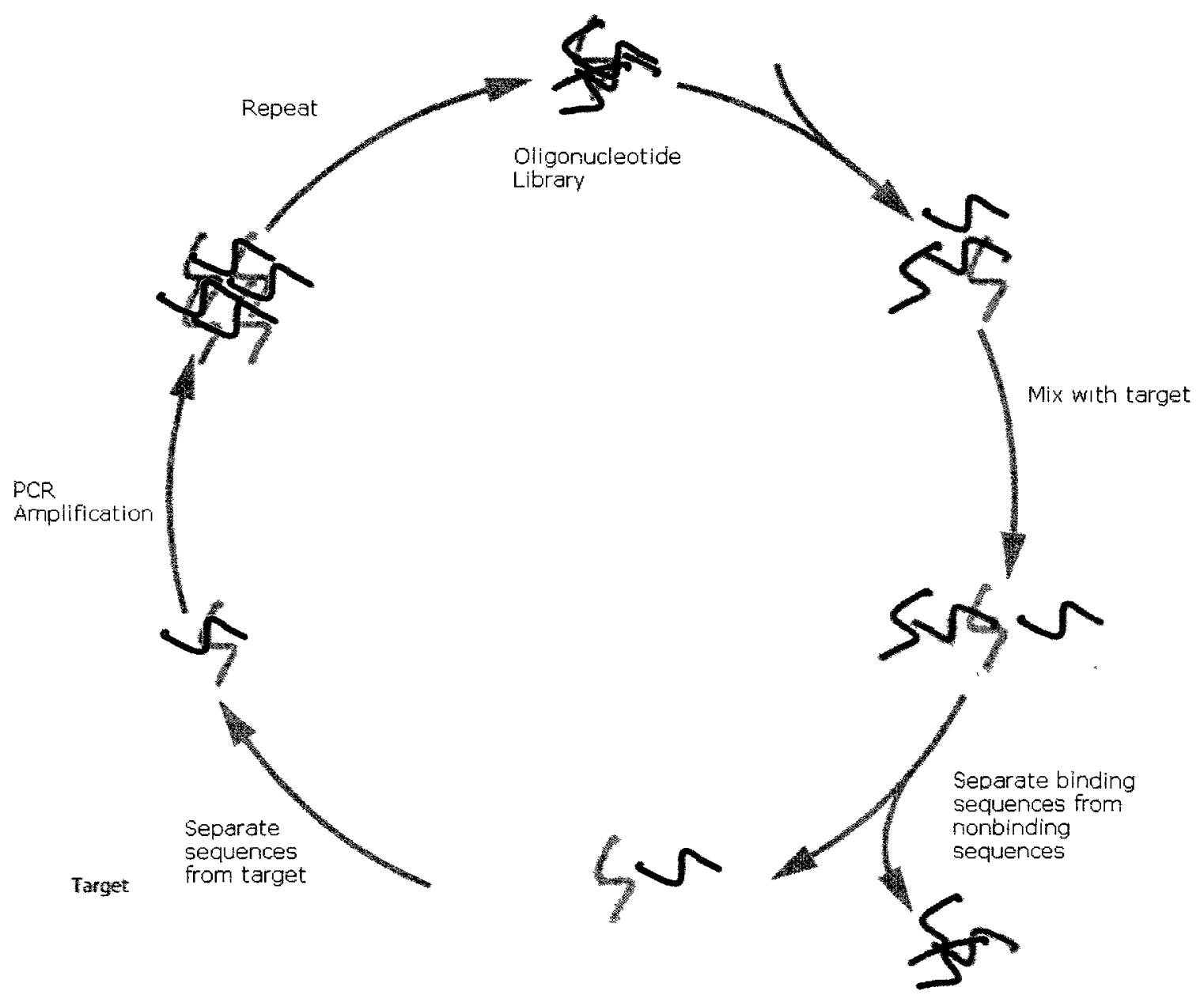

Figure 1.1: Illustration of the SELEX process: A library of random oligonucleotides is mixed with a target; the binding sequences are separated from the nonbinders; the binders are separated from the target and amplified; the process is repeated [adapted from ${ }^{6}$ ]

Aptamers have been used in a variety of techniques that allow for detection of biomolecules. ${ }^{7}$ It is the unique binding properties of aptamers that allow this type of application. Aptamers are frequently compared to antibodies in their behaviour, but have several advantages over antibodies. Antibodies are produced biologically. This type of process is difficult to scale up, whereas aptamers can be produced synthetically on a 
DNA/RNA synthesizer. As such, aptamer production is readily scalable. ${ }^{5}$ Antibodies are often immunogenic ${ }^{5}$, meaning that they illicit an immune response from the body. Aptamers on the other hand do not illicit such a response. ${ }^{5}$ This is highlighted by the fact that some aptamers are in clinical trials for treatment of ocular disease, haematological disease, and cancer. ${ }^{8}{ }^{9}$ Furthermore, the first therapeutic aptamer, Macugen, was approved in $2004 .{ }^{8}$ The limitations of aptamers as therapeutics are not significant - in fact it is hypothesized that aptamers can be used for any disease in which an extracellular blockade of protein-protein interactions is required. ${ }^{5}$ Currently, several targets of therapeutic interest have had aptamers identified for them. Many of these aptamers, such as the Tenascin $\mathrm{C}$ aptamer, have application in preventing tumour development. ${ }^{5}$ However, the advantages of aptamers are not purely therapeutic. The stability of the phosphodiester bond allows for reversible denaturing. As a result, an aptamer can capture and release its target. This has major ramifications for the development of aptamers into practical point-of-care diagnostic tools. ${ }^{5}$ Antibodies, on the other hand, have a limited shelf life as they are susceptible to irreversible denaturation. Finally, aptamers are easily modifiable. Conjugation chemistry for the attachment of different transducer molecules is readily available and can be incorporated directly into the automated synthesis or as a post-synthesis workup. ${ }^{5}$ Unlike aptamers, specific modifications on antibodies are difficult to achieve as they are stochastic - meaning that the conjugation process is nondeterministic and will yield a mixture of products. ${ }^{5}$ This adds an extra layer of complication when attempting to use modified antibodies. As a result, aptamers are an attractive option for the development of selective, high affinity biosensors. 


\subsection{Biosensors}

Biosensors are devices that determine the concentration of an analyte, through various means of transduction, with the final measurement of either photons or electrons from a transducing element. ${ }^{10}$ By definition, true biosensors are solid state devices that give a reading when they come into contact with their analyte. ${ }^{10}$ Biosensors fall into two main classifications: catalytic biosensors and affinity biosensors. Catalytic biosensors are typically enzyme-based, in that they use a biological component to recognize a chemical species and transform it into a product via a chemical reaction. ${ }^{10}$ Affinity-based sensors utilize the affinity between a target and a biorecognition element. A classic example of this type of interaction is the antibody-antigen interaction. Other types of affinity interactions are that of complementary oligonucleotides. ${ }^{10}$ There is increased motivation to develop DNA-based sensors because of their potential application to gene analysis, detection of biological warfare agents, and forensic applications. ${ }^{11}$

As an aptamer target interaction is an affinity interaction, aptamers are well suited for utilization in biosensors. ${ }^{12}$ Many types of aptamer-based sensors have been reported, utilizing various techniques such as fluorescence, colorimetric, electrochemical, optical, surface plasmon resonance, and mass spectrometric means of detection. ${ }^{13,14}$

Fluorescence-based aptamer sensors depend on the covalent attachment of a fluorophore to an aptamer. ${ }^{13}$ As a result of such a modification, the aptamer can be utilized as a signaling molecule. ${ }^{13}$ This is achieved through measuring the fluorescence intensity, lifetime, fluorescence resonance energy transfer (FRET), or anisotropy of an 
aptamer-target interaction. ${ }^{13}$ Fluorescent labels are typically fluoresceins, rhodamines, and cyanines. ${ }^{13}$ A range of work has been conducted on fluorescence-based aptamer sensors. ${ }^{15-21}$ Recently, Brennan and coworkers reported the development of aptamers immobilized on a sol-gel platform via the biotin-streptavidin interaction. In this system, an aptamer is covalently modified with fluorescein and a complementary strand modified with a quencher, dabcyl. Upon target recognition the complementary strand denatures from the aptamer, allowing the free fluorescein to fluoresce and thus confirming target binding. ${ }^{18}$ This system was applied to the detection of adenosine 5 '-triphosphate and platelet-derived growth factor. ${ }^{18} \mathrm{Yu}$ and coworkers have recently developed another strand displacement system that involves the use of the cocaine aptamer. In this system, addition of the target results in an unfolding of a DNA duplex - the unfolded DNA is then amplified and a fluorescent molecule intercalates with the newly generated duplex. The resulting DNA complex generates a detectable signal. ${ }^{19}$ Despite these advances, a disadvantage to fluorescent-based sensors lies within the transduction of the signal. In order to quantify a target recognition event, the fluorescent response must be converted into an electrical signal. Furthermore, the cost of fluorescence instrumentation is far greater than that of other techniques, such as electrochemical means.

Colorimetric-based sensors typically depend upon the optical properties of gold nanoparticles. ${ }^{22}$ However, colorimetric-based sensors involving the encapsulation of dye within an aptamer which releases upon target binding have also been reported. ${ }^{23}$ The work in this field of nanoscience was pioneered by Mirkin and coworkers. ${ }^{22}$ Recently, Yang and coworkers have developed a sensor for Ochratoxin A (OTA) utilizing gold 
nanoparticles and aptamers. The general concept is that the OTA aptamer prevents aggregation of the nanoparticles. Addition of OTA to the system results in folding of the aptamer, allowing the nanoparticles to aggregate. This affects their optical properties and a colour change is observed. ${ }^{22} \mathrm{Zhu}$ and coworkers performed similar work using the lysozyme and ATP aptamers. ${ }^{24}$ The results, although positive, still suffer from the need for an efficient method of quantization, as this method also involves additional levels of transduction.

Mass spectrometric aptamer sensing platforms utilize a variety of different approaches. Famulok and coworkers developed a Matrix Assisted Laser Desorption Ionization Time Of Flight mass spectrometry (MALDI-TOF) platform to characterize the interaction of the HIV-1 protein bound to its aptamer..$^{25}$ The L-Arginimade aptamer was studied via electrospray ionization Fourier transform mass spectrometry by Guo et al. ${ }^{26}$ McGown and coworkers have utilized aptamers in conjunction with matrix-assisted laser desorption/ionization mass spectrometry for capture and detection of immunoglobulin $\mathrm{E}$ both from a simple solution and from serum. ${ }^{14}$ This builds on a work describing a similar experiment in the detection of thrombin by MALDI-TOF-MS. ${ }^{27}$ Although promising, this avenue of sensor development has a significant limitation in that the equipment is not practical when considering a platform for use in a point-of-care diagnostic.

The projects described herein came about as a result of the need, not only to develop aptamer-based sensors, but to address the requirement for a practical approach to their application. As such the platforms that have been investigated in this thesis are 
electrochemical-based aptamer biosensors and surface plasmon resonance-based aptamer biosensors.

\subsection{Electrochemical Aptamer Based Biosensors}

Development of electrochemical biosensors is driven in part by the desire to accommodate and emulate the compactness and operating efficiency of modern electronic devices. ${ }^{28}$ The ability to transduce an aptamer-target binding event electrically without having to interpret additional levels of transduction (e.g. fluorescence) gives this technique an even greater applicability. ${ }^{28}$

Typical electrochemical cells are designed using three main components - the working electrode, the counter electrode, and the reference electrode. ${ }^{29}$ This is known as a three-electrode system. ${ }^{29}$ In general, the principle of electrochemical sensors is that the electroactive species present is either oxidized or reduced on the working electrode surface. ${ }^{30}$ A potential is applied across the working electrode and the auxiliary electrode. This potential is either fixed or varying in nature. ${ }^{30}$ The electroactive analyte responds to the potential through a redox reaction and as a result changes the electrical parameters at the electrode surface. ${ }^{30}$ The principle types of electrochemical sensors are potentiometric, amperometric, impedimetric and conductometric. ${ }^{31}$ Potentiometric sensors rely on a local equilibrium being established at the sensor interface. From this, either the electrode or the membrane potential is measured, and information about the sample composition is obtained from the measured potential difference between the two electrodes. ${ }^{31}$ 
Conductometric sensors rely on the measurement of conductance at a series of frequencies. ${ }^{31}$ Finally, amperometric sensors apply a potential across a reference and working electrode. This causes oxidation or reduction of an electroactive species; the resulting current is measured. ${ }^{31}$ Another technique that has been applied is impedimetric aptasensors. ${ }^{28}$ This technique involves the measurement of resistance in the presence of a redox mediator, such as $\left[\mathrm{Fe}\left(\mathrm{CN}_{6}\right)\right]^{3-4-28}$ Over half of all publications on electrochemical aptasensors in a given year use amperometry as the method of transduction. ${ }^{32}$ Impedimetric-based aptasensors make up almost a third, with the rest being allocated over the other techniques. ${ }^{32}$

DNA-based electrochemical biosensors are advantageous because of their ability to bind with a high degree of affinity and in a variety of media. ${ }^{29}$ Generic DNA biosensors are limited in that they can only bind to nucleic acid complementary sequences. ${ }^{29}$ The application of aptamers to electrochemical biosensing further adds to the advantages because of an aptamer's ability to bind specifically to its target. ${ }^{29}$ 


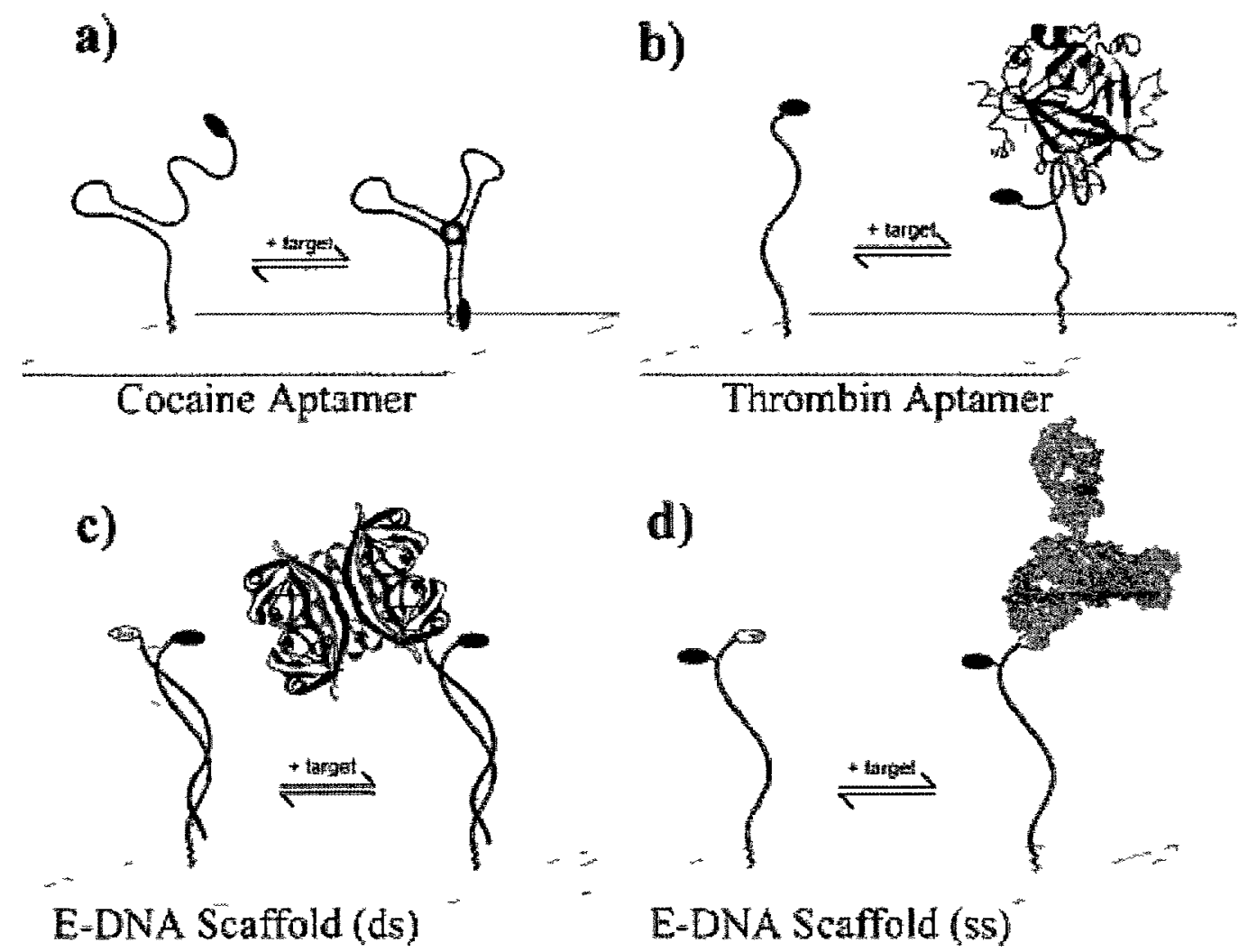

Figure 1.2: Different types of architectures for electrochemical aptamer biosensors. a) and b) show detection of cocaine and thrombin respectively; c) and d) show similar interactions with protein and small molecules in both single and double stranded cases.[adapted from ${ }^{33}$ ]

There are already many different types of electrochemical sensor platforms that have been used in the detection of specific oligonucleotides, small molecules and proteins (Figure 1.2). ${ }^{33}$ The detectable signals arise from a change in 'floppiness' that occurs when the DNA binds or interacts with a target. ${ }^{33}$ 
For example, Rodriguez et al. have recently applied the use of aptamers to the electrochemical detection of lysozyme via amperometric means. ${ }^{34}$ This is achieved through the immobilization of the lysozyme aptamer on the electrode surface. Addition of lysozyme causes a reduction in the observed current. ${ }^{34}$ Niazi and coworkers developed a chip-based electrochemical apparatus that contained the standard three-electrode system of working electrode, reference electrode and auxiliary electrode. ${ }^{35}$ This system was applied to the detection of tetracycline using amperometric techniques. ${ }^{35}$ This system is also a 'signal-off' system - as the presence of target increases, the current decreases. In a practical sense this means that the observed redox peaks disappear as the concentration of target analyte increases.

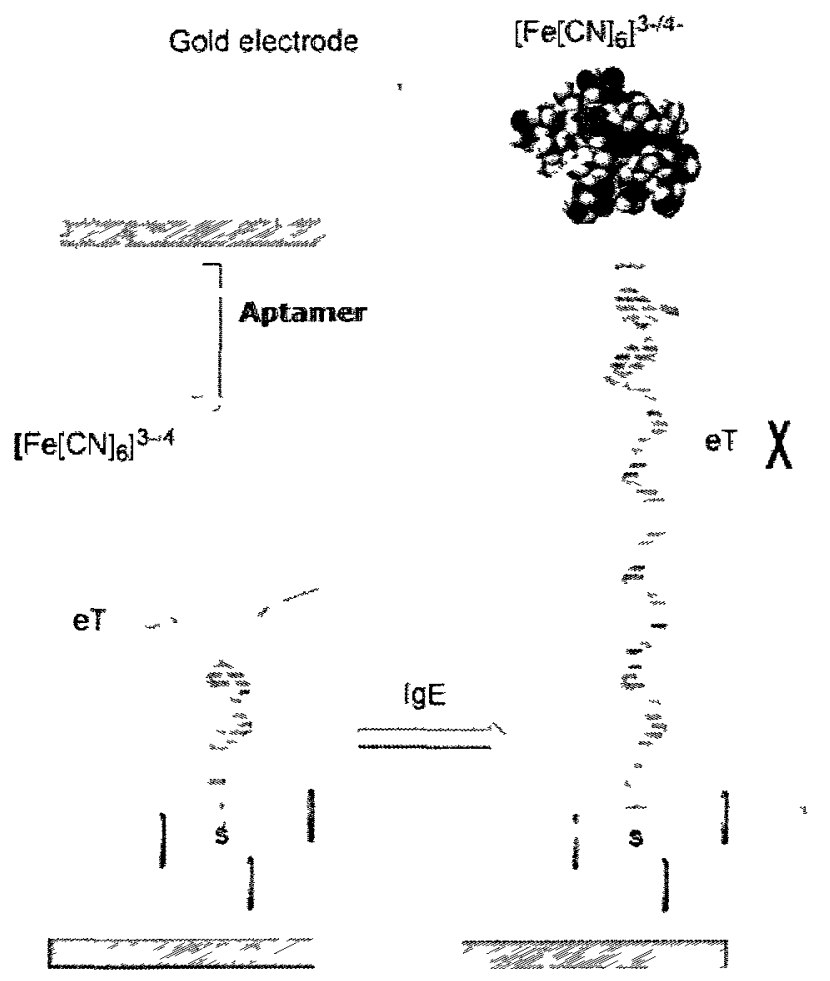

Figure 1.3: A schematic of a "signal off" electrochemical based aptasensor. Upon target binding the pathway for the redox probe becomes increasingly obstructed, thus limited electron transfer and thus reducing the signal.[adapted from ${ }^{36}$ ] 
Figure 1.3 illustrates an example by $\mathrm{Yu}$ and coworkers using a standard threeelectrode system for the detection of immunoglobulin $\mathrm{E}(\operatorname{IgE}) .{ }^{36}$ This system is another example of a signal-off system. Initially, the aptamer is immobilized on a gold surface. In the presence of target, a change in structure of the aptamer occurs that results in an increase in the electron-transfer distance between the biomolecule/electrolyte interface. This results in a suppression of current. ${ }^{36}$

Recently, Chen et al. have developed a "signal on" sensor scheme. This sensor scheme involves the use of the 15 -mer thrombin aptamer in two fragments. One of the fragments is immobilized to a gold surface and the other modified with a redox active probe - ferrocene..$^{37}$ In the presence of target, the two fragments come together and the redox probe is brought into close proximity to the electrode surface. This results in a detectable signal. ${ }^{37}$
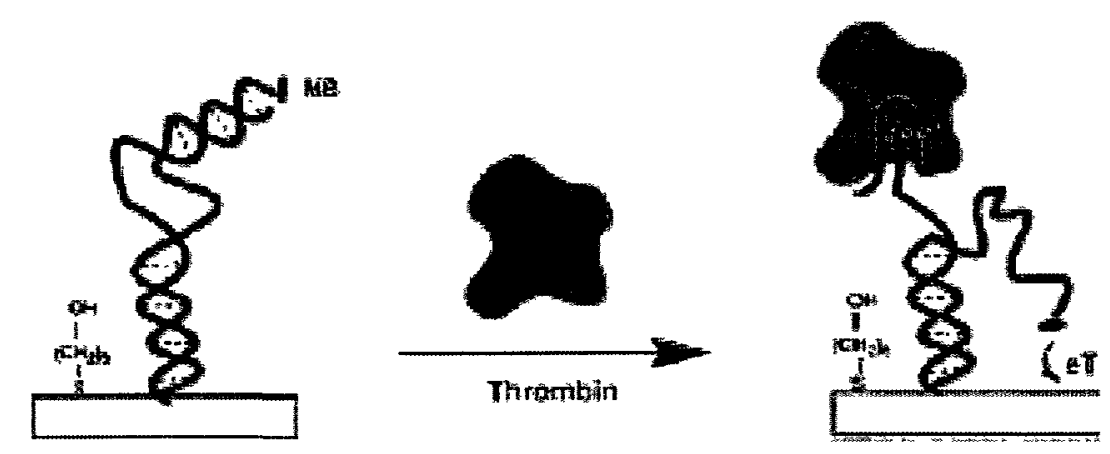

Figure 1.4: Schematic of a signal on electrochemical based aptasensor. Upon target recognition the electrochemical probe is free to migrate to the surface of the electrode and thus generate a signal [Reprinted with permission from Xiao, Y.; Piorek, B. D.; Plaxco, K. W.; Heeger, A. J. A Reagentless Signal-On Architecture for Electronic, Aptamer- 
Based Sensors via Target-Induced Strand Displacement. J. Am. Chem. Soc. 2005, 127, 17990-17991. Copyright 2005 American Chemical Society] ${ }^{38}$

Figure 1.4 illustrates another example of a signal-on electrochemical aptasensor. In this setup, reported by Heeger and coworkers, a double-stranded sequence of thrombin aptamer and redox-tagged complement are hybridized on the surface of a gold electrode. Upon target binding, the thrombin aptamer preferentially binds to its target, leaving a portion of the complementary strand free to come into close contact with the electrode and generate a signal. ${ }^{38}$

\subsection{Aptamer-Based Surface Plasmon Resonance Biosensors}

Surface Plasmon Resonance (SPR) is a unique electromagnetic phenomenon that occurs at the interface between two materials with opposite dielectric constants. ${ }^{39}$ The Kretschmann configuration is considered the most popular SPR configuration available. ${ }^{40}$ This setup consists of a metallic layer deposited on the base of a prism. ${ }^{40}$ Silver or gold can be used as the metallic layer; each has advantages and disadvantages. Silver has a much lower chemical stability than gold but can provide a better signal-to-noise ratio. ${ }^{40}$ Gold, on the other hand, increases the sensitivity to changes in refractive index, and has a greater stability than silver. ${ }^{40}$ In this system, polarized light passes from a layer of material with a high refractive index to a layer of material with a low refractive index. ${ }^{39}$ Typically, the prism serves as the high refractive index material, and a thin film of gold acts as the low index material. ${ }^{39}$ When the incident light passes through the high 
refractive index layer at an angle greater than or equal to the critical angle, the light is totally reflected back into the high refractive index layer. At this point, the angle of incidence reaches the resonance angle and the optical energy is transferred to the surface of the metal. The resonance condition depends on the incident angle, wavelength of light, and dielectric functions of the two layers. ${ }^{40}$ This resonance of surface electrons creates an electrical field about $100 \mathrm{~nm}$ above and below the metal surface. ${ }^{39}$ Most changes occurring in a sample on the gold surface will alter the refractive index between the sample and surface and will appear as a change in the resonance angle. ${ }^{39}$ The change in resonance angle, also known as an SPR shift, is directly and linearly proportional to the change in adsorbed mass at the surface. ${ }^{39}$ Such a change in mass can arise as a result of a binding event, such as an antigen-antibody binding event, or an aptamer-target binding event, an example of which is shown in Figure 1.5. ${ }^{39}$

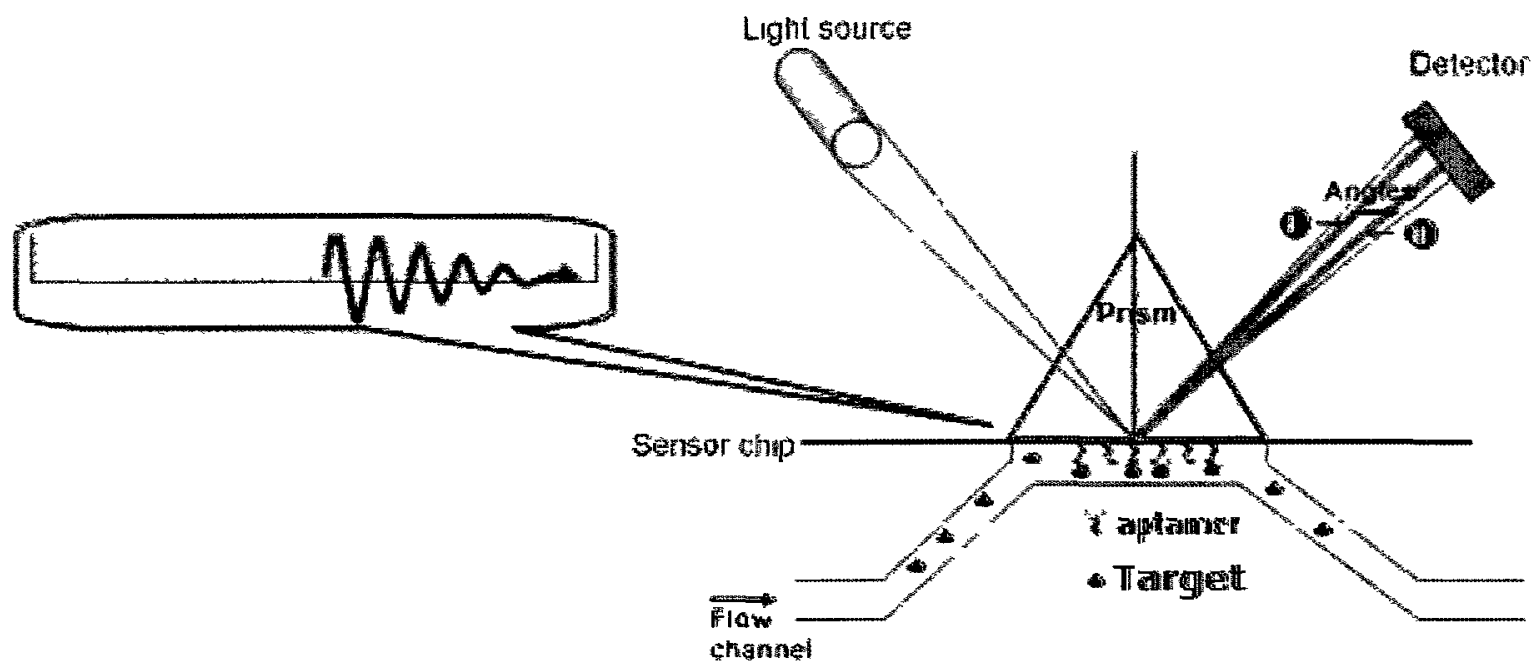

Figure 1.5: A biosensor using the Kretschmann configuration: Total internal reflection of incident light occurs resulting in the generation of surface plasmons; the frequency of which can be used to detect an analyte passing over a modified gold surface.[adapted from ${ }^{41}$ ] 
As a result of the ability to discern a binding event taking place on the surface, SPR-based platforms are of interest in the field of biosensing. The major advantage to using a SPR-based sensing system is that it can provide label-free detection of analytes. ${ }^{41}$ For example, Polonschii et al. have recently reported the application of a Biacore SPR sensing system for the detection of thrombin utilizing the 15 -mer thrombin aptamer. ${ }^{42}$ Using a similar instrument, Kim et al. have used the human immunoglobulin $\mathrm{E}$ aptamer in conjunction with SPR to design a sensor for label-free detection of IgE. Gyurcsanyi and coworkers have used an IBIS SPR instrument in conjunction with aptamers to detect plant virus coat proteins; in this example apple stem pitting virus coat proteins. ${ }^{43}$ All of these examples involve the use of gold instead of silver as the metallic layer due to the higher chemical stability. ${ }^{40}$

\subsection{Techniques}

\subsubsection{Oligonucleotide Synthesis}

A single nucleotide of DNA/RNA consists of a pentose sugar, a nitrogenous base, and a phosphate group. The nitrogenous base is variable and may be one of adenine, guanine, cytosine, or thymine/uracil. DNA synthesis is now typically carried out via phosphoramidite chemistry pioneered by Beaucage and Caruthers. ${ }^{44,45}$ In this synthesis, each of the building blocks consists of a dimethoxytrityl (DMT) group protecting the $5^{\prime} \mathrm{OH}$ of the sugar and a phosphoramidite group protecting the $3^{\prime} \mathrm{OH}{ }^{44}$ A synthesis cycle begins with removal of the DMT group using dichloroacetic acid; this leaves the $5^{\prime} \mathrm{OH}$ 
readily available for reaction with the next phosphoramidite. The phosphoramidite conjugation is catalyzed with the use of $1 \mathrm{H}$-tetrazole. Following the addition of the next phosphoramidite, the intermediate phosphite is oxidized so it will form a more stable phosphotriester. Sequences that failed to couple with the phosphoramidite are capped by acetylation in order to prevent further reaction. This cycle is repeated until the sequence is complete and the strand cleaved from the support. Following synthesis, typical cleanup procedure involves the use of either polyacrylamide gel electrophoresis (PAGE) or high performance liquid chromatography (HPLC). Characterization and quantification is typically conducted utilizing ultraviolet absorption (UV) and one of matrix assisted laser desorption/ionization time of flight mass spectrometry or electrospray ionization mass spectrometry. ${ }^{44}$

\subsubsection{Electrochemistry}

Electrochemistry is the branch of chemistry that focuses on the relation of electrical and chemical effects. ${ }^{46}$ The field of electrochemistry encompasses a vast array of subfields and techniques. ${ }^{46}$ Electroanalytical sensors are one such subfield. ${ }^{46}$ As with all techniques, electrochemistry has both advantages and limitations. The methods by which electrochemical measurements are conducted are well established, and require relatively inexpensive equipment. ${ }^{47}$ Furthermore, electrochemical techniques are sensitive and are able to detect sub-picomole quantities of electroactive material. ${ }^{47}$ Despite having several advantages electrochemistry does have addressable limitations. The electrochemical reactions take place at an interface between two phases - this region 
is called the double layer. ${ }^{47}$ The double layer is the region where most of the potential difference between electrodes exists. ${ }^{47}$ As a result this layer behaves like a capacitor some of the current that flows upon a sudden change in potential results in charging the double layer capacitance. ${ }^{47}$ This can be addressed by utilizing ultramicroelectrodes. ${ }^{47}$ Finally, mass transport must be considered when addressing any electrochemical procedure. This is crucial because the electrochemical reaction takes place at the interface rather than in solution. As such, diffusion, convection (stirring), and migration (movement of ions resulting from the generated electrical field), are all factors that must be considered. Adding an electrolyte - dissolved salt - addresses issues such as migration because it makes a good ionic conductor. ${ }^{47}$

Electrode reactions are heterogeneous in nature and take place at the double layer. ${ }^{48}$ The double layer is a portion of the interfacial region between the bulk electrode and bulk solution. ${ }^{48}$ It is the region where the value of electrostatic potential differs from that in the bulk solution. ${ }^{48}$ The electrode can act as either a source or sink of electrons (for reduction and oxidation, respectively). ${ }^{48}$ This can be represented by $\mathrm{O}+\mathrm{ne} \rightarrow \mathrm{R}$ where $O$ and $R$ are the oxidized and reduced species respectively. ${ }^{48}$ In general, for an oxidation there is a maximum energy that the electrode can have in order to receive electrons, and correspondingly a reduction has a minimum energy that the transferable electrons must have in order for a transfer to occur. ${ }^{48}$ 


\subsubsection{The Three Electrode System}

Measurements involving current flow typically involve a three-electrode set up. A three-electrode set up involves a working electrode, reference electrode, and auxiliary electrode. $^{49}$

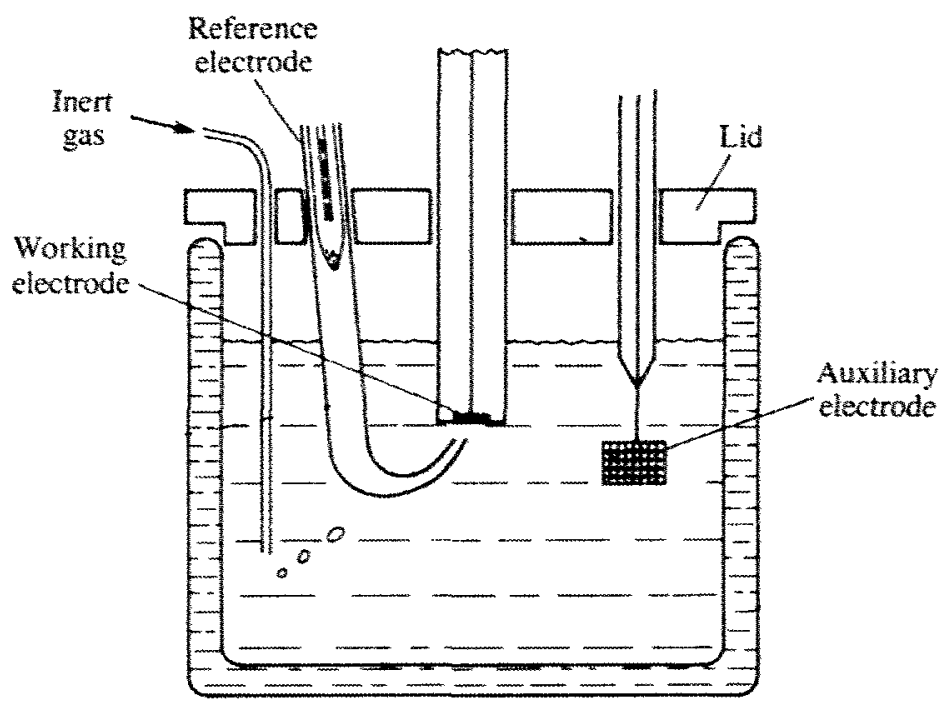

Figure 1.6: An example of a 3 electrode system illustrating the working electrode, auxiliary electrode and reference electrode [adapted from ${ }^{48}$ ]

The working electrode is typically a solid state electrode. Commonly, working electrodes are made of glassy carbon or gold. ${ }^{48}$ In a research context, the interest resides in investigating the electrode process at the working electrode. ${ }^{48}$ The auxiliary electrode, typically made of platinum, is used to pass current and thus complete the circuit. ${ }^{48}$ The reference electrode serves as a reference potential for the system. ${ }^{48}$ Thus it does not pass current or take part in the electrochemical experiment taking place. ${ }^{48}$ The potential of a given reference electrode under specified experimental conditions is given as zero. ${ }^{49}$ This is so it can act as a point of reference for the findings taking place at the working 
electrode. ${ }^{49}$ There are three types of reference electrodes - the hydrogen electrode, the calomel electrode and glass electrodes (e.g. $\mathrm{Ag} / \mathrm{AgCl}$ electrodes). ${ }^{48}$ The standard hydrogen electrode is considered the most important as it is used to define the electrode potential scale. $^{48}$

\subsubsection{Cyclic Voltammetry}

An important application of electrochemistry is the ability to measure speciesspecific concentrations. ${ }^{47}$ The primary technique utilized to achieve these ends is cyclic voltammetry $(\mathrm{CV})$, as it can be used to acquire qualitative information about electrochemical reactions. ${ }^{50}$ The basic approach in this technique is to control the potential while measuring the resultant current. ${ }^{47}$ It is often the first technique called upon when conducting an electroanalytical study. ${ }^{50}$ This is because it offers rapid location of the redox potentials of the electroactive species in solution. ${ }^{50} \mathrm{CV}$ scans across the potential of a working electrode. ${ }^{50}$ This potential scan is conducted at a constant rate. ${ }^{49}$ During this sweep the resultant current is measured. ${ }^{50}$ As a result a plot of current versus potential is created - this is termed a cyclic voltammogram. 


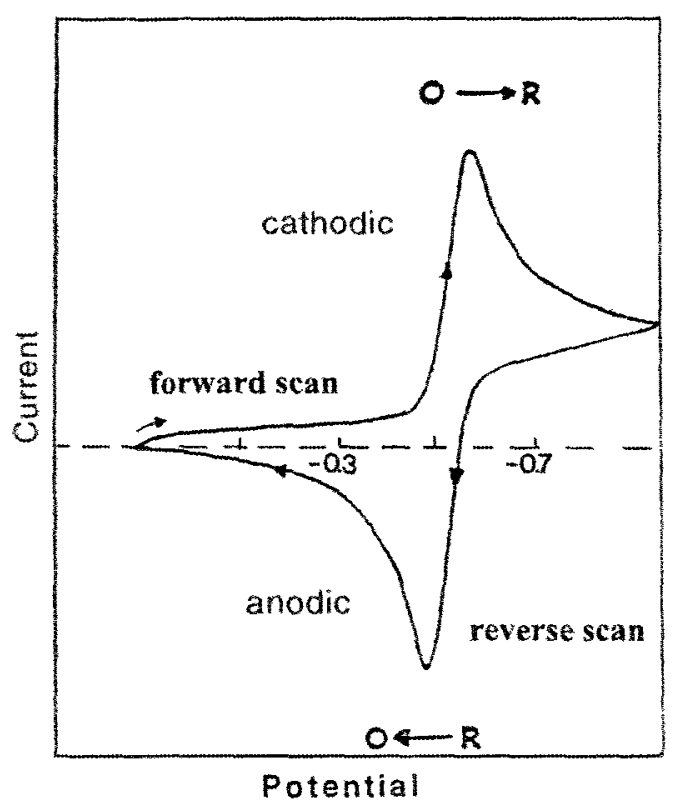

Figure 1.7: Example of a cyclic voltammogram for the process $O+n e^{-} \rightleftharpoons R$ [adapted from ${ }^{50}$ ]

Figure 1.7 is an example of a cyclic voltammogram after a single cycle. When the potential approaches the standard electrode potential for the process, the current begins to increase and form a peak - termed the cathodic peak. After the reduction process takes place, the potential is reversed and the reduced molecules are reoxidized - this is indicated by the anodic peak present in the reverse scan in Figure 1.7. ${ }^{50}$

\subsubsection{Square Wave Voltammetry}

Pioneered by Barker in 1952, square wave voltammetry is considered to be an important and exceptionally versatile analytical technique. ${ }^{46,48}$ The advantage to square wave voltammetry is its high sensitivity to surface-confined electrode reactions. ${ }^{47,51}$ 


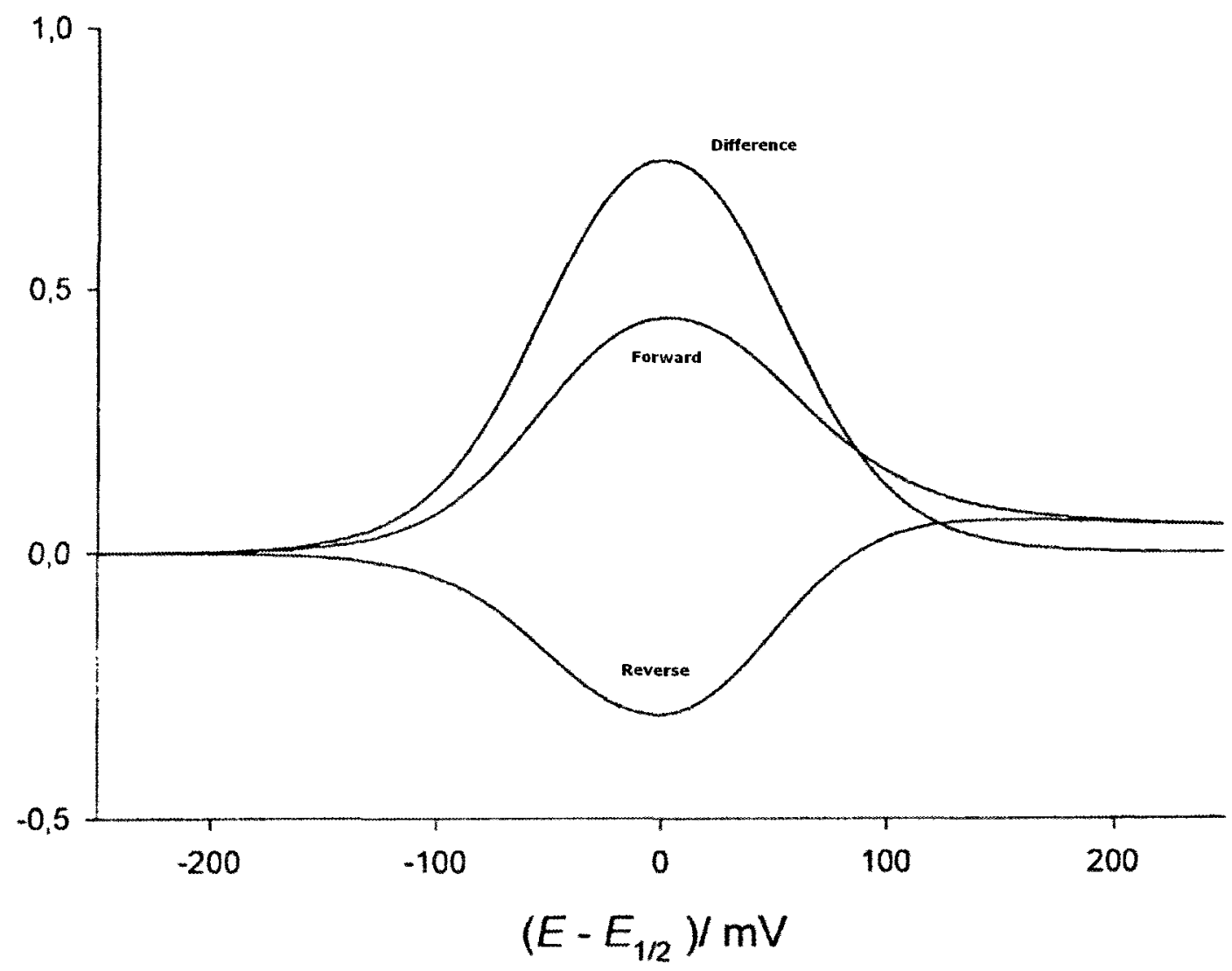

Figure 1.8: Example of a square wave voltammogram. "Forward" and "Reverse" are the response to the forward and backward components of the square wave.[adapted from ${ }^{51}$ ]

Figure 1.8 shows the model response of the reaction $R \rightleftharpoons O+n e^{-} .^{51}$ The interpretation of Figure 1.8 requires knowing that the waveform consists of a staircase scan, each step of which has a symmetrical double pulse - one in the forward direction and one in the reverse. ${ }^{46}$ At the end of each pulse the current is measured. ${ }^{46}$ The analytical curve of interest is taken as the difference between the forward current and the reverse current. ${ }^{46}$ In Figure 1.8 this difference is identified as $\Delta \Phi_{\text {nett }}$. Figure 1.9 illustrates this staircase scan. 


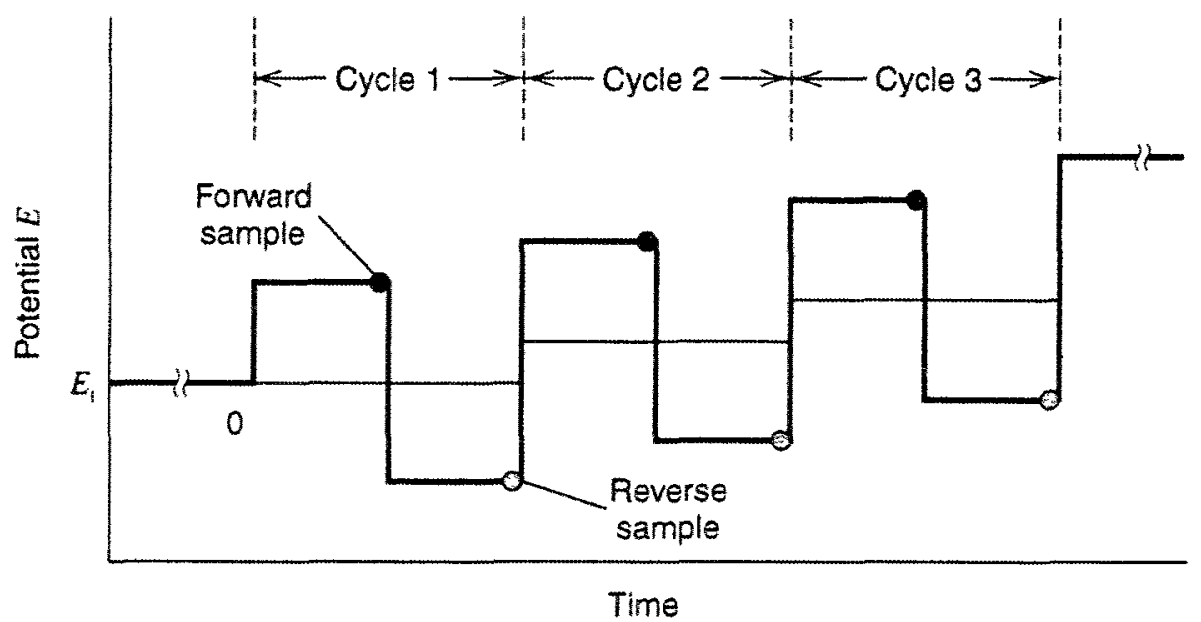

Figure 1.9: The driving signal behind a square wave voltammogram - the bold lines represent the potential waveform applied to the working electrode. The light lines indicate the 'staircase' onto which the square wave has been superimposed. Each cycle has a forward current sample (indicated by the solid dot) and a reverse current sample (indicated by the shaded dot).[adapted from ${ }^{46}$ ]

\subsection{Objectives of this Thesis}

The goal of the work described here is to contribute to the field of aptamer-based biosensing. The first of the projects, discussed in Chapter 2, involves the development of a new class of inorganic redox molecule for use in electrochemical sensing. The synthesis of this molecule, conjugation to ssDNA, and initial electrochemical characterization will be discussed. The second project, described in Chapter 3, involves the use of an optical fibre for use in aptamer-based biosensing. In this collaborative work, an optical fibre was coated with a thin film of gold. To this, a layer of thiolated aptamers was immobilized and used for the detection of target. Finally, additional work involving the use of mass spectrometry for DNA analysis will be described in Appendix 1.0. 


\section{Chapter 2}

\section{Development of a Cobalt Reporter probe complex for use in an aptamer based biosensor}

Statement of Contributions: All work reported herein was conducted by Tariq Francis. Synthesis of $\left[\mathrm{Co}(\mathrm{bpy})_{2} \mathrm{bpy}^{\prime}\right]\left(\mathrm{PF}_{6}\right)_{3}$ was conducted by either Tariq Francis or David Blair. 


\section{1: Introduction}

As discussed in Chapter 1.3 the field of electrochemical aptamer based biosensors is a fast growing field. The DNA-electrode interface is a unique platform and has attracted a diverse pool of researchers. ${ }^{52}$ This is largely due to the fact that the structure of DNA is readily modifiable and has specific base pairing properties. ${ }^{52}$ The utility of these features is exploited for biosensing applications. ${ }^{52}$ The key component in electrochemical biosensing is transducing the molecular recognition event. Many different redox labels have been reported as transducers of a recognition event with the most common being methylene blue $e^{38,53}$, anthroquinone $e^{53}$, and ferrocene ${ }^{53,54}$. The issue with organic labels such as methylene blue and anthroquinone is that they have limited tenability. In order to attain a variety of redox potentials complex organic manipulations must be conducted to alter the redox potential of the given label. To compound this, organic molecules are considered to be not as robust as inorganic complexes. Ferrocene is an example of an inorganic label. Although robust, the issue with ferrocene is the range of potentials that have to be scanned are either too positive or too negative ${ }^{54}$ and as such there exists the possibility of affecting the DNA on the surface before a target is actually present to detect. The following report is a response to these limitations. Described here is the synthesis and characterization of a new class of redox label: a cobalt-bipyridine based complex with modest redox potential. This type of complex is advantageous due to the nature of inorganic complexes. As discussed above, inorganic complexes are more resilient than their organic counterparts, and are tunable. By altering the ligand system of the cobalt complex one can adjust (tune) the redox potential accordingly. 
The electrochemical properties of cobalt-containing compounds have been widely studied; some examples include cordierites on graphite electrodes ${ }^{55}, \pi$-acetylene complexes $^{56}$, and liquid crystal films ${ }^{57}$.

DNA has been reported to be attracted to an electrode surface at potentials $\geq 400 \mathrm{mV}$ vs $\mathrm{Ag} / \mathrm{AgCl}$ and dissociate from the surface at potentials $\leq 400 \mathrm{mV}$ vs $\mathrm{Ag} / \mathrm{AgCl} .^{58} \mathrm{As}$ a result, cobalt is our preferred choice of transducer for electrochemical aptasensing because it has been reported that complexes of tris (2,2'-bipyridine)-Cobalt are oxidized and reduced at more moderate potentials than that of single stranded DNA (ssDNA). It has been recently reported that Tris (2,2'-bipyridyl)Co(III) has a redox potential of $56 \mathrm{mV}$ vs $\mathrm{Ag} / \mathrm{AgCl}^{53}$. To this end, it would be beneficial to use a cobalt complex as a reporter probe. A modification of one of the bipyridines with a carboxylic acid functional group will be conducted to allow for attachment to amino-modified ssDNA via a peptide coupling reaction. A structure of the cobalt complex with modified bipyridine $\left(\mathrm{bpy}^{\prime}\right)$ is given in Figure 2.1

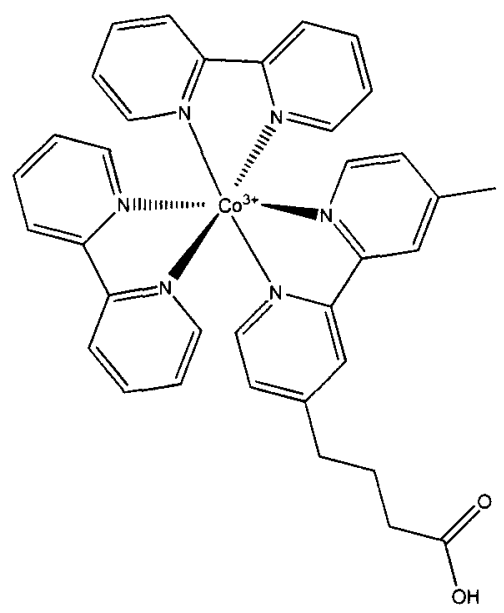

Figure 2.1: Structure of the reporter probe, $\left[\mathrm{Co}(\mathrm{bpy})_{2} \mathrm{bpy}^{\prime}\right]^{3+}$, including the modified bipyridine to allow for attachment to DNA 


\subsubsection{The Molecular Beacon Architecture}

Molecular beacons are a class of oligonucleotides that form a stem and loop during a recognition event. An example, using ATP as a target, is given in Figure 2.2.

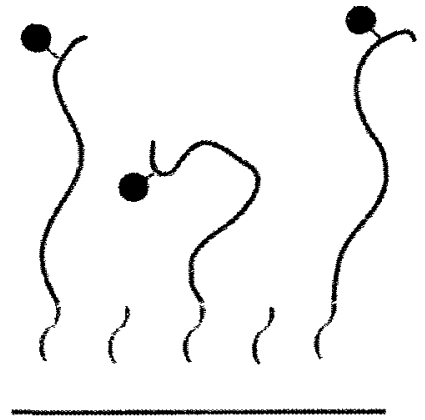

No signal

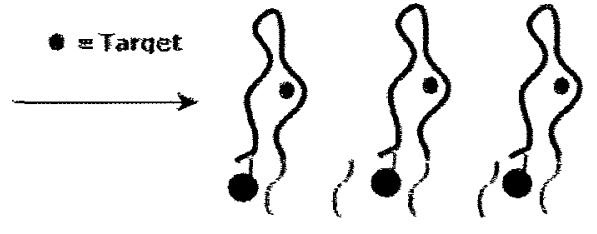

Signal

Figure 2.2: Molecular Beacon Architecture, the red dot represents the transducer; the red line represents the aptamer attached to the gold electrode, which is represented by the yellow bar.

To form a molecular beacon using the above reporter probe complex, the complex must first be attached to ssDNA, and then the ssDNA attached to the surface of a gold electrode.

The reporter probe complex will be attached to ssDNA (Figure 2.3). To do this a variety of coupling chemistries were applied with a view to developing the ideal synthetic pathway for the coupling. 


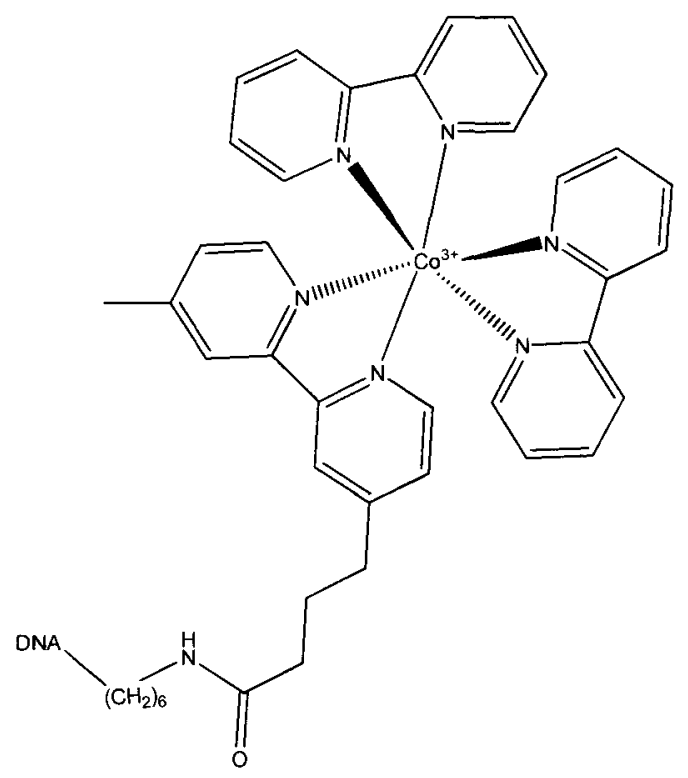

Figure 2.3: Structure of $\left[\mathrm{Co}(\mathrm{bpy})_{2} \mathrm{bpy}^{\prime}\right]^{3+}$ attached to DNA

The ssDNA will be modified with a thiol modification to allow for attachment to a surface of a gold electrode via the gold-thiol reaction. In general, thiols chemisorbed on a metallic surface form a passivating film that acts as a barrier between the surface and the environment. ${ }^{59}$ Long chain, alkanethiols, dialkyl disulfides and dialkyl sulfides chemisorb strongly and form highly ordered stable self-assembled monolayers on a variety of surfaces such as gold, silver and copper ${ }^{60}$ Introducing a functional group to the end of the alkane thiol chain is essential for a functional surface. In general, the gold-thiol interaction can be expressed as shown in Figure 2.4:

$$
R-S H+A u^{o} \rightarrow R-S^{-} A u^{+}+\frac{1}{2} H_{2}
$$

Figure 2.4: Gold-Thiol interaction - although ionic in appearance it is considered a type

$$
\text { of covalent bond }{ }^{61}
$$


The stability behind this interaction is explained through hard-soft acid-base theory. A soft Lewis acid is one whose orbitals are readily available for $\pi$-bonding - in the case of gold these would be d-orbitals. Furthermore, the larger the atom the softer it is, because of the larger number of inner electrons that shield the outer ones, making the atom more polarizable. In this manner, gold is a soft Lewis acid. The same reasoning can be used for sulfur; it is a soft Lewis base because it is a large polarizable atom and is readily available to donate an electron pair to the Lewis acid. As a result, the gold thiol interaction can be characterized as a soft-soft acid base interaction that is covalent in nature. This favourable interaction leads to the stability of this type of monolayer. ${ }^{62,63}$

To put this into the context of this research, the $\mathrm{R}$ group can be considered the aptamer modified with the reporter probe. Essentially, the aptamer forms a monolayer at the surface with the cobalt reporter probe exposed at the top. When a target is introduced, the aptamer changes conformation, and the redox-active reporter probe approaches the double layer close enough for electron transfer to occur. The signal can then be transduced and quantified.

Furthermore, inorganic complexes can be tuned to give different redox couples. This arises as a result of the redox potential. A mixed ligand complex's redox potential is equal to the sum of the weighted average of the redox potentials for the parent binary complexes. ${ }^{64}$ Knowing this, the possibility exists for the development of sensor arrays by switching the ligands chelating the metal. 
The stability of the thiol-monolayers, as well as the versatility of the gold substrate, makes them easily investigated by several methods including electrochemical means. This has led to the investigation of these types of surface films being used in electrochemical sensing ${ }^{63}$.

\subsubsection{The Reporter Probe: $\left[\mathrm{Co}(\mathrm{bpy})_{2} \mathrm{bpy}^{\prime}\right]\left(\mathrm{PF}_{6}\right)_{3}$}

To begin the development of the described molecular beacon sensor, the reporter probe (Figure 2.3) must first be synthesized. The following is a brief description of the precursors and the ensuing reporter probe complex.

The modified bipyridine ligand, bpy', 4-(3-carboxypropyl)-4'-methyl-2,2'bipyridine, is the first of the two precursors that will be synthesized. An efficient way to functionalize bipyridine is via the addition of 2-(2-bromoethyl)-1-3-dioxolane to a solution of lithiated 4,4'-dimethyl-2,2'-bipyridine. Acid hydrolysis of this side chain allows for deprotection to yield an aldehyde functionalization. Oxidation of this group yields the desired carboxylic acid. ${ }^{65}$ The details regarding this synthesis were previously reported. ${ }^{66}$

The second precursor, $\left[\mathrm{Co}(\mathrm{bpy})_{2} \mathrm{Cl}_{2}\right] \mathrm{Cl}$ is a trivalent complex. Most preparations of these types of complexes consist of oxidation via hydrogen peroxide or oxygen. This method of synthesis consists of utilizing a halogen (chlorine) to oxidize the cobalt from 
$2^{+}$to $3^{+}$in a one step reaction. ${ }^{67,68}$ The synthesis of this complex has also been previously reported $^{66}$.

The synthesis of $\left[\mathrm{Co}(\mathrm{bpy})_{2} \mathrm{bpy}^{\prime}\right]\left(\mathrm{PF}_{6}\right)_{3}$ involves the reaction of both precursors, followed by precipitation with $\mathrm{NH}_{4} \mathrm{PF}_{6}$. Various types of purification attempts and characterization have been previously reported ${ }^{66,69}$. Herein the most recent synthesis will be presented with characterization including ${ }^{1} \mathrm{H}$, and COSY NMR, as well as electrospray ionization mass spectrometry.

Following this, coupling experiments will be described and discussed including the use of EDC/NHS chemistry as well as TSTU coupling chemistries. Finally, electrochemical characterization of $\left[\mathrm{Co}(\mathrm{bpy})_{2} \mathrm{bpy} \mathrm{y}^{\prime}\right]^{3+}$-DNA conjugate on a gold electrode will be shown and the utility of this system to the development of a biosensing application will be discussed. 


\subsection{Experimental}

2.2.1 Synthesis of $\left[\mathrm{Co}(\mathrm{bpy})_{2} \mathrm{bpy}^{\prime}\right]\left(\mathrm{PF}_{6}\right)_{3}$
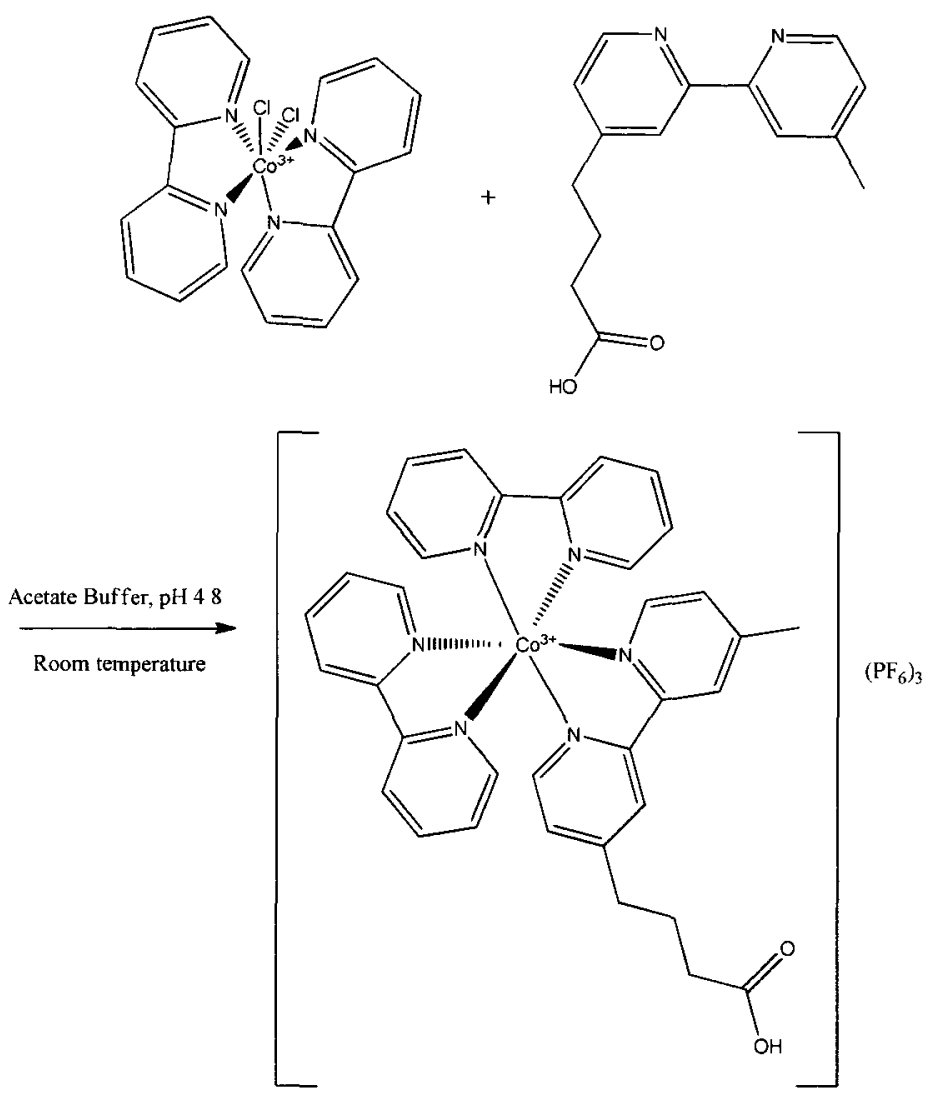

Figure 2.5: Overall synthesis scheme for of $\left[\mathrm{Co}(\mathrm{bpy})_{2} \mathrm{bpy}\right]\left(\mathrm{PF}_{6}\right)_{3}$

The synthesis of the precursors $\left[\mathrm{Co}(\mathrm{bpy})_{2} \mathrm{Cl}_{2}\right] \mathrm{Cl}$ and 4-(3-carboxypropyl)-4'methyl-2,2'-bipyridine (bpy') have been previously reported ${ }^{66,69} \cdot\left[\mathrm{Co}(\mathrm{bpy})_{2} \mathrm{Cl}_{2}\right] \mathrm{Cl}$ $\left(0.1655 \mathrm{~g}, 3.47 \times 10^{-4} \mathrm{~mol}\right)$ was dissolved in $\sim 25 \mathrm{~mL}$ of acetate buffer $(\mathrm{pH} 4.8)$ at room temperature. Additional solvent was added via Pasteur pipette until all of the $\left[\mathrm{Co}(\mathrm{bpy})_{2} \mathrm{Cl}_{2}\right] \mathrm{Cl}$ was dissolved. This required an additional $5-10 \mathrm{~mL}$ of acetate buffer. After complete dissolution, 4-(3-carboxypropyl)-4'-methyl-2,2'-bipyridine $(0.0934 \mathrm{~g}$, $3.60 \mathrm{x}^{-4} \mathrm{~mol}$ ) was added to the solution. At this point the solution turned orange in colour. 
The reaction was left for 4 hours at which time ammonium hexafluorophosphate was added to precipitate the crude product. [Co(bpy $\left.)_{2} \mathrm{bpy}^{\prime}\right]\left(\mathrm{PF}_{6}\right)_{3}(22.24 \%$ yield, $0.082 \mathrm{~g}$, $7.7 \times 10^{-5} \mathrm{~mol}$ ) was filtered and stored in a vial. Further precipitation occurred after filtering. This product was also filtered and stored.

\subsubsection{Oligonucleotide Synthesis}

DNA synthesis was conducted using standard phosphoramidite chemistry on a BioAutomation Mermade 6 synthesizer (Irving, TX).$^{45}$ All phosphoramidite reagents and anhydrous acetonitrile were purchased from Glen Research (Sterling, VA). Activator, deblock, capping, and oxidizer solutions used in the DNA synthesis were purchased from BioAutomation (Irving, TX). DNA synthesis was conducted on $1000 \AA$ CPG $1 \mu \mathrm{mol}$ support columns (Glen Research) for sequences without a 3' modification or $500 \AA 1 \mu \mathrm{mol}$ support columns for those with a 3 ' modification.

The sequences synthesized were as follows:

1. $\mathrm{H}_{2} \mathrm{~N}-\left(\mathrm{CH}_{2}\right)_{6}-5^{\prime}$-ATG ATA GCA TCG GTC-3'

2. $\mathrm{H}_{2} \mathrm{~N}-\left(\mathrm{CH}_{2}\right)_{6}-5^{\prime}-\mathrm{ACG}$ TTA GCA TCG GTC-3'

3. $\mathrm{H}_{2} \mathrm{~N}-\left(\mathrm{CH}_{2}\right)_{6}-5^{\prime}-\mathrm{ACG}$ TTA GCA TCG GTC-3'-( $\left.\mathrm{CH}_{2}\right)_{6}-\mathrm{S}-\mathrm{S}-\left(\mathrm{CH}_{2}\right)_{6}-\mathrm{OH}$

4. HO- $\left(\mathrm{CH}_{2}\right)_{6}$-S-S- $\left(\mathrm{CH}_{2}\right)_{6}-5^{\prime}$-CTGGCTACGATTGCA-3'-( $\left.\mathrm{CH}_{2}\right)_{6}$-NHFmoc 
Sequences 1 and 2 contain a $5^{\prime}$ amino modifier that was protected with a 4,4'dimethoxy-4"-methylsulfonyl-trityl group. Sequence 3 contained the same amino modifier, as well as a $3^{\prime}$ thiol modification. After a complete synthesis cycle, the columns were either deblocked and conjugated (see Chapter 2.2.3, 2.2.4 and 2.2.5), or stored in the freezer for future use.

Prior to conjugation, the $5^{\prime}$ amino modifier had to be deblocked to remove either the 4,4'-Dimethoxy-4"-methylsulfonyl-trityl or 1-O-Dimethoxytrityl-hexyl protecting group. Deblocking was conducted using a BioAutomation cleaving chuck. This cleaving chuck uses suction to draw liquids through the columns. The columns were initially treated with $300 \mu \mathrm{L}$ of anhydrous acetonitrile. Following this, $3 \times 300 \mu \mathrm{L}$ of $10 \%$ diethylamine (DEA) in anhydrous acetonitrile was passed through the columns. The DEA was left in the column to react for 2 minutes. The DEA was washed off the column using $2 \times 300 \mu \mathrm{L}$ of anhydrous acetonitrile. The columns were then treated with $2 \times 300 \mu \mathrm{L}$ of deblock solution. The solutions were left in the columns to react for approximately 1 minute. The columns were then washed with $2 \times 300 \mu \mathrm{L}$ of acetonitrile. Conjugation reactions were conducted immediately on deblocked CPG's.

Sequence 4 required a different deprotecting strategy. As the amine was protected with Fluorenylmethyloxycarbonyl (Fmoc), it required the use of a solution of $20 \%$ piperidine as opposed to deblock solution. In a similar fashion to the standard deblocking procedure, the DNA column was placed on a BioAutomation cleaving chuck and $26 \times 300 \mu \mathrm{L}$ of a solution of $20 \%$ piperidine in DMF. Removal of the Fmoc protecting 
group could be quantified using UV-Vis given the absorbance $301 \mathrm{~nm}$ when in a solution of $20 \%$ piperidine in DMF in accordance with the manufacturer's instructions.

\subsubsection{Conjugation of bpy' to DNA via EDC-NHS Chemistry, and purification}

\subsubsection{Conjugation of bpy' to DNA using EDC-NHS Chemistry}
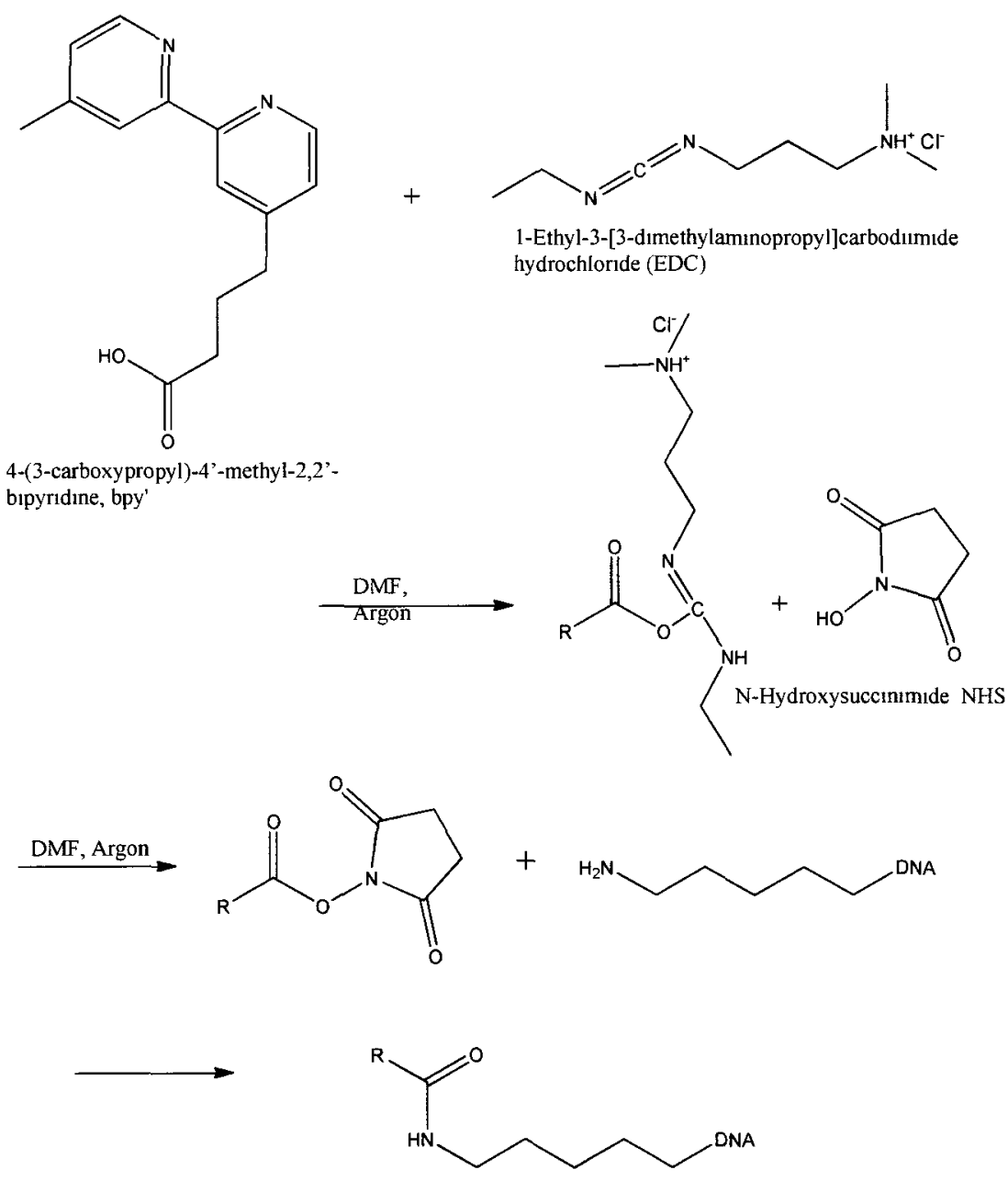

Figure 2.6: Overall Synthesis scheme for the conjugation of and 4-(3-carboxypropyl)-4'methyl-2,2'-bipyridine to DNA using EDC/NHS 
The activation of the bpy' was conducted prior to the deblocking step reported in Chapter 2.2.2 in order to perform the conjugation reaction as quickly as possible.

1-Ethyl-3-[3-dimethylaminopropyl]carbodiimide hydrochloride (EDC, 0.021g, $110 \mu \mathrm{mol}$ ) was dissolved in $\sim 1 \mathrm{~mL}$ of dimethylformamide (DMF). To this solution, bpy' $(0.0026 \mathrm{~g}, 10 \mu \mathrm{mol})$ was added and allowed to mix for 10 minutes. After 10 minutes, NHydroxysuccinimide (NHS, $0.0368,320 \mu \mathrm{mol}$ ) was added and dissolved in the solution. This was left to react for 30 minutes to create the 'activated' bpy'. At this time, the deblocking step reported in Chapter 2.2.2 was conducted. The CPG beads from the DNA synthesis column were removed from the column and placed in an Eppendorf tube. The activated bpy' solution was added to the beads and left to react under Argon overnight.

After the reaction was deemed complete, the reaction mixture was centrifuged at $13000 \mathrm{~g}$ for 5 minutes. The supernatant DMF solution was removed. The beads were washed with two $500 \mu \mathrm{L}$ portions of DMF, each time the solution was centrifuged and the supernatant removed.

DNA deprotection was conducted with the addition of $1 \mathrm{~mL}$ of $28 \%$ ammonium hydroxide. This solution was sealed under argon, at $37^{\circ} \mathrm{C}$ for 24 hours. After this reaction time, the beads were removed from the ammonium hydroxide/DNA solution using a $0.45 \mu \mathrm{m}$ nylon microfilterfuge (Rainin Instrments, Woburn, MA), and the filtrate was evaporated in vacuo, leaving only DNA in the Eppendorf tube. 


\subsubsection{Ethanol Precipitation}

The DNA was ethanol precipitated. $100 \mu \mathrm{L}$ of deionized water was used to dissolve the sample. To this, $50 \mu \mathrm{L}$ of $3 \mathrm{M} \mathrm{NaCl}$ and $1 \mathrm{~mL}$ of anhydrous ethanol was added. The solution was briefly vortexed and placed on dry ice for 30 minutes and centrifuged at $-9^{\circ} \mathrm{C}$ for 20 minutes on a Sorvall Legend 21R Microcentrifuge (Thermo Scientific) at $10000 \mathrm{~g}$. The supernatant solution was removed and the pellet was dried in vacuo.

\subsubsection{Quantification}

DNA was quantified using a Varian Cary 300 Bio UV-Visible spectrophotometer. The DNA was dissolved in deionized water and spectra were collected. Dilutions were made as necessary. The peak at $260 \mathrm{~nm}$ was used in conjunction with the extinction coefficient to determine the concentration and thus the amount of DNA present in the stock sample.

2.2.3.4 Purification by polyacrylamide gel electrophoresis (PAGE)

Urea (molecular biology grade), ammonium persulfate (electrophoresis grade), (TEMED, >99\%), N,N'-methylenebisacrylamide, sodium dodecyl sulphate, acrylamide (DNA-sequencing grade), and tris(hydroxymethyl)aminomethane were ordered from BioShop Canada (Burlington, ON). Boric acid was purchased from BDH (through VWR, 
Mississauga, ON). Magnesium acetate tetrahydrate (minimum 98\%) was purchased from Sigma-Aldrich (Oakville, ON).

An acrylamide stock solution was already prepared. It contained $190 \mathrm{~g}$ of acrylamide, and $10 \mathrm{~g}$ of $\mathrm{N}, \mathrm{N}^{\prime}$-methylenebisacrylamide in $250 \mathrm{~mL}$ of deionized water. The solution was then made up to $500 \mathrm{~mL}$ using deionized water and filtered by gravity. PAGE experiments were performed on a Hoefer 600X Chroma vertical electrophoresis system. The power supply used was a Fisher Scientific FB1000 Electrophoresis Power Supply. Gels were imaged using an Alpha Innotech AlphaImager EC.

A stock solution of $5 \times$ TBE buffer was previously prepared by dissolving tris(hydroxymethyl)aminomethane (Tris, $107.8 \mathrm{~g}, 0.89 \mathrm{~mol})$, boric acid $(55.0 \mathrm{~g}, 0.89 \mathrm{~mol})$ and ethylenediaminetetraacetic acid $(7.44 \mathrm{~g}, 0.0200 \mathrm{~mol})$ in $2 \mathrm{~L}$ of deionized water and filtering through a $0.22 \mu \mathrm{m}$ cellulose acetate sterilizing filter.

The gel was prepared by dissolving urea $(31.5 \mathrm{~g})$ in $37.5 \mathrm{~mL}$ of acrylamide stock solution. To this $15 \mathrm{~mL}$ of $5 \mathrm{xTBE}$ buffer was added. The solution was stirred and heated to $37^{\circ} \mathrm{C}$ until all of the components had dissolved. The solution was filtered while hot into a $250 \mathrm{~mL}$ beaker and left to cool. $450 \mu \mathrm{L}$ of a solution of $10 \%$ ammonium persulfate $(0.1 \mathrm{~g}$ in $1 \mathrm{~mL}$ of deionized water) was added dropwise. $35 \mu \mathrm{L}$ of TEMED was added and the solution swirled to ensure sufficient mixing. Immediately after addition of the TEMED the gel was cast. It was then left to polymerize for 30 minutes. Upon polymerization, the 
gel was run in $1 \times \mathrm{TBE}$ (prepared via diluting $400 \mathrm{~mL}$ of $5 \times \mathrm{TBE}$ to $2 \mathrm{~L}$ ) for 30 minutes at a constant current of $35 \mathrm{~mA}$ to equilibrate.

During the equilibration run, DNA samples were prepared by taking $20 \mu \mathrm{L}$ of sample (4-6 $\left.\mathrm{ODs}_{260}\right)$ and adding an equivalent volume of formamide. This solution was heated at $55^{\circ} \mathrm{C}$ for 5 minutes.

After the equilibration run, the prepared samples were loaded onto the gel and run for an amount of time determined by observing the movement of a fluorescein tagged DNA strand of equal size to the DNA in a control lane. When the fluorescein tagged sequence was approximately half way down the gel, the gel run was deemed complete. Upon completion, the gel was imaged and the bands were cut out of the gel. The bands were pushed through $5 \mathrm{~mL}$ syringes into $15 \mathrm{~mL}$ Eppendorf tubes. Approximately $7 \mathrm{~mL}$ of elution buffer (10mM Tris) was added to facilitate elution. The DNA was eluted by incubating the tubes in a Labnet Mini Incubator at $37^{\circ} \mathrm{C}$ overnight. After elution was complete, the gel was removed via syringe filtration using $0.45 \mu \mathrm{m}$ syringe filters (Pall Life Sciences).

After removal of the gel fragments, the solution was lyophilized to dryness. The dried samples were desalted using Amicon 30k ultrafiltration tubes as per the manufacturer's instructions. DNA was quantified as per Chapter 2.2.3.3. 
2.2.4.1 First attempt at DNA- bpy' conjugation: TSTUDDMAP
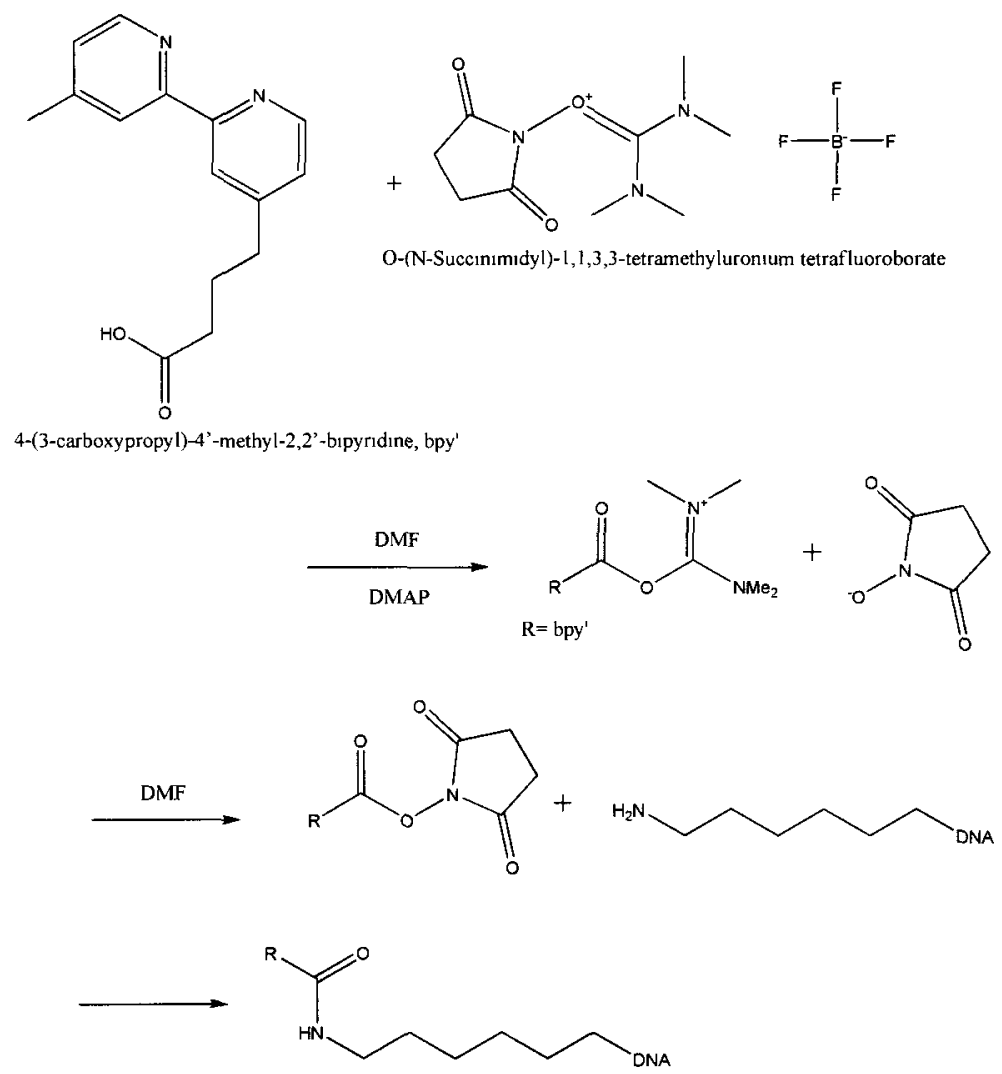

Figure 2.7: Overall Synthesis scheme for the conjugation of and 4-(3-carboxypropyl)-4'methyl-2,2'-bipyridine to DNA using TSTU-DMAP chemistry

DNA was synthesized in accordance with Chapter 2.2.2. Bpy' $(2.7 \mathrm{mg}, 10 \mu \mathrm{mol})$ was weighed into an Eppendorf tube and dissolved in $500 \mu \mathrm{L}$ of DMF. 4dimethylaminopyridine (DMAP, $1.9 \mathrm{mg}, 15.6 \mu \mathrm{mol}$ ) was added to the solution and allowed to dissolve. Upon dissolution, O-(N-Succinimidyl)-1,1,3,3-tetramethyluronium tetrafluoroborate (TSTU, $4.3 \mathrm{mg}, 14.2 \mu \mathrm{mol}$ ) was added to the solution. Upon dissolution, the solution was shaken for 10 minutes. After the 10 minute period, the solution was 
added to an Eppendorf tube containing deblocked DNA on CPG's. This was left to react for 10 minutes. After the reaction was deemed complete, the Eppendorf tube containing the CPG-DNA-bpy' reaction product was centrifuged at $21,100 \mathrm{~g}$ for 2 minutes. The supernatant was removed and the beads were washed with $5 \times 500 \mu \mathrm{L}$ portions of DMF; each time the CPG-DMF solution was vortexed, centrifuged, and supernatant removed. After the last DMF wash, $1 \mathrm{~mL}$ of $28 \%$ ammonium hydroxide was added and the CPGDNA-bpy'-ammonium hydroxide solution was placed on the heating block at $37^{\circ} \mathrm{C}$ for 24 hours.

The deprotected DNA-bpy' conjugate was separated from the beads via the protocol described in Chapter 2.2.3.1. Ethanol precipitation, quantification and PAGE were conducted using the same procedures described in Chapters 2.2.3.2-2.2.3.4. 
2.2.4.2 Second attempt at DNA-bpy' conjugation: TSTU\DIPEA

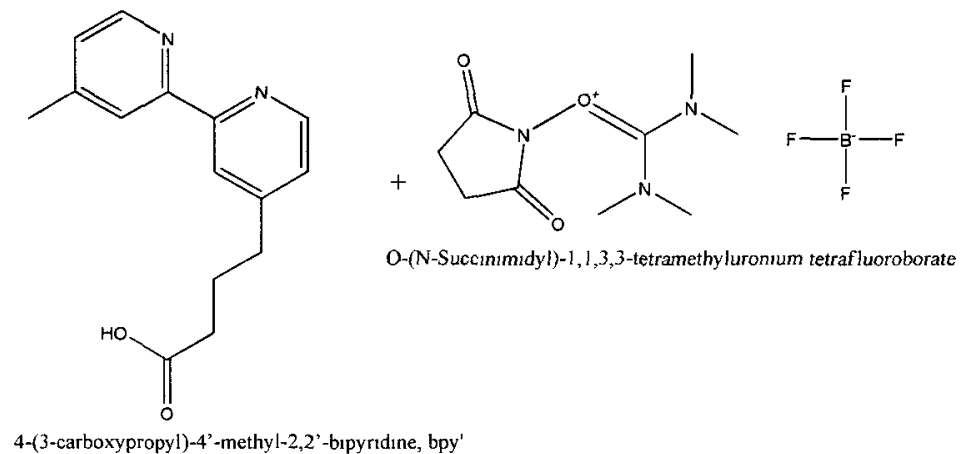

4-(3-carboxypropy1)-4'-methyl-2,2'-bipyndıne, bpy'
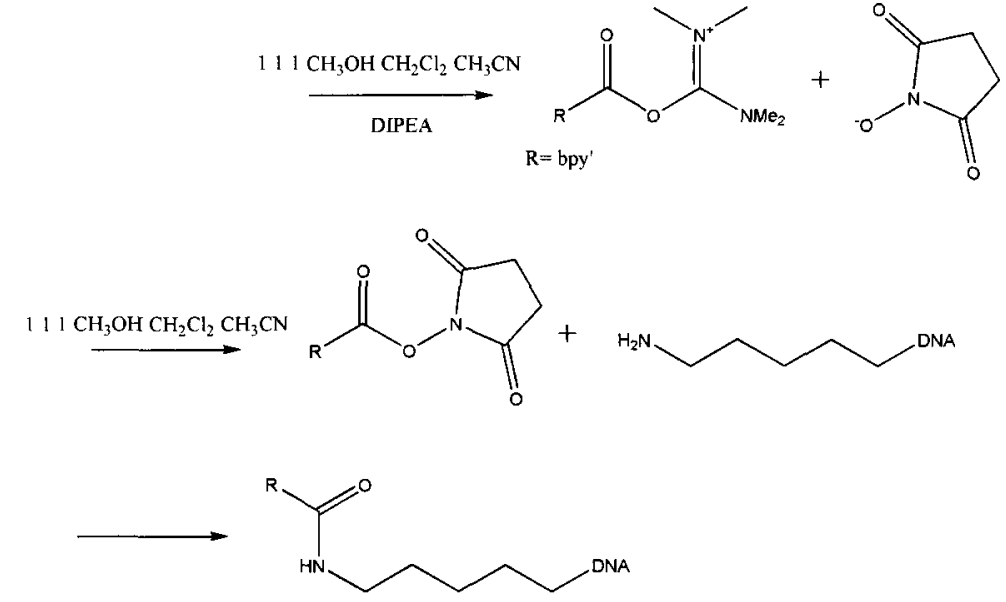

Figure 2.8: Overall Synthesis scheme for the conjugation of and 4-(3-carboxypropyl)-4'methyl-2,2'-bipyridine to DNA using TSTU-DIPEA chemistry

Bpy' $(1.8 \mathrm{mg}, 7 \mu \mathrm{mol})$ was dissolved in $700 \mu \mathrm{L}$ of $1: 1: 1 \mathrm{CH}_{3} \mathrm{OH}: \mathrm{CH}_{2} \mathrm{Cl}_{2}: \mathrm{CH}_{3} \mathrm{CN}$ in a glass vial. To this, N,N-Diisopropylethylamine $(4 \mu \mathrm{L}, 23 \mu \mathrm{mol})$ and $\mathrm{O}-(\mathrm{N}-$ Succinimidyl)-1,1,3,3-tetramethyluronium tetrafluoroborate $(11.1 \mathrm{mg}, 36 \mu \mathrm{mol})$ were added and dissolved in the solution. This was left to react for 1 hour during which time 5 ' amino modified DNA was deblocked in accordance with Chapter 2.2.3.1. After the hour reaction time, the CPGs containing deblocked amino modified DNA were added to the 
reaction vessel. Along with the DNA, N,N-Diisopropylethylamine $(7.4 \mu \mathrm{L}, 42.5 \mu \mathrm{mol})$ was added and the reaction left to stir slowly overnight. After the overnight synthesis, the CPGs were carefully transferred via glass pipette to an Eppendorf tube. This tube was centrifuged to allow the supernatant solution to be removed from the CPGs. The CPGs were washed with $2 \times 500 \mu \mathrm{L}$ of $1: 1: 1 \mathrm{CH}_{3} \mathrm{OH}: \mathrm{CH}_{2} \mathrm{Cl}_{2}: \mathrm{CH}_{3} \mathrm{CN}$. After washing was complete, the CPGs were placed in $1 \mathrm{~mL}$ of $28 \%$ ammonium hydroxide on a heating block at $37^{\circ} \mathrm{C}$ for 24 hours to separate the DNA-bpy' conjugate from the CPGs. After the 24 hour reaction with $\mathrm{NH}_{4} \mathrm{OH}$ the CPGs DNA- $\mathrm{NH}_{4} \mathrm{OH}$ solution was separated from the CPGs via pipette and the solution was evaporated in vacuo. The dried DNA-bpy' conjugate was ethanol precipitated in accordance with Chapter 2.2.3.2 and quantified using UV-Vis as per the procedure described in Chapter 2.2.3.3. The sample was analyzed via Electrospray mass spectrometry, PAGE (Chapter 2.2.3.4), and High Performance Liquid Chromatography.

\subsubsection{High Performance Liquid Chromatography (HPLC)}

HPLC was conducted on an Agilent 1200 Series HPLC using a Phenomenex Oligo Reverse Phase HPLC column. The solvent system was a solution of 5\% HPLC grade acetonitrile in $50 \mathrm{mM}$ triethyl ammonium acetate. Table 1 illustrates the gradient used during HPLC analytical and collection runs. 
Table 1: HPLC gradient used for collection of DNA-Conjugates

\begin{tabular}{|l|l|l|}
\hline Time & Percent Acetonitrile & Percent Triethyl ammonium \\
& & acetate \\
\hline $0-5$ minutes & $0 \%$ & $100 \%$ \\
\hline $5-10$ minutes & $2.3 \%$ & $97.7 \%$ \\
\hline $10-30$ minutes & $40 \%$ & $60 \%$ \\
\hline
\end{tabular}

The desired peak eluted at $\sim 22.5$ minutes. A typical collection involved collecting the eluent from 22-23 minutes. To be certain of peak positions in the chromatogram before each collection day an analytical chromatogram was run using $5 \mu \mathrm{L}$ of sample. A typical collection run was conducted using $50 \mu \mathrm{L}$ of sample. After collection, samples were lyophilized, desalted and quantified for further use.

2.2.5 Conjugation of $\left[\mathrm{Co}(\mathrm{bpy})_{2} \mathrm{bpy}^{\prime}\right]\left(\mathrm{PF}_{6}\right)_{3}$ to DNA via TSTU-DIPEA Chemistry
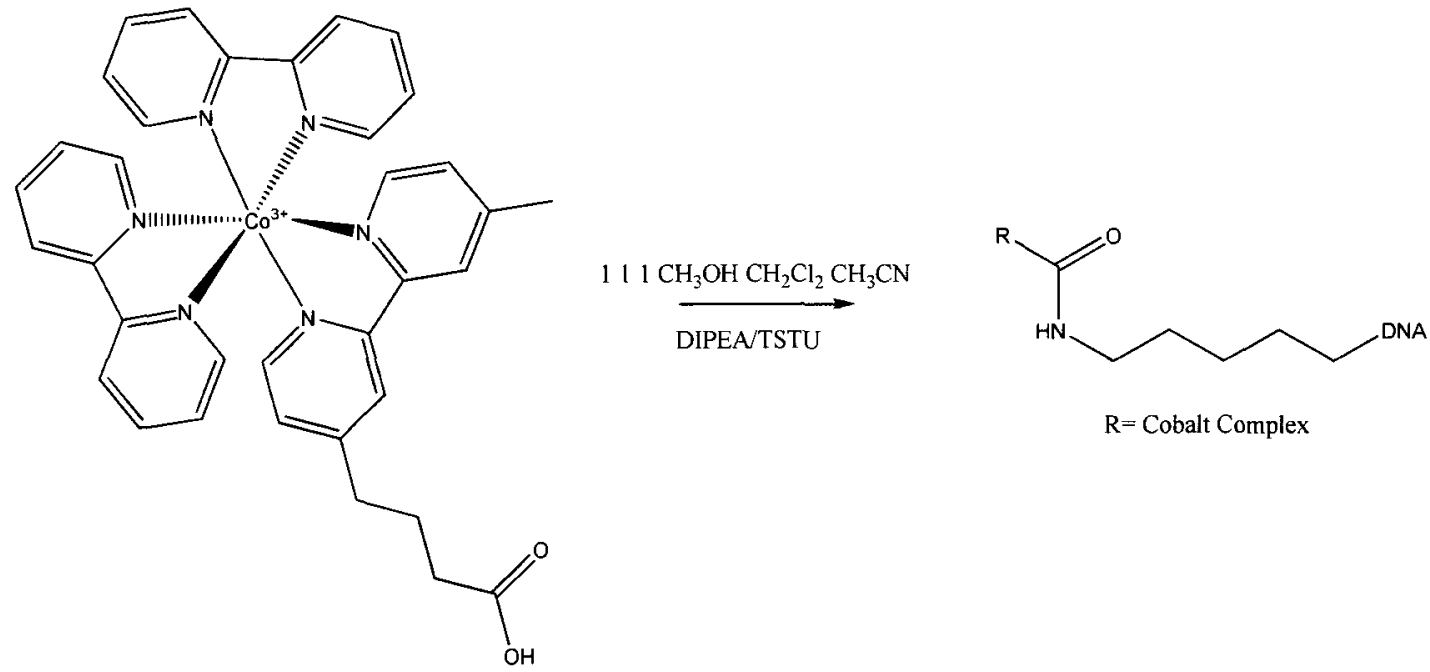

Figure 2.9: Overall Synthesis scheme for the conjugation of and $\left[\mathrm{Co}(\mathrm{bpy})_{2} \mathrm{bpy}^{\prime}\right]\left(\mathrm{PF}_{6}\right)_{3}$ to DNA using TSTU-DIPEA chemistry 
$\left[\mathrm{Co}(\mathrm{bpy})_{2} \mathrm{bpy}^{\prime}\right]\left(\mathrm{PF}_{6}\right)_{3}(8.28 \mathrm{mg}, 7.8 \mu \mathrm{mol})$ was dissolved in 1:1:1

$\mathrm{CH}_{3} \mathrm{OH}: \mathrm{CH}_{2} \mathrm{Cl}_{2}: \mathrm{CH}_{3} \mathrm{CN}$. To this N,N-Diisopropylethylamine $(4 \mu \mathrm{L}, 23 \mu \mathrm{mol})$ and $\mathrm{O}-(\mathrm{N}-$ Succinimidyl)-1,1,3,3-tetramethyluronium tetrafluoroborate $(9.39 \mathrm{mg}, 31 \mu \mathrm{mol})$ were added and dissolved in the solution. This was left to react for 1 hour during which time $5^{\prime}$ amino modified DNA was deblocked in accordance with Chapter 2.2.3.1. After the hour reaction time, the CPGs containing deblocked amino modified DNA were added to the

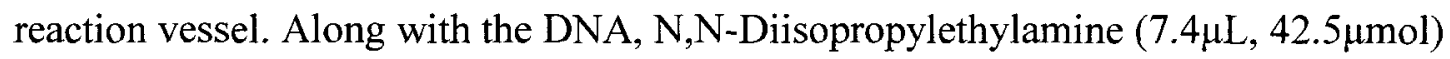
was added and the reaction left to stir slowly overnight. After the overnight synthesis, the CPGs were carefully transferred via glass pipette to an Eppendorf tube. It was observed that the CPGs were orange. This tube was centrifuged to allow the supernatant solution to be removed from the CPGs. The CPGs were washed with $2 \times 500 \mu \mathrm{L}$ of $1: 1: 1$ $\mathrm{CH}_{3} \mathrm{OH}: \mathrm{CH}_{2} \mathrm{Cl}_{2}: \mathrm{CH}_{3} \mathrm{CN}$. It was observed that the $\mathrm{CPGs}$ remained orange after the washing indicating that the cobalt complex had successfully attached to the DNA. After washing was complete, the CPGs were placed in $1 \mathrm{~mL}$ of $28 \%$ ammonium hydroxide on a heating block at room temperature for 24 hours to separate the DNA-Cobalt conjugate from the CPGs. After the 24 hour reaction with $\mathrm{NH}_{4} \mathrm{OH}$ the CPGs DNA- $\mathrm{NH}_{4} \mathrm{OH}$ solution was separated from the CPGs via pipette and the solution was evaporated in vacuo. The dried DNA-bpy' conjugate was ethanol precipitated in accordance with Chapter 2.2.3.2 and quantified using UV-Vis as per the procedure described in Chapter 2.2.3.3. The sample was analyzed via Electrospray mass spectrometry, and High Performance Liquid Chromatography (Chapter 2.2.4.3). 
2.2.6 Coordination of $\left[\mathrm{Co}(\mathrm{bpy})_{2}\right]^{3+}$ to bpy' modified DNA
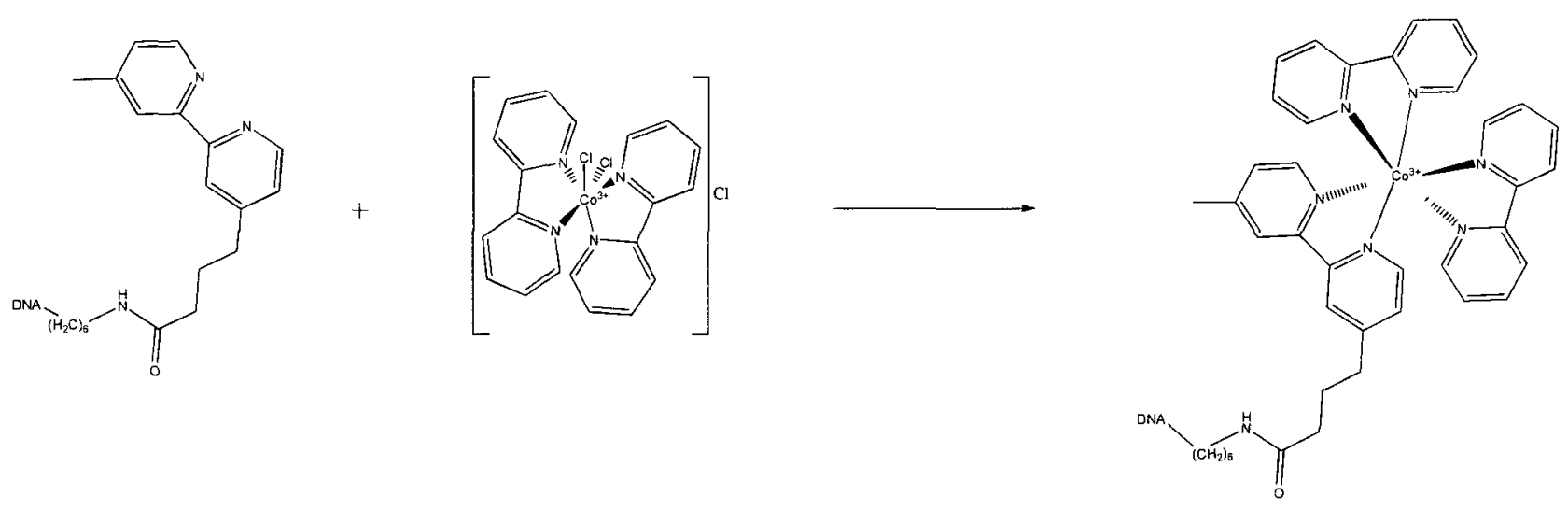

Figure 2.10: Overall Synthesis scheme for the conjugation of $\left[\mathrm{Co}(\mathrm{bpy})_{2} \mathrm{Cl}_{2}\right] \mathrm{Cl}$ to DNAbpy' $^{\prime}$

HPLC purifed, bpy' modified (Chapter 2.2.4.2, 8nmol) sequence 3 DNA was dried in vacuo. $\left[\mathrm{Co}(\mathrm{bpy})_{2} \mathrm{Cl}_{2}\right] \mathrm{Cl}\left(1.3 \mathrm{mg}, 2.7 \times 10^{-6} \mathrm{~mol}\right)$ was dissolved in $300 \mu \mathrm{L}$ of deionized water. Complete dissolution was not observed, so the solution was centrifuged and the supernatant was removed and placed in an Eppendorf tube. The solution was quantified by UV-Vis using an extinction coefficient of $47.3 \mathrm{Lmol}^{-1} \mathrm{~cm}^{-1}$. It was found that the solution contained $1.28 \mu \mathrm{mol}$ of $\left[\mathrm{Co}(\mathrm{bpy})_{2} \mathrm{Cl}_{2}\right] \mathrm{Cl}$ in $200 \mu \mathrm{L}$ of water. $100 \mu \mathrm{L}$ of Phosphate buffer ( $5 \mathrm{mM}$ phosphate, $100 \mathrm{mM} \mathrm{MgCl}_{2}, 50 \mathrm{mM} \mathrm{NaCl}$, $\mathrm{pH} 7$ ) was used to dissolve the DNA-bpy' conjugate. The $200 \mu \mathrm{L}\left[\mathrm{Co}(\mathrm{bpy})_{2} \mathrm{Cl}_{2}\right] \mathrm{Cl}$ solution was added to the DNA-bpy' solution. This was left to react for 4 hours. After the reaction period the solution was desalted using Amicon 30k ultrafiltration tubes as per the manufacturer's 
instructions. The recovered product was dried in vacuo, quantified, and a portion sent for electrospray mass spectrometry.

\subsubsection{Electrochemistry Procedures}

\subsubsection{Gold Electrode Cleaning Procedure}

A fine cleaning pad (Bioanalytical Systems Inc.) was wetted with deionized water and a few drops of Alumina polish were placed on the wet pad. A gold electrode $(\mathrm{CH}$ Instruments) was polished by gently performing a series of figure-eights over the pad for $\sim 10$ minutes. After this, the electrode was sonicated for $\sim 5-10$ minutes in deionized water. The electrode was then connected to the electrochemistry system (CHI Instruments). The reference electrode, $\mathrm{Ag} / \mathrm{AgCl}$, was connected after being refilled with electrode filling solution as per the manufacturer's instructions. A platinum wire was also connected to the system to act as an auxiliary electrode, thereby completing the standard 3-electrode setup. The electrode was etched using Cyclic voltammetry (CV) performed in $1 \mathrm{M} \mathrm{H}_{2} \mathrm{SO}_{4}$ using the settings reported in Table 2. A 15 minute degassing step using argon was conducted before any scans were taken. A sample of a clean electrode is shown in Figure

\subsection{1 .}


Table 2: Electrochemistry settings for cleaning a gold electrode

\begin{tabular}{|l|l|}
\hline Initial & $0 \mathrm{~V}$ \\
\hline High & $1.65 \mathrm{~V}$ \\
\hline Low & $-0.25 \mathrm{~V}$ \\
\hline Initial Polarity & Negative \\
\hline Scan Rate & $0.2 \mathrm{~V} / \mathrm{s}$ \\
\hline Segments & 20 \\
\hline Intervals & $0.001 \mathrm{~s}$ \\
\hline Quiet Time & $2 \mathrm{~s}$ \\
\hline Sensitivity & $1 \times 10^{-4}$ \\
\hline
\end{tabular}

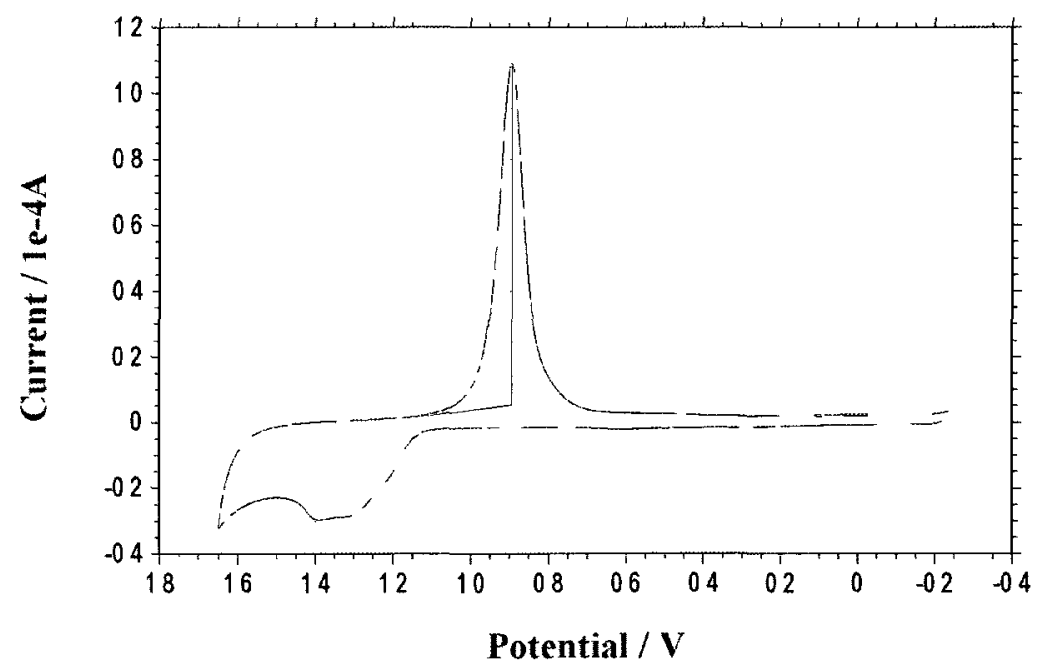

Figure 2.11: Cyclic Voltammogram of a clean gold electrode; conducted using the settings described in Table 2 
In the event that the CV did not look like the voltammogram shown in Figure 2.11 the cleaning cycle was repeated. Typically $2-3$ cleaning cycles are needed in order for the surface to be suitable for deposition experiments.

\subsubsection{Deposition procedure}

DNA (either conjugated with bpy', [Co(bpy) $\left.)_{2} \mathrm{byy}^{\prime}\right]\left(\mathrm{PF}_{6}\right)_{3}$ or unmodified $5^{\prime} \mathrm{NH}_{2}$ DNA) was synthesized in accordance with the reported protocols using sequence 3. Prior to deposition, it was necessary to cleave the $3^{\prime} \mathrm{S}-\mathrm{S}$ bond to create a free thiol to allow for a thiol-gold bond to form upon deposition. This was conducted by dissolving the desired amount of DNA (typically $\sim 7 \mathrm{nmols}$ ) in $100 \mu \mathrm{L}$ of a dithiothreitol solution $(16.4 \mathrm{mg}$, $1.0 \times 10^{-4} \mathrm{~mol}$ in $1 \mathrm{~mL} \mathrm{pH} 8.2$ Tris Buffer). This was left to react for 30 minutes. After the reaction, ethanol precipitation of the sample was carried out (Chapter 2.2.3.2). Following this, the sample was dissolved in $500 \mu \mathrm{L}$ of phosphate buffer $(5 \mathrm{mM}$ phosphate, $100 \mathrm{mM}$ $\mathrm{MgCl}_{2}, 50 \mathrm{mM} \mathrm{NaCl}, \mathrm{pH} 7$ ) and desalted and collected using Amicon 30k ultrafiltration tubes as per the manufacturer's instructions. Initial experiments involved the dilution of the sample as to allow for quantification of the DNA. However, after verifying that the procedure yielded an acceptable amount of DNA, the sample was instead directly deposited as a concentrated drop onto the electrode surface. The electrode was stored in a plastic vessel that contained vials filled with water to ensure sufficient humidity to prevent the concentrated drop from evaporating. Deposition was carried out for 24 hours. 


\subsubsection{Electrochemistry of the modified electrodes}

After deposition, the electrode was washed with a stream of deionized water for $\sim 20$ seconds. The electrode was then connected to the electrochemistry workstation in a 3 electrode setup with a $\mathrm{Ag} / \mathrm{AgCl}$ reference electrode and $\mathrm{Pt}$ auxiliary electrode. Phosphate buffer ( $5 \mathrm{mM}$ phosphate, $100 \mathrm{mM} \mathrm{MgCl}_{2}, 50 \mathrm{mM} \mathrm{NaCl}$, $\mathrm{pH}$ 7) was used to conduct measurements and was degassed for 15 minutes with argon prior to experiments being conducted. Cyclic voltammetry and square wave voltammetry were conducted using the settings described in Table 3.

Table 3: Electrochemistry settings used for DNA experiments

\begin{tabular}{|l|l|l|l|}
\hline \multicolumn{2}{|c|}{ Cyclic Voltammetry } & \multicolumn{2}{c|}{ Square Wave Voltammetry } \\
\hline Initial & $0 \mathrm{~V}$ & Initial & $-0.35 \mathrm{~V}$ \\
\hline High & $0.35 \mathrm{~V}$ & High & $0.35 \mathrm{~V}$ \\
\hline Low & $-0.35 \mathrm{~V}$ & Increment & $0.001 \mathrm{~V}$ \\
\hline Initial Polarity & Negative & Amplitude & $0.025 \mathrm{~V}$ \\
\hline Scan Rate & $0.2 \mathrm{~V} / \mathrm{s}$ & Frequency & $15 \mathrm{~Hz}$ \\
\hline Segments & 20 & Quiet Time & $2 \mathrm{~s}$ \\
\hline Intervals & $0.001 \mathrm{~s}$ & Sensitivity & $1 \times 10^{-5}$ \\
\hline Quiet Time & $2 \mathrm{~s}$ & & \\
\hline Sensitivity & $1 \times 10^{-4}$ & & \\
\hline
\end{tabular}

After initial electrochemistry experiments involving DNA-bpy', and unmodified

DNA-NH ${ }_{2}$, the electrodes were placed in the plastic deposition vessel and a concentrated 
drop of $\left[\mathrm{Co}(\text { bpy })_{2} \mathrm{Cl}_{2}\right] \mathrm{Cl}(\sim 0.09 \mathrm{M}, 30 \mu \mathrm{L})$ was placed on the electrode surface and left to react for 1 hour. After the reaction time, the electrodes were washed with a stream of deionized water for 20 seconds. Each electrode had the same CV and SW measurements taken as before the $\left[\mathrm{Co}(\text { bpy })_{2} \mathrm{Cl}_{2}\right] \mathrm{Cl}$ conjugation (settings in Table 3 ).

Quantitation of DNA surface coverage was conducted using a previously reported protocol utilizing Hexaammine Ruthenium (III) Chloride. A $1 \mu \mathrm{M}$ solution of Ruthenium Hexaammine was made by dissolving Ruthenium Hexaammine $\left(12.6 \mathrm{mg}, 4.0 \times 10^{-5} \mathrm{~mol}\right)$ in $20 \mathrm{~mL}$ of $10 \mathrm{mM}$ Tris buffer. From this solution, $\sim 10 \mu \mathrm{L}$ was diluted with $19.9 \mathrm{~mL}$ of $10 \mathrm{mM}$ Tris buffer to give a $1 \mu \mathrm{M}$ solution. This $1 \mu \mathrm{M}$ solution was used for electrochemical experiments using the settings described in Table 4. Quantification was conducted using reported methods. ${ }^{70,71}$

Table 4: Electrochemistry settings used for Ruthenium Hexaammine experiments

\begin{tabular}{|l|l|}
\hline \multicolumn{2}{|c|}{ Cyclic Voltammetry } \\
\hline Initial & $0 \mathrm{~V}$ \\
\hline High & $0.1 \mathrm{~V}$ \\
\hline Low & $-0.45 \mathrm{~V}$ \\
\hline Initial Polarity & Negative \\
\hline Scan Rate & $0.05 \mathrm{~V} / \mathrm{s}$ \\
\hline Segments & 20 \\
\hline Intervals & $0.001 \mathrm{~s}$ \\
\hline Quiet Time & $2 \mathrm{~s}$ \\
\hline Sensitivity & $1 \times 10^{-4}$ \\
\hline
\end{tabular}




\subsection{Results and Discussion}

Table 5: Summary of all attempted conjugation pathways

\begin{tabular}{|c|c|c|}
\hline Conjugation & Conditions/Characterization & Result (Success/Fail) \\
\hline \multirow[t]{3}{*}{$\begin{array}{l}\text { Sequence } 1+ \\
\text { bpy' }\end{array}$} & $\begin{array}{l}\text { Coupling reagents: EDC-NHS } \\
\text { Solvent: DMF } \\
\text { Characterization: PAGE, ESI-MS } \\
\text { Further work: Reacted gel bands with } \\
\mathrm{Co}\left(\text { bpy }{ }_{2} \mathrm{Cl}_{2}\right) \mathrm{Cl}\end{array}$ & $\begin{array}{l}\text { Failed - Discussed in } \\
\text { section } 2.2 .3,2.3 .2\end{array}$ \\
\hline & $\begin{array}{l}\text { Coupling reagents: EDC-NHS with 2- } \\
\text { Mercaptoethanol and Hydroxylamine } \\
\text { Solvent: DMF } \\
\text { Characterization:ESI-MS }\end{array}$ & $\begin{array}{l}\text { Failed - Discussed in } \\
\text { section 2.3.2 and A2.0 }\end{array}$ \\
\hline & $\begin{array}{l}\text { Coupling reagents: TSTU-DMAP } \\
\text { Solvent: DMF } \\
\text { Characterization: PAGE, ESI-MS }\end{array}$ & $\begin{array}{l}\text { Failed - Discussed in } \\
\text { section } 2.2 .4,2.3 .3\end{array}$ \\
\hline \multirow[t]{2}{*}{$\begin{array}{l}\text { Sequence } 2+ \\
\text { bpy' }^{\prime}\end{array}$} & $\begin{array}{l}\text { Coupling reagents: EDC-NHS } \\
\text { Solvent: } 1: 1: 1 \mathrm{CH}_{3} \mathrm{OH} / \mathrm{CH}_{3} \mathrm{CN} / \mathrm{CH}_{2} \mathrm{Cl}_{2} \\
\text { Characterization: ESI-MS }\end{array}$ & $\begin{array}{l}\text { Failed - Discussed in } \\
\text { section 2.3.2 and A2.0 }\end{array}$ \\
\hline & $\begin{array}{l}\text { Coupling reagents: TSTU-DIPEA } \\
\text { Solvent: } 1: 1: 1 \mathrm{CH}_{3} \mathrm{OH} / \mathrm{CH}_{3} \mathrm{CN} / \mathrm{CH}_{2} \mathrm{Cl}_{2} \\
\text { Characterization: PAGE, ESI-MS } \\
\text { Further work: Reacted crude product } \\
\text { with } \mathrm{Co}\left(\text { bpy } \mathrm{Cl}_{2}\right) \mathrm{Cl}\end{array}$ & $\begin{array}{l}\text { Succeeded - Discussed in } \\
\text { section } 2.2 .4,2.3 .4\end{array}$ \\
\hline $\begin{array}{l}\text { Sequence } 2+ \\
\mathrm{Co}\left(\mathrm{bpy}_{2}\right. \\
\left.\mathrm{bpy}^{\prime}\right)\left(\mathrm{PF}_{6}\right)_{3}\end{array}$ & $\begin{array}{l}\text { Coupling reagents: TSTU-DIPEA } \\
\text { Solvent: } 1: 1: 1 \mathrm{CH}_{3} \mathrm{OH} / \mathrm{CH}_{3} \mathrm{CN} / \mathrm{CH}_{2} \mathrm{Cl}_{2} \\
\text { Characterization: ESI-MS }\end{array}$ & $\begin{array}{l}\text { Succeeded - Discussed in } \\
\text { section } 2.3 .4\end{array}$ \\
\hline $\begin{array}{l}\text { Sequence } 3+ \\
\text { bpy' }\end{array}$ & $\begin{array}{l}\text { Coupling reagents: TSTU-DIPEA } \\
\text { Solvent: } 1: 1: 1 \mathrm{CH}_{3} \mathrm{OH} / \mathrm{CH}_{3} \mathrm{CN} / \mathrm{CH}_{2} \mathrm{Cl}_{2} \\
\text { Characterization: } \mathrm{HPLC}, \mathrm{ESI}-\mathrm{MS} \\
\text { Further work: Reacted crude and } \\
\text { HPLC purified product with } \\
\mathrm{Co}\left(\text { bpy }_{2} \mathrm{Cl}_{2}\right) \mathrm{Cl}\end{array}$ & $\begin{array}{l}\text { Succeeded - Discussed in } \\
\text { section } 2.2 .4,2.2 .6,2.3 .4\end{array}$ \\
\hline $\begin{array}{l}\text { Sequence } 3+ \\
\mathrm{Co}\left(\mathrm{bpy}_{2}\right. \\
\left.\mathrm{bpy}^{\prime}\right)\left(\mathrm{PF}_{6}\right)_{3} \\
\end{array}$ & $\begin{array}{l}\text { Coupling reagents: TSTU-DIPEA } \\
\text { Solvent: } 1: 1: 1 \mathrm{CH}_{3} \mathrm{OH} / \mathrm{CH}_{3} \mathrm{CN} / \mathrm{CH}_{2} \mathrm{Cl}_{2} \\
\text { Characterization: ESI-MS, ICP-MS }\end{array}$ & $\begin{array}{l}\text { Succeeded - Discussed in } \\
\text { section } 2.2 .5,2.3 .4\end{array}$ \\
\hline $\begin{array}{l}\text { Sequence } 4+ \\
\text { bpy }^{\prime}\end{array}$ & $\begin{array}{l}\text { Coupling reagents: TSTU-DIPEA } \\
\text { Solvent: } 1: 1: 1 \mathrm{CH}_{3} \mathrm{OH} / \mathrm{CH}_{3} \mathrm{CN} / \mathrm{CH}_{2} \mathrm{Cl}_{2} \\
\text { Characterization: ESI-MS }\end{array}$ & $\begin{array}{l}\text { Failed - Discussed in } \\
\text { section 2.3.4 and A2.0 }\end{array}$ \\
\hline
\end{tabular}




\subsubsection{Discussion of the Synthesis of $\left[\mathrm{Co}(\mathrm{bpy})_{2} \mathrm{bpy}^{\prime}\right]\left(\mathrm{PF}_{6}\right)_{3}$}

The synthesis of $\left[\mathrm{Co}(\mathrm{bpy})_{2} \mathrm{bpy}^{\prime}\right]\left(\mathrm{PF}_{6}\right)_{3}$ has been previously reported. ${ }^{66,69}$ The report herein will supplement those previous two works. The previous reports described issues with the synthesis of $\left[\mathrm{Co}(\mathrm{bpy})_{2} \mathrm{bpy}^{\prime}\right]\left(\mathrm{PF}_{6}\right)_{3}$, in particular an inability to get the sample pure enough to have the correct integration of the proton NMR. ${ }^{66,69}$ It should be noted that the synthesis previously reported was based on a different protocol. The use of 4-(3-carboxypropyl)-4'-methyl-2,2'-bipyridine creates an asymmetric complex.

Furthermore, the ligand that creates this situation is zwitterionic - meaning it has both acidic and basic sites. As a result, the synthesis reported herein was conducted in buffer. The choice of $\mathrm{pH}$ was 4.8 , as this is the $\mathrm{pH}$ in between the pKa's of the carboxylic acid and amine of 4-(3-carboxypropyl)-4'-methyl-2,2'-bipyridine. This synthesis was characterized using IR, electrospray MS, Proton NMR, and COSY NMR. 


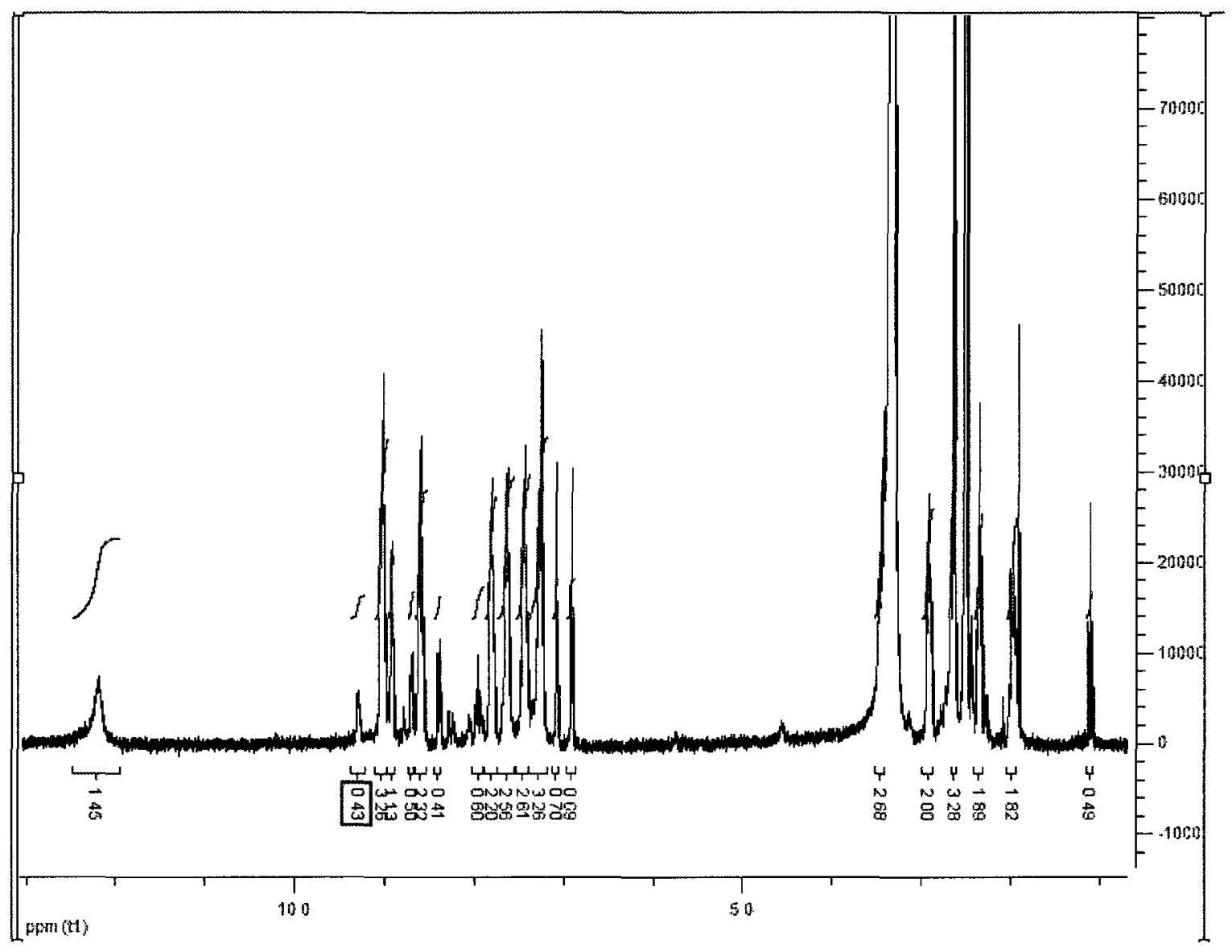

Figure 2.12: Proton NMR of crude [Co(bpy $)_{2}$ bpy $\left.^{\prime}\right]\left(\mathrm{PF}_{6}\right)_{3}(\mathrm{DMSO})$

Figure 2.12 shows the proton NMR of crude $\left[\mathrm{Co}(\mathrm{bpy})_{2} \mathrm{bpy} \mathrm{p}^{\prime}\right]\left(\mathrm{PF}_{6}\right)_{3}$. Previous reports have indicated an issue with the NMR integration in the aromatic region. Given the structure of the complex it is expected to have an overall integration in the aromatic region of 22 protons. Previous reports indicate finding 11-19 protons when comparing the spectrum to the methyl peak in the alkyl region. ${ }^{66,69}$ A single example of a successful integration exists as a result of crystal formation. ${ }^{66}$ As Figure 2.12 reveals the integration of the aromatic region was 22 . This is the first example of a planned attempt at controlling the synthesis to achieve the correct integration. Furthermore the carboxylic acid peak and alkyl regions of the NMR have the correct integration. 


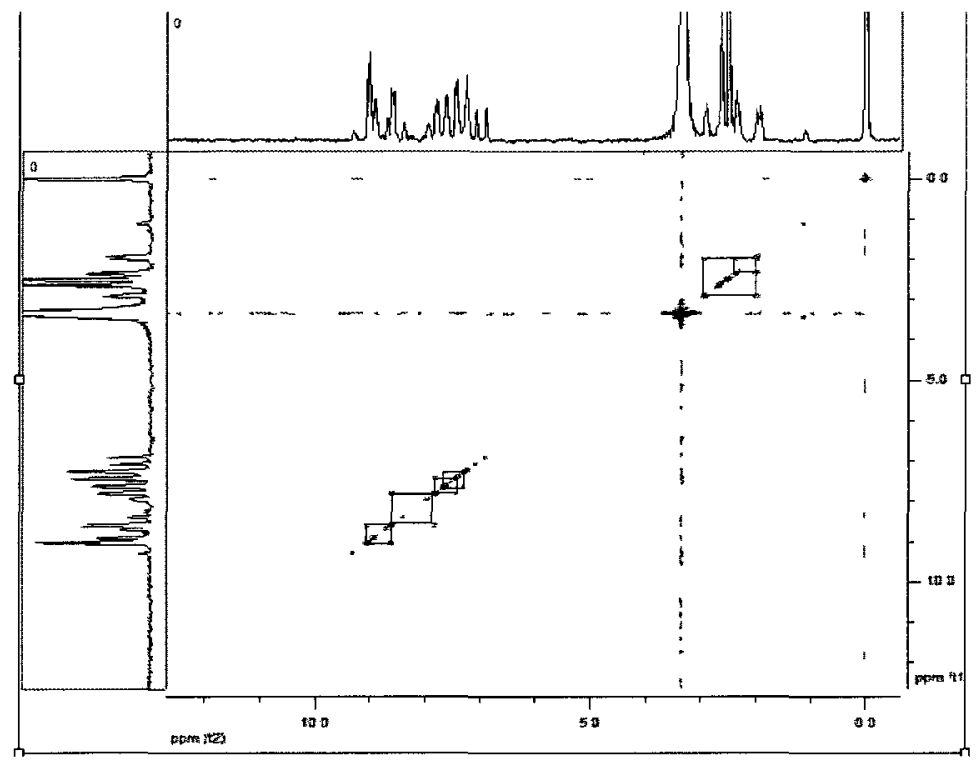

Figure 2.13: COSY spectrum of crude $\left[\mathrm{Co}(\mathrm{bpy})_{2} \mathrm{bpy}^{\prime}\right]\left(\mathrm{PF}_{6}\right)_{3}(\mathrm{DMSO})$

The COSY spectrum of $\left[\mathrm{Co}(\mathrm{bpy})_{2} \mathrm{bpy}^{\prime}\right]\left(\mathrm{PF}_{6}\right)_{3}$ is shown in Figure 2.13. Peak assignments have been previously reported in David Blair's Masters Thesis ${ }^{69}$. However this spectrum was collected in acetone- $\mathrm{d}_{6}$. A spectrum collected in DMSO is presented here. Correlations shown as black boxes connecting related peaks.

In both the proton NMR and COSY spectrum the aliphatic region showed similar chemical shifts as to those previously reported ${ }^{69}$. Due to the enhanced peak splitting in the aromatic region peak comparison to previously reported spectra was difficult. The peaks located at $\sim 9.00 \mathrm{ppm}, \sim 8.50 \mathrm{ppm}, \sim 7.8 \mathrm{ppm}$, and $\sim 7.4 \mathrm{ppm}$ were all coupled as can be seen in the COSY spectrum in Figure 2.13. As a result of this, identification of the unmodified bipyridine was made possible. The only peaks whose explicit identification was not possible were the aromatic peaks corresponding to bpy' although based on 
coupling it is suspected that the peaks at $\sim 7.30 \mathrm{ppm}$ and $\sim 7.60 \mathrm{ppm}$ as well as a peak at $\sim 8.90 \mathrm{ppm}$ correlate to the three aromatic protons present on bpy'. This is in fairly close agreement with the previously reported peak assignment of $\left[\mathrm{Co}(\mathrm{bpy})_{2} \mathrm{bpy} \mathrm{Py}^{\prime}\left(\mathrm{PF}_{6}\right)_{3}\right.$ in acetone- $\mathrm{d}_{6}{ }^{66}$

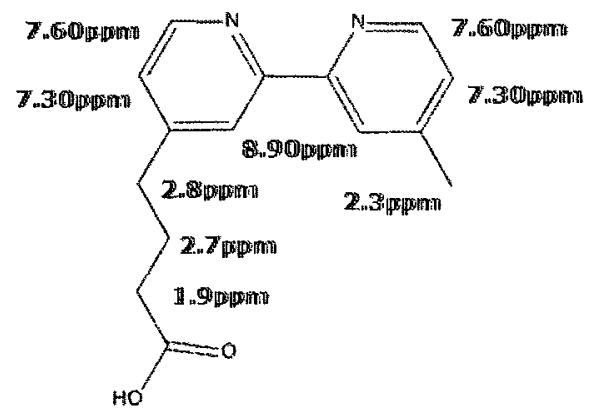

Figure 2.14: Summary of the peak assignment in bpy'

Further characterization was conducted. Electrospray Mass Spectrometry revealed the molecular ion at $628.232 \mathrm{Da}$ as well as peaks at $772.185 \mathrm{Da}$ and $917.160 \mathrm{Da}$ that pertain to the molecular ion with one $\left(\mathrm{PF}_{6}\right)^{-}$and two $\left(\mathrm{PF}_{6}\right)^{-}$ions respectively (See Appendix 2.0, Figure A2.4).

2.3.2 Discussion of conjugation of $\mathrm{bpy}^{\prime}$ to DNA via EDC-NHS chemistry

Conjugation of bpy' to DNA was first conducted utilizing sequence 1 and analysis conducting by PAGE and ESI-MS. 


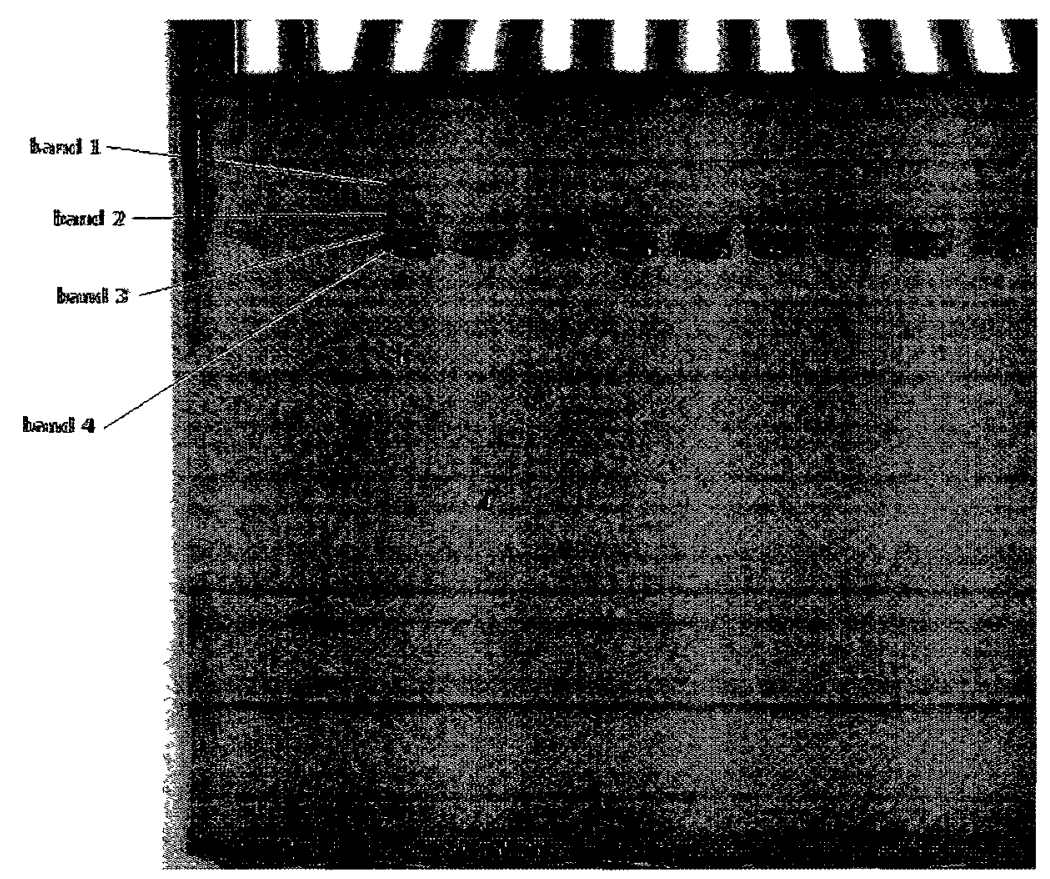

Figure 2.15: PAGE image of DNA-bpy'. Each lane is an identical sample of EDC-NHS based DNA-bpy' coupling.

It was expected that the PAGE image would show two bands - one for reacted DNA-bpy' and one for unreacted DNA-NH $\mathrm{NH}_{2}$. As can be seen in Figure 2.15 a series of four bands were observed. The heaviest being labeled 'band 1', and subsequent bands labeled 'band 2' through 'band 4'. This was the first indication that the reaction had not gone as planned. Each band was removed and analyzed by electrospray mass spectrometry. 

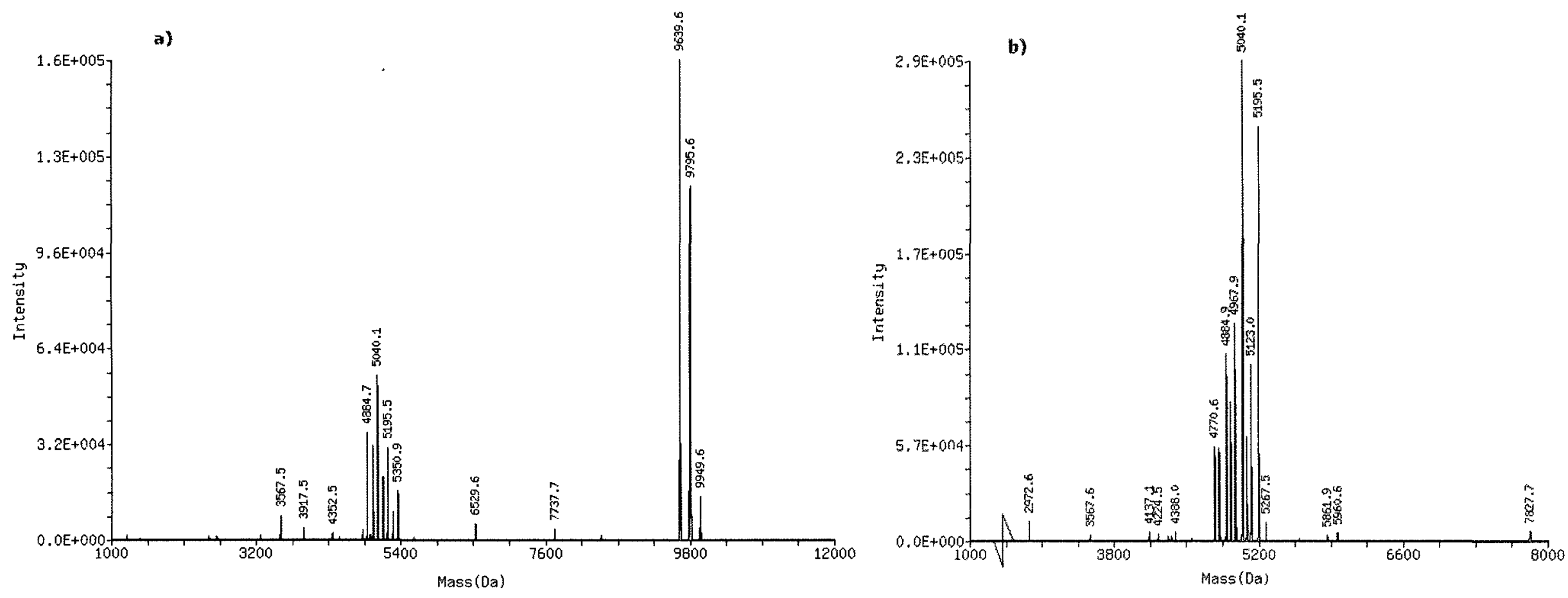

Figure 2.16: Deconvoluted electrospray mass spectrum of a) Band 1 and b) Band 2 

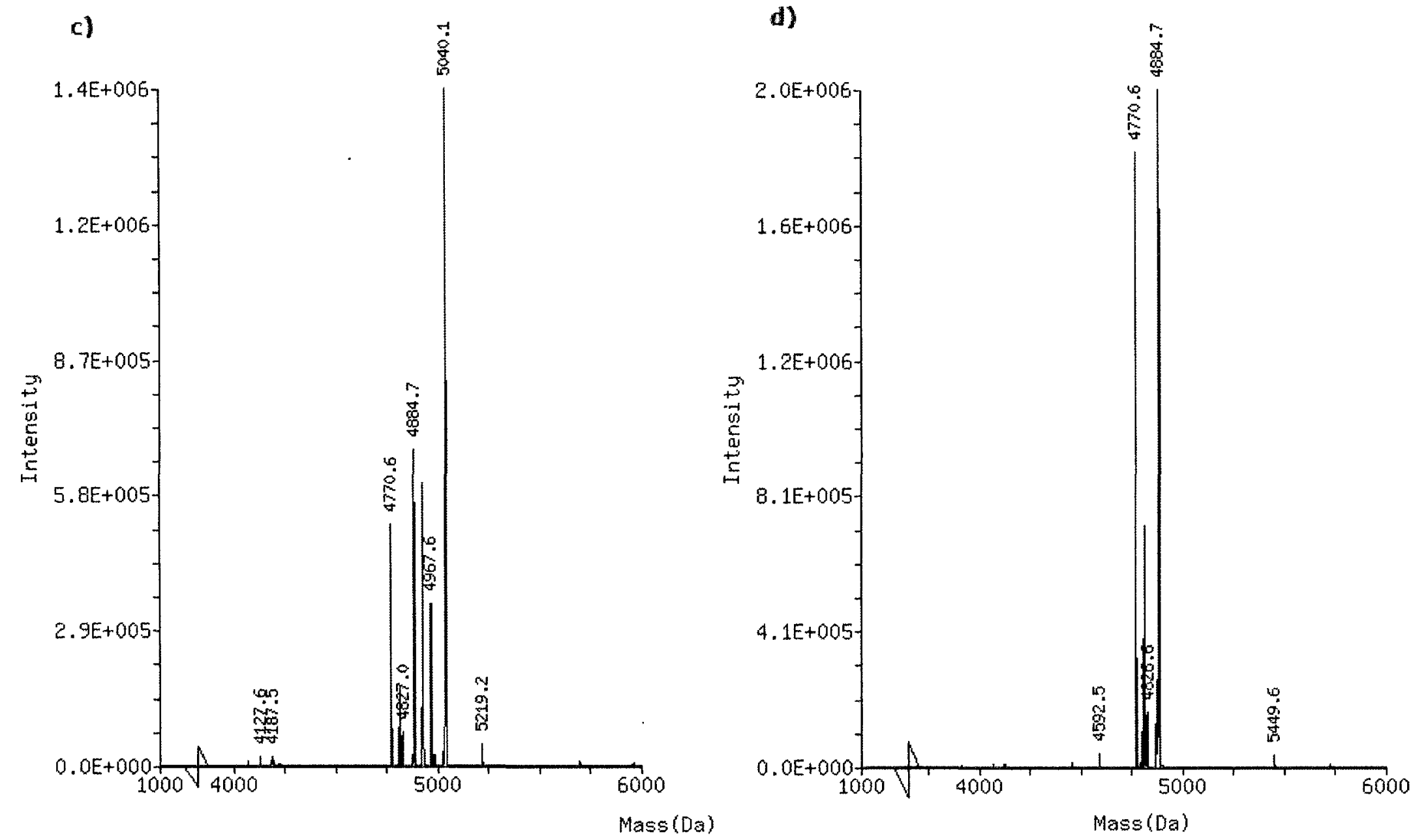

Figure 2.16: Deconvoluted electrospray mass spectrum of c) Band 3 and d) Band 4 
Figure 2.16 a)-d) are electrospray mass spectra of bands 1 to 4 respectively. The ESI-MS of band 4 (Figure 2.16 d)) had major peaks at 4770.6 Da and 4884.7 Da. 4770.6 Da is unreacted sequence 1 DNA. The product at 4884.7 Da was of an unknown composition. It is suspected that it was a conjugation byproduct of EDC because it has been reported ${ }^{72,73}$ that EDC can shift from an $O$-acylisourea intermediate to an $N$ acylisourea intermediate resulting in product contamination and low yields. Furthermore it can rearrange to form $5(4 H)$-oxazolones. ${ }^{73}$

Figure $2.16 \mathrm{c}$ ) yielded the most interest. The desired mass for sequence 1 DNAbpy' was 5009Da. As described above, it was expected that the products of this reaction would yield two bands - one containing reacted product and one containing unreacted starting material. As a result it was expected that band 3 (Figure $2.16 \mathrm{c}$ )) contained the desired product. As the mass spectrum shows, the predominant peak was $5040.1 \mathrm{Da}-$ 31.1 Daltons too high. After numerous attempts at explaining the mass, it was concluded that no reasonable conclusion could be drawn from this mass. As such, experiments were conducted to study it in comparison to band $4-$ the starting material. Band 3 and band 4 were reacted with $\left[\mathrm{Co}(\text { bpy })_{2} \mathrm{Cl}_{2}\right] \mathrm{Cl}$ and compared via $\mathrm{UV}$-Vis. 


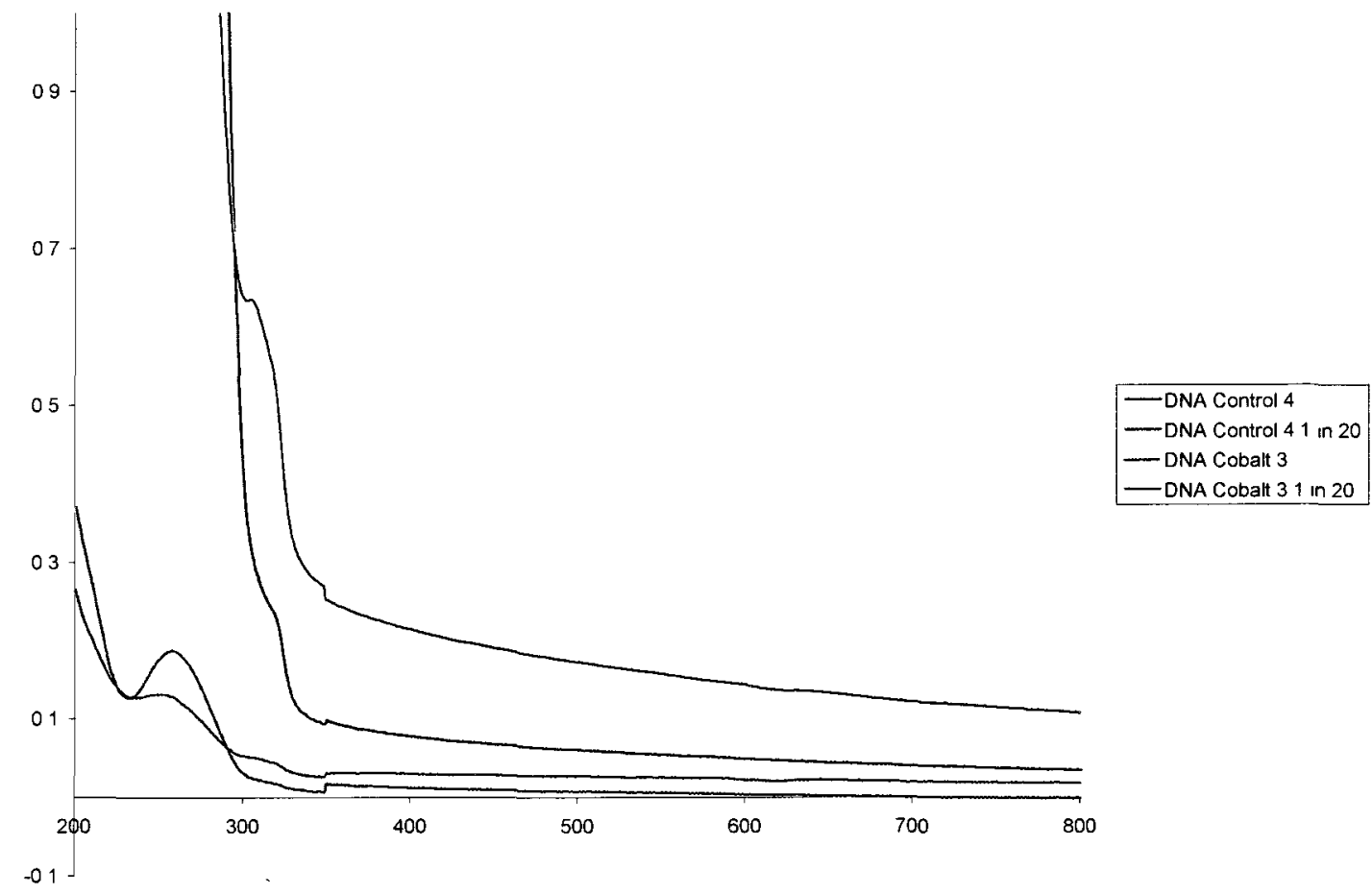

Figure 2.17: UV Spectra of DNA recovered from gel bands 3 and 4 and reacted with $\left[\mathrm{Co}(\text { bpy })_{2} \mathrm{Cl}_{2}\right] \mathrm{Cl}$ : concentrated band $4 \mathrm{DNA}$ (black trace), concentrated band 3 DNA (dark blue trace), diluted band 4 DNA (light blue trace) and diluted band 3 DNA (red trace)

As can be seen in concentrated traces (black and dark blue) traces in Figure 2.17 there is a shoulder at $\sim 305 \mathrm{~nm}$. The shoulder is more pronounced in the DNA from band 3 than the DNA from band 4. It was hypothesized that this more intense shoulder was as a result of bpy' chelating the $\left[\mathrm{Co}(\mathrm{bpy})_{2} \mathrm{Cl}_{2}\right] \mathrm{Cl}$ as desired. However, ESI-MS analysis showed that no such reaction had taken place (see Figure 2.18). 


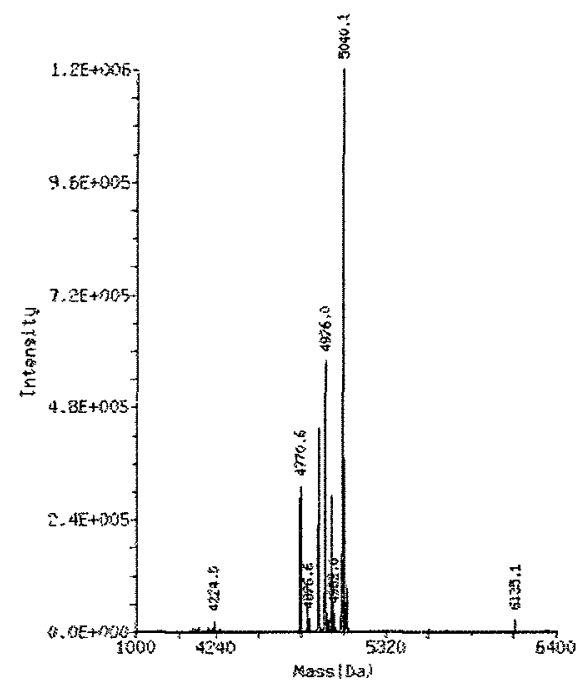

Figure 2.18: ESI MS of band 3 after reaction with $\left[\mathrm{Co}(\mathrm{bpy})_{2} \mathrm{Cl}_{2}\right] \mathrm{Cl}$

Despite this negative result, it was likely that the desired cobalt complex would not survive an ESI-MS analysis. This is a result of several factors. Firstly, the analysis of an oligonucleotide in a mass spectrometer is conducted in negative ion mode; as a result the positively charged complex would experience electrostatic attraction in the ESI source while entering the mass spectrometer. If sufficient, this could facilitate decomposition of the complex. Secondly, part of the preparation for mass spectrometry of oligonucleotides is desalting to eliminate the possible formation of complex salt adducts due to binding along the DNA phosphate backbone. To facilitate this ethylenediaminetetraacetic acid is used to chelate the metal salt ions. A side effect of efficient chelation could be the chelation and removal of the cobalt via ligand substitution.

The mass spectrum of band 2 (Figure $2.16 \mathrm{~b}$ )) showed two predominate masses, 5040.1Da and 5195.5Da. 5040.1Da was mainly seen in band 3 and discussed above. The 
mass of 5195.5Da remained unidentified, despite best efforts to find a reaction pathway that would yield this mass.

Band 1 was the most unusual - ESI-MS revealed (Figure 2.16 a)) several large masses of around double the expected mass. The predominate mass was $9639.6 \mathrm{Da}$. After careful investigation and literature review of potential side reactions that can take place during a peptide coupling a potential explanation was found. The Lossen rearrangement is a common byproduct of N-hydroxy succinimidyl esters and carbonates and has been well documented. ${ }^{74}$ The result of this rearrangement is the formation of an isocyanate terminated $\beta$-alanine. The mechanism of this is shown in Figure 2.19.

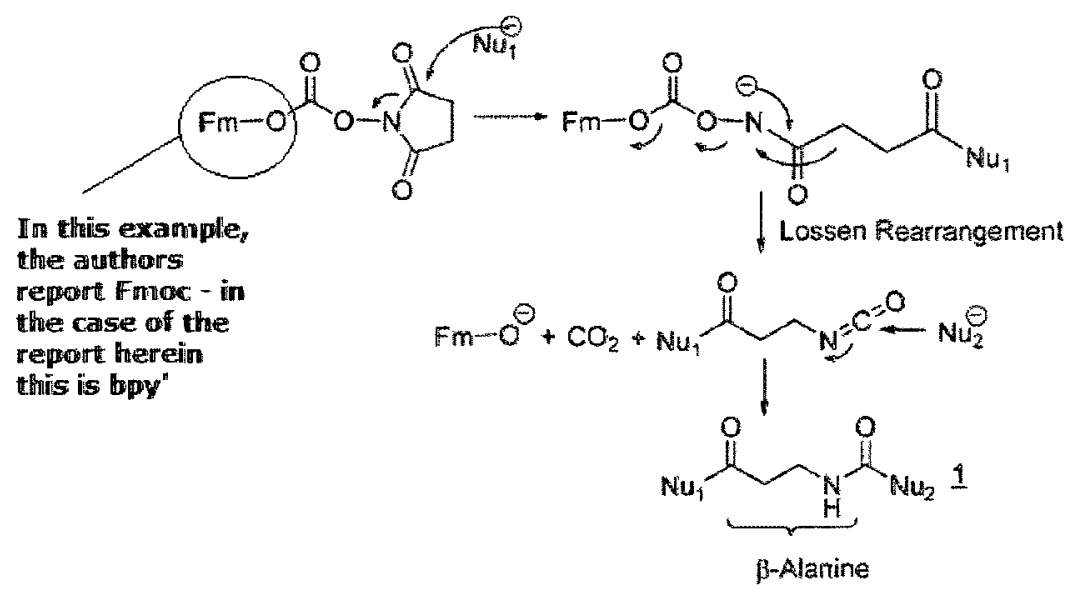

Figure 2.19: Mechanism of the Lossen Rearrangement observed in band 1. Figure adapted from ${ }^{75}$. The nucleophilic amino DNA attacks the carbonyl carbon of the NHS instead of the carbonyl carbon of the desired ligand.

Figure 2.19 illustrates the mechanism of the Lossen rearrangement. The amino terminated DNA attacks the carbonyl carbon of the NHS as opposed to the carbonyl 
carbon of the desired ligand. This results in an opening of the NHS ring structure and a rearrangement that removes the desired ligand and results in a DNA- $\beta$-alanineisocyanate species. A second molecule of amino-terminated DNA attacks the isocyanate, which results in a second DNA strand conjugated to the $\beta$-alanine. Given that mass of sequence 1 was $4770.6 \mathrm{Da}$ the mass of the expected Lossen product could be calculated. The expected mass of a Lossen rearranged product was 9640.2 Da. As the mass spectrum in Figure 2.16a) shows a mass of 9639.Da; It can be concluded that one of the issues with EDC-NHS chemistry is that a significant amount of undesired Lossen product forms.

Further to this, it has been reported that carbodiimides, a family of chemicals of which $\mathrm{EDC}$ is a part, can react with carboxylic acids to form stable $\mathrm{N}$-acyl ureas (Figure 2.20). ${ }^{76}$

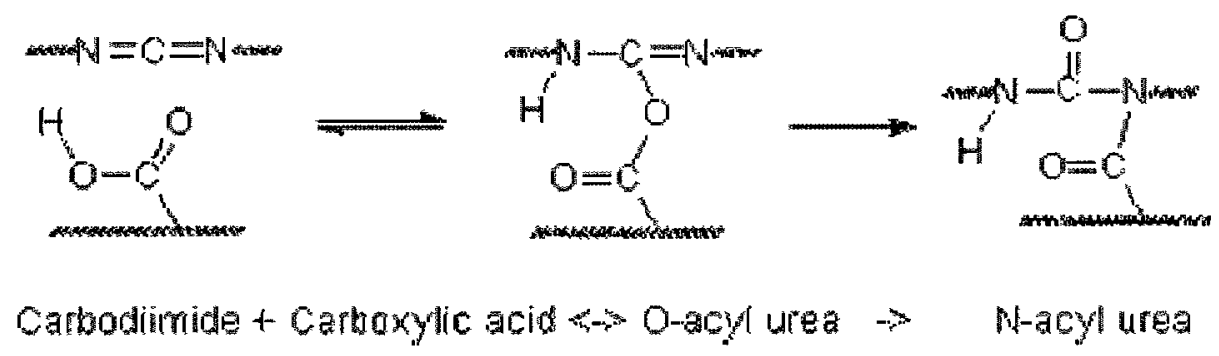

Figure 2.20: Scheme adapted from Posthumus et al. ${ }^{76}$ illustrating the formation of the Oacyl urea and the shift to the $\mathrm{N}$-acyl form.

As a result of the complications encountered during the EDC-NHS reaction, alternate chemistry was desired. A protocol published by Fisher Scientific called for the use of quenchers during the reaction process. Specifically, it called for quenching of the EDC with 2-Mercaptoethanol and quenching of the NHS reaction with Hydroxylamine. Attempts using this modification to the reported procedure yielded no reaction - the 
solution turned dark pink and when analyzed by ESI-MS it was observed that only unreacted sequence 1 DNA was in the sample. Furthermore, the EDC-NHS coupling was attempted using conditions identical to the TSTU-DIPEA chemistry and no reaction was observed.

The conclusions drawn from these results were to pursue alternate coupling chemistries.

2.3.3 Discussion of conjugation of bpy' to DNA via TSTU-DMAP chemistry

A modified protocol based on a protocol using $\mathrm{N}, \mathrm{N}, \mathrm{N}^{\prime}, \mathrm{N}^{\prime}-$ Tetramethyl(succinimido) uronium tetrafluoroborate (TSTU) and 4-(dimethylamino)pyridine (DMAP) originally reported by Miron and coworkers. ${ }^{77}$ The results of this reaction were analyzed using PAGE and ESI-MS. 

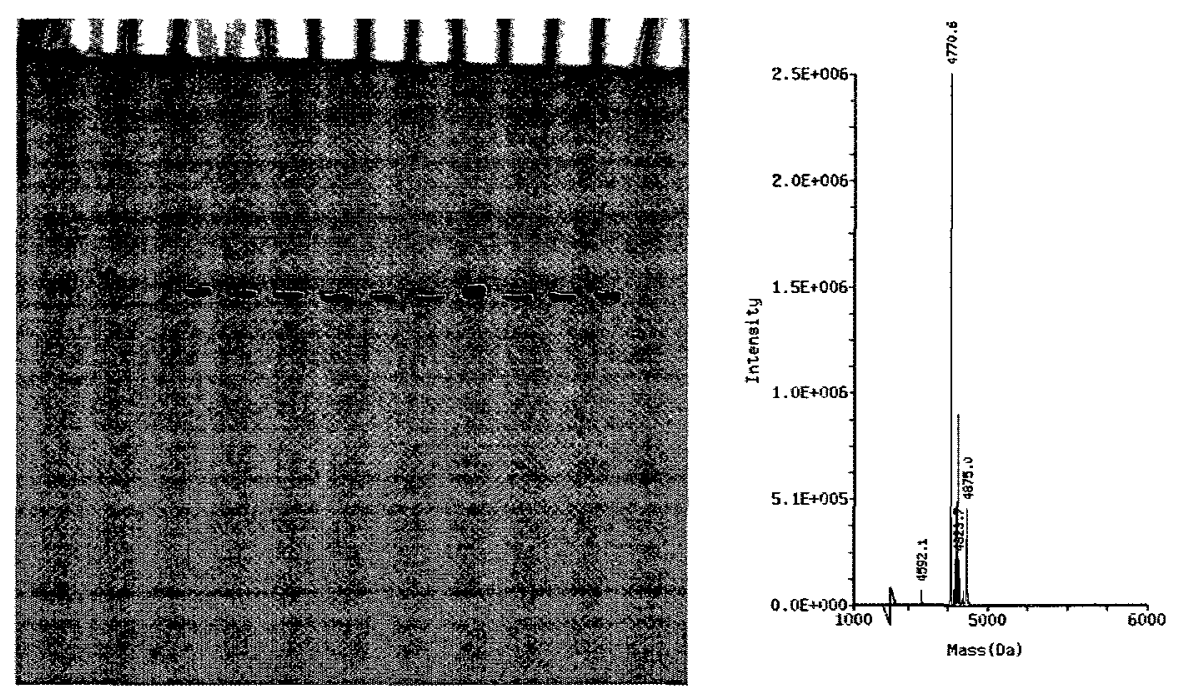

Figure 2.21: PAGE gel of the reaction product of the TSTU-DMAP conjugation attempt. Each lane consists of identical samples (left) and ESI-MS of the DNA extracted from the gel (right)

Figure 2.21 (left) is an image taken of the PAGE experiment of the reaction product of the TSTU-DMAP reaction. As can be seen from the single band present, no reaction took place. Confirmation of this was conducted using ESI-MS (Figure 2.21, right). As shown, the major peak is at $4770.6 \mathrm{Da}$ which corresponds to unreacted amino modified DNA. Initially, it was unknown as to why the reaction did not work. Upon literature review it was found that the amount of DMAP added to the reaction can greatly affect the success or failure of the reaction. ${ }^{78}$ As the desired quantity of DMAP was unknown a procedure using an alternate base was sought. 
2.3.4 Discussion of conjugation of bpy' and [Co(bpy $\left.)_{2} \mathrm{bpy}^{\prime}\right]\left(\mathrm{PF}_{6}\right)_{3}$ to DNA via TSTUDIPEA chemistry

A protocol reported by Barton and coworkers utilizing the same ligand (bpy') was applied to the synthesis herein. ${ }^{79}$ First of all, this protocol contained a desired alternate base - Diisopropylethylamine. Second, it used a different solvent system - until now all reactions had taken place in dimethylformamide (DMF). This protocol called for the use of a multisolvent system; 1:1:1 methanol:acetonitrile:dichloromethane. As before, the reaction product was analyzed by PAGE and ESI-MS. Furthermore, this experiment was conducted utilizing a different DNA sequence: sequence 2 as reported in the experimental. The change in DNA sequence was conducted to test the generality of the approach.

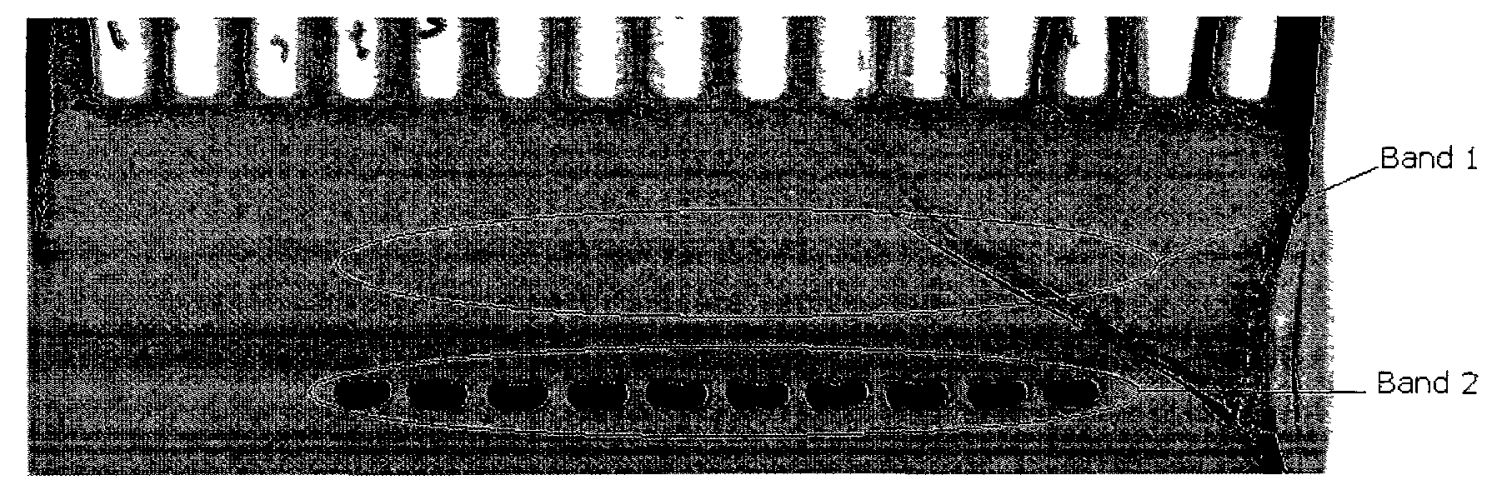

Figure 2.22: Image of the results of PAGE of the TSTU-DIPEA coupled reaction. Each lane consists of identical samples

The gel in Figure 2.22 reveals two bands. It was hypothesized that the large separation of the two bands meant that the Lossen rearrangement had taken place again. 
To properly analyze this reaction ESI-MS was conducted on band 1, band 2, and unpurified sample.
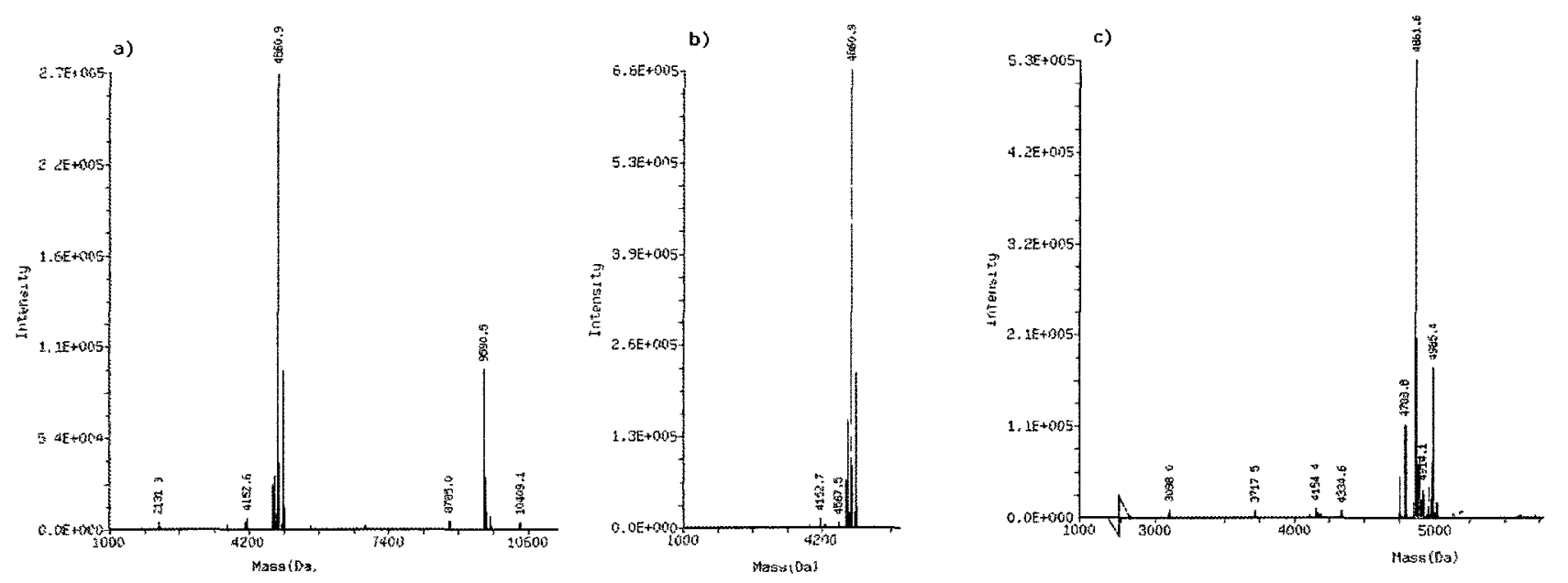

Figure 2.23: a) ESI-MS of gel band 1 b) ESI-MS of gel band 2 and c) ESI-MS of crude reaction product

Figure 2.23 a) shows the Lossen product present at $9590.5 \mathrm{Da}$ which confirms what was hypothesized about the level of separation observed in gel bands in Figure 2.23. Figure $2.23 \mathrm{a}$ )-c) show an unidentified peak at $4860.9 \mathrm{Da}$. The most important peak present in all of these spectra is located at 4985.4Da. This is the expected mass of DNAbpy' conjugated together in the expected fashion. Although not the dominant peak in the mass spectrum, this result indicates that this reaction protocol works in the coupling of bpy' to amino modified DNA.

Despite the positive result, there were several questions raised. The first of which involved purification of the reaction product - as is evident by the ESI-MS spectra 
collected, PAGE did not sufficiently separate the desired product, from starting material and side products. The second question was whether or not $\left[\mathrm{Co}(\mathrm{bpy})_{2} \mathrm{Cl}_{2}\right] \mathrm{Cl}$ could be conjugated to the free bpy' while conjugated to the DNA. To answer this, crude reaction product was reacted with $\left[\mathrm{Co}(\text { bpy })_{2} \mathrm{Cl}_{2}\right] \mathrm{Cl}$ in accordance with the protocol reported in Chapter 2.2.6. The results of this reaction were investigated by ESI-MS. The desired DNA-Cobalt complex conjugate would have an expected molecular weight of 5356.3 Da. This mass was found in the ESI-MS mass spectrum at a very low intensity. Further to this, DNA-bpy' conjugate was also found in the spectrum at a lower intensity than in Figure 2.24 .

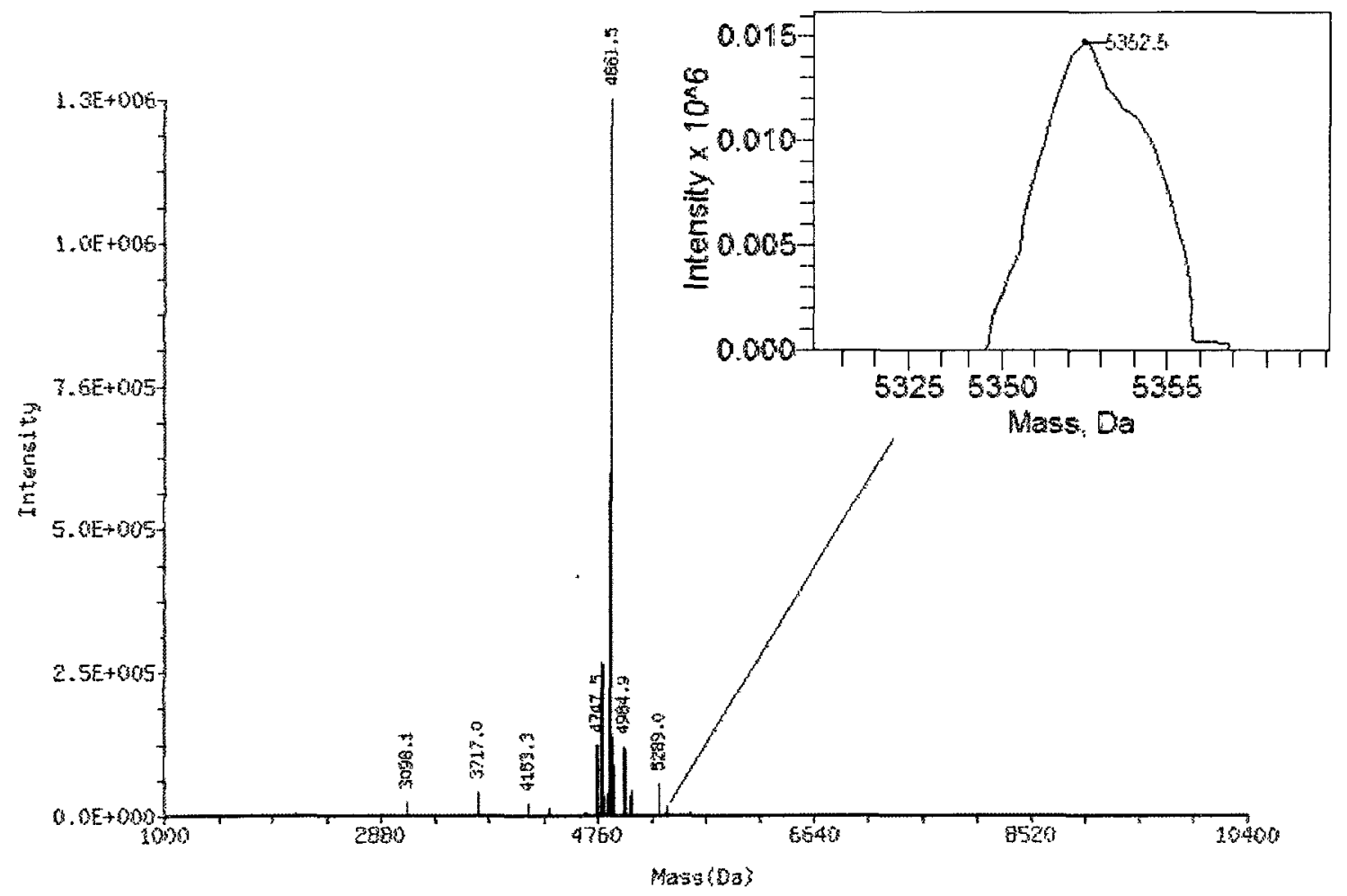

Figure 2.24: ESI-MS of sequence 2 DNA-Cobalt conjugate; inset shows the DNA-cobalt conjugate at $5353 \mathrm{Da}$ 
This result allowed several conclusions to be drawn. Firstly, the previous EDCNHS reaction did not work, despite the UV-Vis evidence. This can be inferred from the fact ESI-MS did not yield even a low intensity peak in the spectrum. Secondly, and most importantly, $\left[\mathrm{Co}(\mathrm{bpy})_{2} \mathrm{bpy}^{\prime}\right]\left(\mathrm{PF}_{6}\right)_{3}$ can be conjugated to DNA. Following this successful synthesis, the reaction was repeated using sequences 3 and 4 . The rationale behind this was that without a thiol present on the DNA, any further work would be superfluous to the end goal - which was to immobilize the DNA-Cobalt conjugate on an electrode surface.

Sequence 4 DNA contained a $3^{\prime}$ amino modifier and a $5^{\prime}$ thiol modifier. Removal of the Fmoc-protecting group was conducted successfully according to the manufacturer's instructions. However, a reaction using the TSTU - DIPEA chemistry was not successful. No product of any kind was observed in ESI-MS. Prior to troubleshooting this reaction, sequence $3 \mathrm{DNA}$ was synthesized and reacted. The rationale being that the failure of the reaction utilizing $3^{\prime}$ amino modifier may have been for steric reasons, as the synthesis is conducted with the DNA immobilized on CPG's and is thus a solid phase reaction. Sequence 3 contained the reverse orientation of sequence 4 . That is it contained a $5^{\prime}$ amino modifier and $3^{\prime}$ thiol modifier. The reaction was conducted as before for sequence 2 DNA and was successful as before. This was verified using ESIMS. 
The issue raised at this point was purification. Figure 2.22 already illustrated the issues with using PAGE to purify this reaction. As such HPLC was utilized for purification.
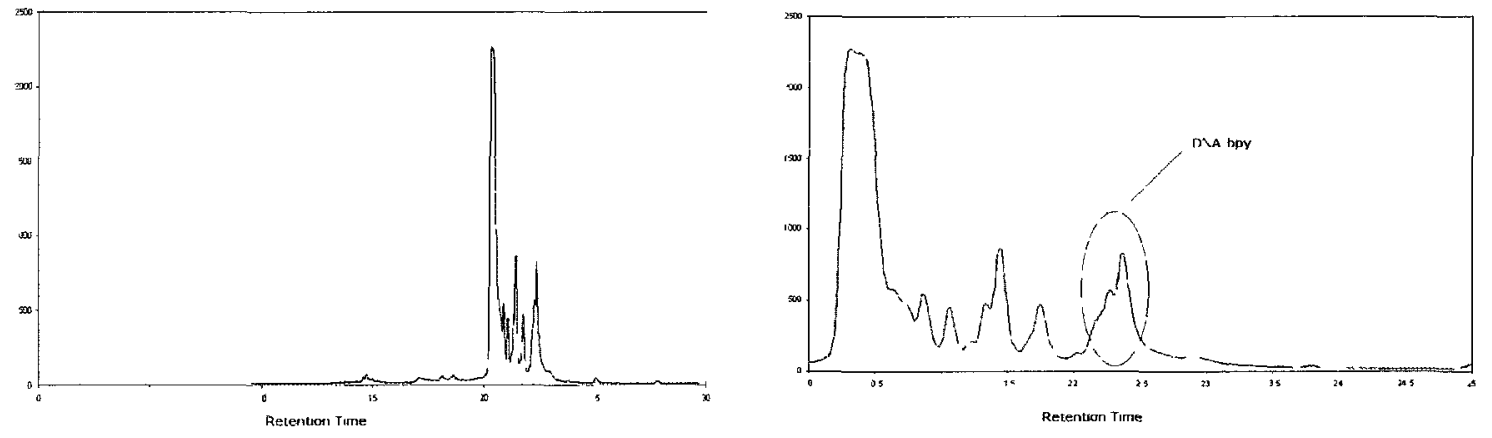

Figure 2.25: HPLC chromatogram of Sequence 3 DNA-bpy' conjugate; left is the entire chromatogram and right is a zoom in of the peaks of interest

HPLC was conducted and several peaks collected between 20 and 25 minutes. Each was analyzed by ESI-MS. The desired product had a retention time of approximately 22-23 minutes. 


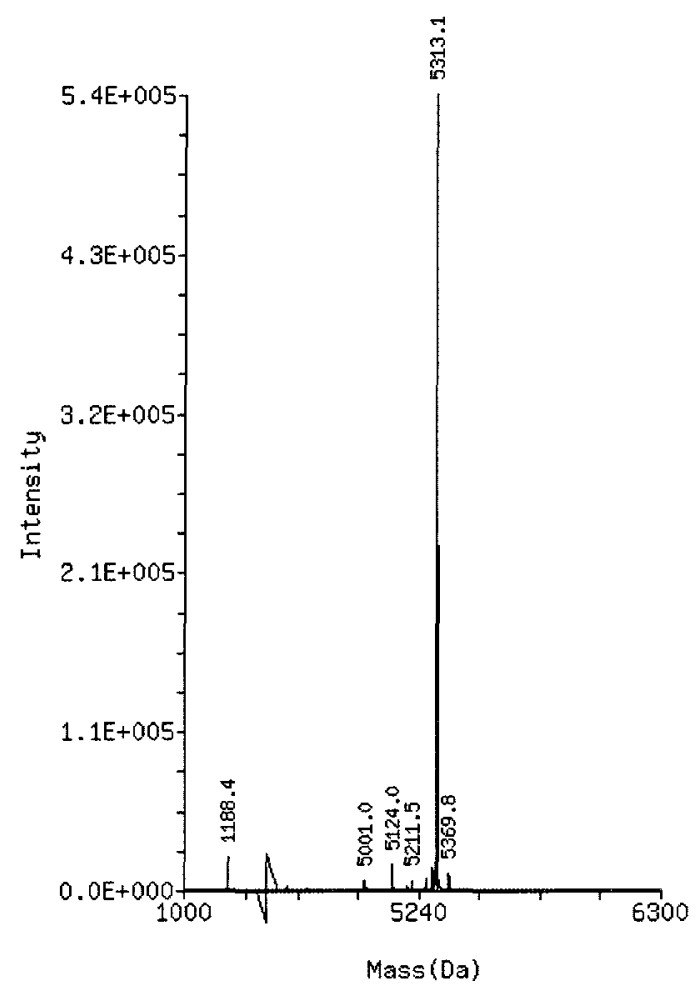

Figure 2.26: ESI-MS of HPLC purified DNA-bpy' conjugate

ESI-MS was used to analyze the peaks of interest in a chromatogram. The ESIMS of the peak collected between 22 and 22.5 minutes is presented in Figure 2.26. As can be seen it is pure DNA-bpy' conjugate. In total 21 nanomols of DNA-bpy' was isolated giving a yield of $6.1 \%$ relative to the quantity of DNA synthesized (341.9 nanomols). Relative to the $1 \mu \mathrm{mol}$ column used for DNA synthesis the final yield was $2.1 \%$. As a result of successfully isolating pure DNA-bpy' conjugate several avenues of interest opened. Firstly, the conjugation of the fully synthesized $\left[\mathrm{Co}(\mathrm{bpy})_{2} \mathrm{bpy}^{\prime}\right]\left(\mathrm{PF}_{6}\right)_{3}$ probe complex was investigated and secondly, the immobilization of DNA-bpy' conjugate on a gold electrode surface, with chelating to $\left[\mathrm{Co}(\mathrm{bpy})_{2} \mathrm{Cl} \mathrm{C}_{2}\right] \mathrm{Cl}$ taking place on the electrode surface, was also to be investigated. 
The ideal case would be to immobilize DNA-Cobalt conjugate on the surface of an electrode and characterize it. As a result, the reaction reported in Chapter 2.2.5 between $\left[\mathrm{Co}(\mathrm{bpy})_{2} \mathrm{bpy}^{\prime}\right]\left(\mathrm{PF}_{6}\right)_{3}$ and sequence 2 DNA was conducted. During the reaction it was observed that the CPGs turned orange, indicating that the cobalt complex had successfully conjugated to the DNA. Upon washing of the beads the orange colour persisted. This was another qualitative indication that the reaction was successful.

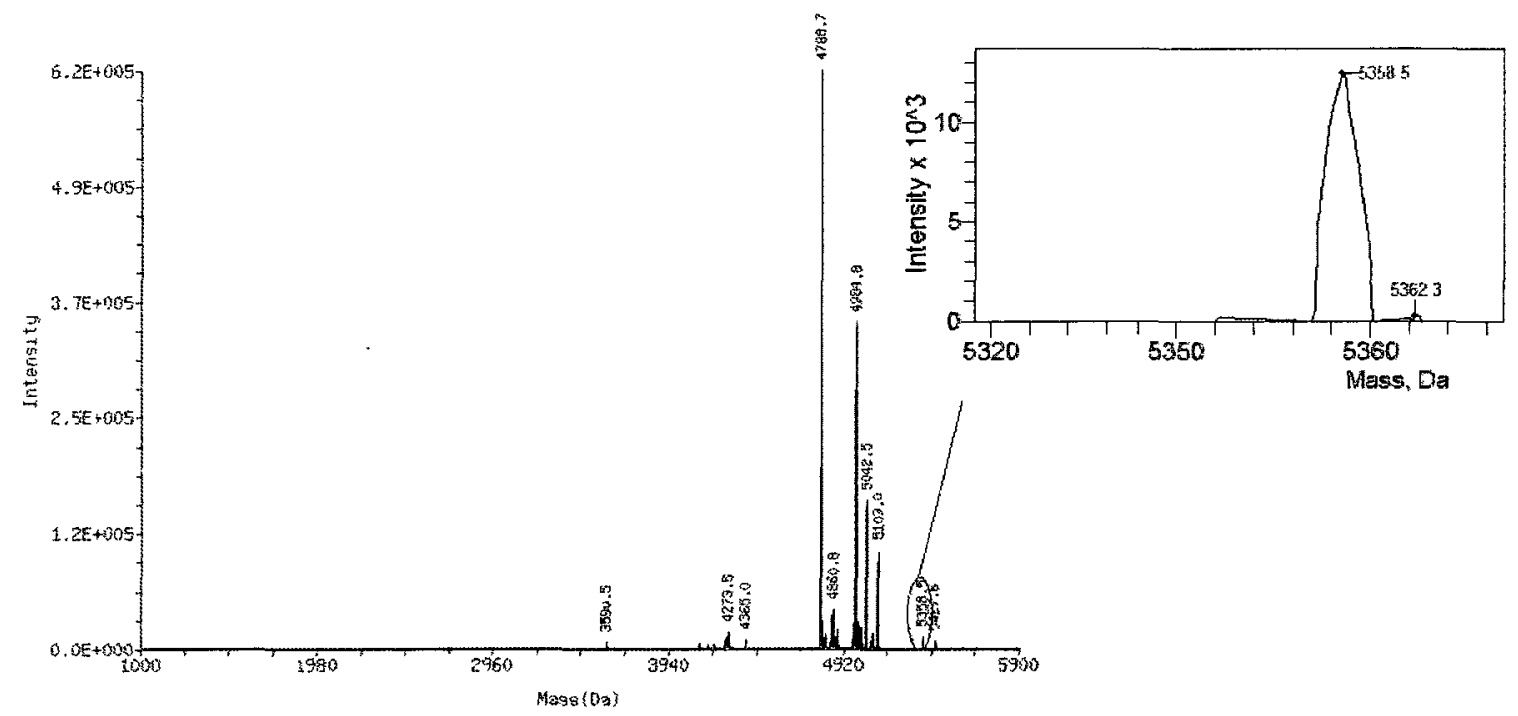

Figure 2.27: ESI-MS spectrum of the DNA-Cobalt conjugate from synthesis 2.2.5. The desired peak was observed at $5358 \mathrm{Da}$.

Figure 2.27 is the ESI-MS spectrum of the crude reaction product. As can be seen both DNA-bpy' conjugate and DNA-Cobalt conjugate are observed at $4985 \mathrm{Da}$ and 5358 Da respectively. As in the previous ESI-MS of DNA-Cobalt, the intensity is very low. 
Again, it is suspected that the use of EDTA as well as negative ion mode is responsible for the low yield of DNA-Cobalt in the ESI-MS spectrum. This reaction was followed up with another reaction - this time utilizing sequence 3 DNA (for the 3 ' thiol modification). ESI-MS verified bpy' conjugation. Furthermore, ICP MS was conducted to verify the presence of Cobalt in the sample. HPLC was conducted on DNA-cobalt conjugates and the material that was eluted between 22 and 23 minutes was collected. This sample and a crude sample were sent for ICP analysis. Cobalt was found in both the crude and purified DNA samples.

Table 6: Results of ICP MS Analysis

\begin{tabular}{|l|l|c|}
\hline & \multicolumn{1}{|c|}{ Cobalt } & \multicolumn{1}{c|}{ Phosphorus } \\
\hline Crude DNA-Cobalt & $0.69 \mu \mathrm{g} / 1.1 \times 10^{-8} \mathrm{~mol}$ & $12 \mu \mathrm{g} / 3.87 \times 10^{-7} \mathrm{~mol}$ \\
\hline Purified DNA-Cobalt & $0.04 \mu \mathrm{g} / 6.78 \times 10^{-10} \mathrm{~mol}$ & $1.2 \mu \mathrm{g} / 3.8 \times 10^{-8} \mathrm{~mol}$ \\
\hline
\end{tabular}

Table 6 shows the results of ICP MS analysis. The ratio of phosphorus to cobalt in sequence 3 is $16: 1$. As can be seen the ratio of phosphorus to cobalt is $35: 1$ in the crude and 56:1 in the pure. The larger than expected quantity of phosphorus was expected in the crude, but not in the HPLC purified sample. It is suspected that during HPLC some of the complex degraded due to the presence of other metals in the HPLC solvents. This is suspected as it has been previously reported that the presence of iron can affect the stability of this cobalt complex. ${ }^{66}$ 
Regardless of the low intensity of the ESI-MS spectrum the qualitative and quantitative evidence was enough to deem the reaction successful. These thiol-containing DNA conjugates were used for electrochemistry experiments.

\subsubsection{Electrochemistry}

Electrochemistry experiments were conducted using a variety of controls to ensure the validity of the experimental results. The first of the controls was to characterize the bare gold electrode. After cleaning, cyclic voltammetry (CV) and square wave voltammetry (SW) was conducted in phosphate buffer to characterize the bare gold surface. Similar characterization was conducted for an electrode with mercaptohexanol deposited on it. Furthermore, electrodes containing DNA-bpy' conjugate, DNA-NH $\mathrm{N}_{2}$ were also characterized by CV and SW. In these cases, the electrodes were exposed to a solution of $\left[\mathrm{Co}(\mathrm{bpy})_{2} \mathrm{Cl}_{2}\right] \mathrm{Cl}$ and $\mathrm{CV}$ and $\mathrm{SW}$ used to compare the results. Also, DNACobalt conjugate was deposited and the results compared to the alternate conjugation method. 


\subsubsection{Control Experiments}
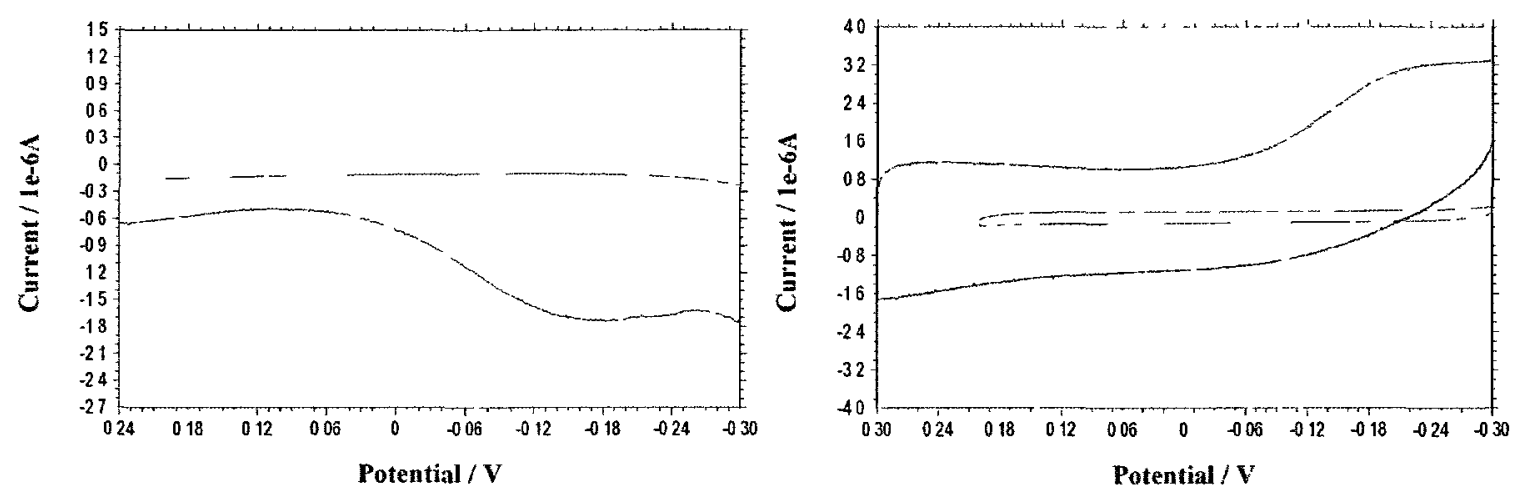

Figure 2.28: Square wave and cyclic voltammograms of a bare gold electrode (blue traces) and mercaptohexanol (red trace)

As is evident from Figure 2.28 a bare gold electrode shows some response to phosphate buffer solution, whereas the mercaptohexanol layer shows little response to either $\mathrm{CV}$ or SW. As such it can be concluded that unless a DNA layer has an electroactive molecule no response should be seen when conducting experiments with DNA immobilized on the electrode surface.
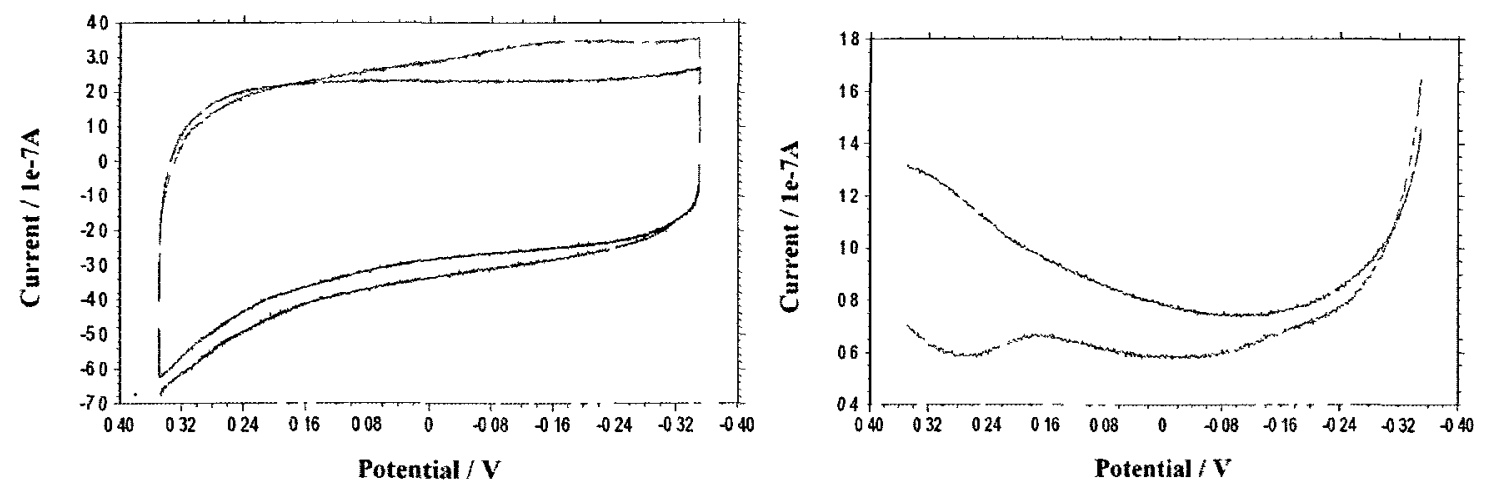

Figure 2.29: Comparison of gold electrodes with immobilized DNA-bpy' (red) and DNA$\mathrm{NH}_{2}$ (blue) 
The overlayed $\mathrm{CV}$ and $\mathrm{SW}$ voltammograms in Figure 2.29 show the difference between a surface containing DNA-bpy' and unreacted DNA- $\mathrm{NH}_{2}$. As can be seen there is a cathodic peak in the DNA-bpy' at $-0.17 \mathrm{~V}$ and a peak in the SW figure located at $0.17 \mathrm{~V}$. It is hypothesized that this was the free bpy' ligand chelating with traces of metal contaminants in the solution.

\subsubsection{Cobalt Experiments}

The electrodes containing immobilized DNA-bpy' and DNA- $\mathrm{NH}_{2}$ used in Figure 2.29 were exposed to a solution of $\left[\mathrm{Co}(\text { bpy })_{2} \mathrm{Cl}_{2}\right] \mathrm{Cl}$.

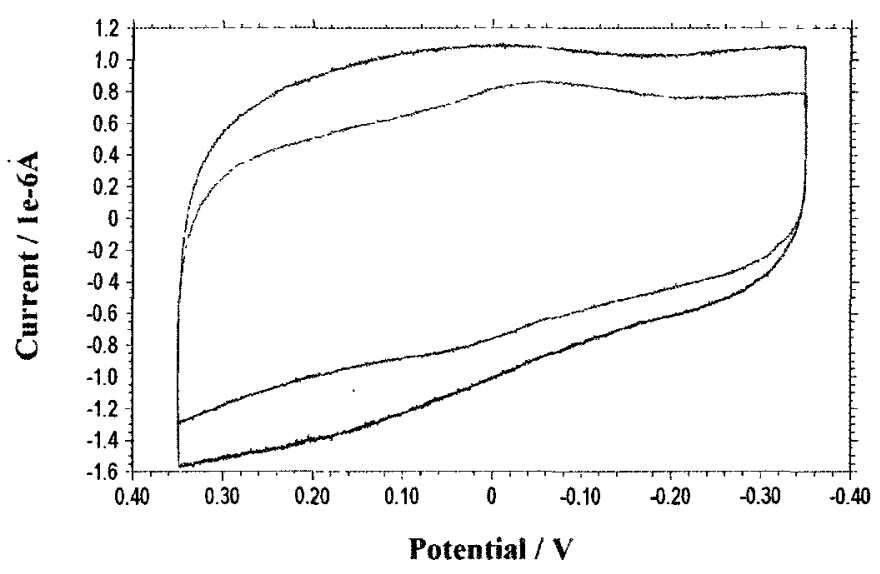

Figure 2.30: Cyclic voltammograms of DNA-bpy' (red) and DNA-NH $\mathrm{N}_{2}$ (blue) containing electrodes after 1 hour of $\left[\mathrm{Co}(\mathrm{bpy})_{2} \mathrm{Cl}_{2}\right] \mathrm{Cl}$ deposition

Figure 2.30 shows the CVs of DNA-bpy' and DNA- $\mathrm{NH}_{2}$ after exposure to $\left[\mathrm{Co}(\text { bpy })_{2} \mathrm{Cl}_{2}\right] \mathrm{Cl}$ for 1 hour. As can be seen the DNA-bpy ${ }^{\prime} \mathrm{CV}$ shows cathodic peak at

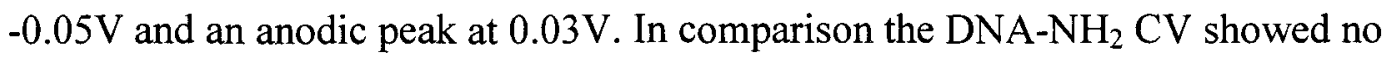


significant peak formation after the exposure to the cobalt solution. This indicated that the free bpy' had successfully formed a complex with the cobalt solution while immobilized on the surface of the electrode. Further to this, the cathodic peak position is similar to that of free Co(bpy $)_{3}$ which shows a redox potential of $0.05 \mathrm{~V} . .^{53}$

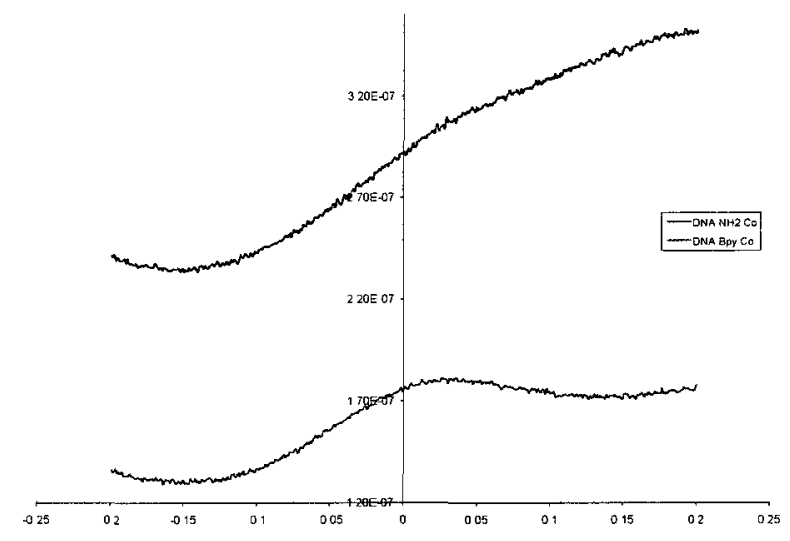

Figure 2.31: Reversed bias SW voltammogram of DNA-bpy' (red) and $\mathrm{DNA}^{-\mathrm{NH}_{2}}$ (blue) containing electrodes after 1 hour of $\left[\mathrm{Co}(\mathrm{bpy})_{2} \mathrm{Cl}_{2}\right] \mathrm{Cl}$ deposition

The SW confirmed the presence of a peak at $\sim 0.02 \mathrm{~V}$ for the DNA-bpy' electrode after the cobalt deposition. Once again, the control electrode containing DNA-NH showed no interaction with $\left[\mathrm{Co}(\mathrm{bpy})_{2} \mathrm{Cl}_{2}\right] \mathrm{Cl}$.

As a result of these experiments, it was concluded that DNA-Cobalt conjugate could be successfully synthesized by first immobilizing DNA-bpy' on the surface of a gold electrode, and then reacting the free $5^{\prime}$ bpy with $\left[\mathrm{Co}(\mathrm{bpy})_{2} \mathrm{Cl}_{2}\right] \mathrm{Cl}$. 
Concurrently with experiments involving DNA-bpy', experiments with DNAcobalt conjugates reported in Chapter 2.2.5 were also conducted.
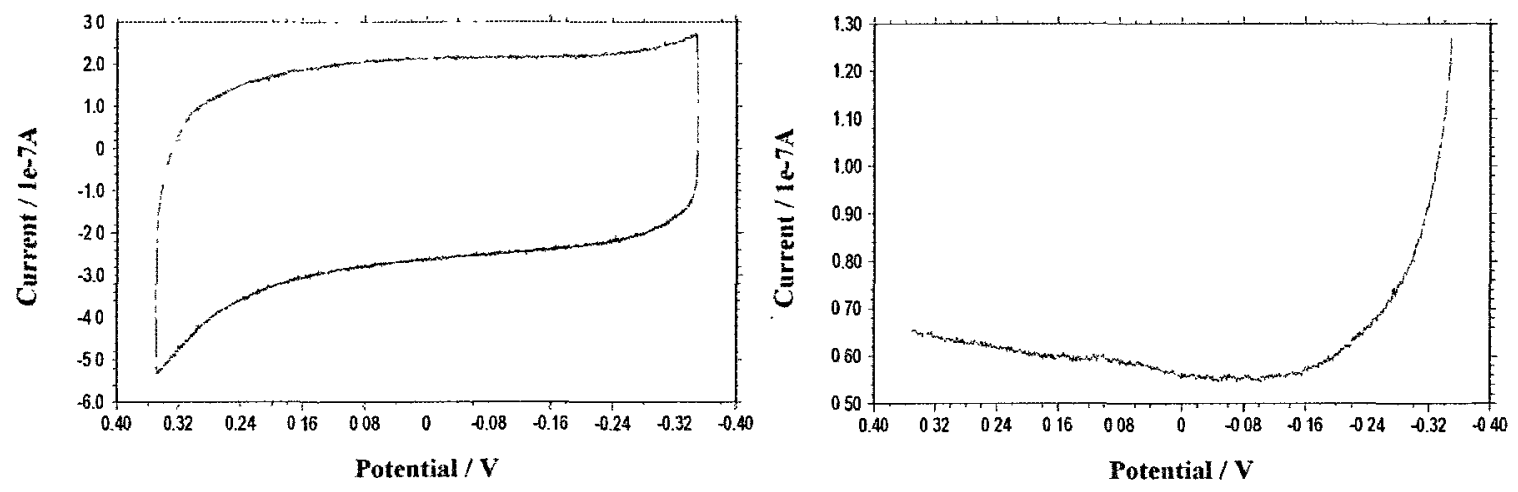

Figure 2.32: CV (left) and SW (right) of DNA-cobalt conjugate

The CV in figure 2.32 is the $\mathrm{CV}$ of DNA-cobalt conjugate. As is evident, there is no cathodic or anodic peak. The poor result is considered a result of the fact that the sample used for deposition was not purified and as a result many unmodified DNA strands may have preferentially bound to the surface. Purification of the DNA-Cobalt conjugates proved challenging as was discussed in Chapter 2.3.4 and thus it was deemed that the best way to synthesize the desired cobalt complex was to first immobilize pure DNA-bpy' and then react it with the desired cobalt complex.

2.3.5.3 Validation of the results: Surface coverage analysis

Surface coverage analysis was conducted by taking the area under the cathodic peak in the ruthenium hexaammine $\mathrm{CV}$. Ruthenium hexaammine is known to bind to the phosphate backbone of DNA in a ratio of 3 phosphates to 1 ruthenium complex. 


$$
\Gamma_{R u}=\frac{Q}{n F A}
$$

Equation 2.1: Calculation of surface density of ruthenium

Equation 2.1 describes the surface density of ruthenium hexaammine where $Q$ is the charge obtainable by integrating the cathodic peak in the ruthenium hexaammine $\mathrm{CV}$, $\mathrm{n}$ is the number of electrons in the reaction, $\mathrm{A}$ is the area of the working electrode, and $\mathrm{F}$ is Faraday's constant. Using this density, the surface coverage of DNA can be determined by utilizing Equation 2.2 .
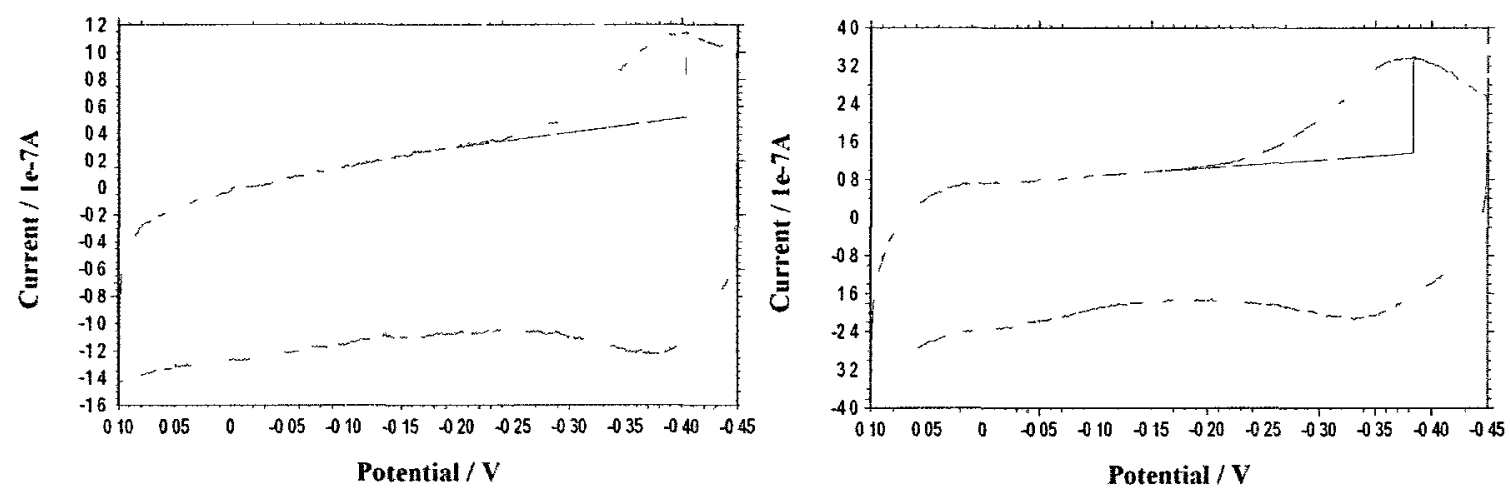

Figure 2.33: CV's of Ruthenium Hexaammine using a DNA- $\mathrm{NH}_{2}$ modified electrode (left) and DNA-bpy'-Cobalt electrode (right)

Figure 2.33 illustrates two examples of ruthenium hexaammine CVs. Upon integration of the cathodic peak, the surface density can be calculated using equation 2.1. The quantity of DNA can then be calculated from the ratio of ruthenium to DNA. 


$$
\Gamma_{D N A}=\Gamma_{R u}\left(\frac{z}{m}\right) N_{A}
$$

Equation 2.2: Calculation of the surface density of DNA based on $\Gamma_{\mathrm{Ru}}$

Equation 2.2 shows the conversion between $\Gamma_{\mathrm{Ru}}$ and $\Gamma_{\mathrm{DNA}}$ where $\Gamma_{\mathrm{Ru}}$ is calculated in Equation 2.1, $\mathrm{z}$ is the charge of the ruthenium complex, $\mathrm{m}$ is the number of nucleotides and $\mathrm{N}_{\mathrm{A}}$ is Avogadro's number.

From the data collected in Figure 2.33, quantification of the surface coverage was made possible. The data from ruthenium hexaammine data from Figure 2.33 is for the electrodes containing DNA- $\mathrm{NH}_{2}$ modified electrode and DNA-bpy'-Cobalt modifications. It was found that the DNA- $\mathrm{NH}_{2}$ had $1.92 \times 10^{-13}$ moles of DNA immobilized on the surface, while the DNA-bpy'-Cobalt had $6.5 \times 10^{-13}$ moles of DNA immobilized. Given that both electrodes had coverage on the same order of magnitude it was deemed that the signals attained from both were comparable.

Further validation can be conducted by applying equation 2.1 to the cathodic cobalt peak (Figure 2.30). Since the ratio of cobalt to DNA is $1: 1$, use of Equation 2.2 is not necessary and as such the surface density of cobalt is equal to the surface density of DNA. Using this it was found that the DNA coverage was $6.5 \times 10^{-13}$ moles of DNA. This is identical to the number calculated using ruthenium hexaammine and serves as further validation of the result. This also shows that the modified bpy' DNA was completely reacted with $\mathrm{Co}\left[\mathrm{bpy}_{2} \mathrm{Cl}_{2}\right] \mathrm{Cl}$ in a $1: 1$ fashion. 


\subsubsection{Applicability}

This platform has potential for application in medical diagnostics. The major factor to consider when discussing applicability is the reactivity of the $\left[\mathrm{Co}(\mathrm{bpy})_{2} \mathrm{bpy}^{\prime}\right]\left(\mathrm{PF}_{6}\right)_{3}$ complex. In general inorganic complexes are susceptible to ligand exchange in cases where a more inert metal is present. An example of such an inert metal is iron. However, in biological samples iron will be bound to heme and thus will not be free for ligand exchange.

\subsection{Conclusion}

The results presented herein lead to the conclusion that a $\left[\mathrm{Co}(\mathrm{bpy})_{2} \mathrm{bpy}\right]$-DNA conjugate has been successfully synthesized and immobilized on a gold electrode. This opens the door to a new class of electrochemical-based biosensor platforms in which $\left[\mathrm{Co}(\mathrm{bpy})_{2}\right.$ bpy'] is the redox element. As inorganic complexes are more robust than organic molecules, this platform may address issues of long term reusability of current electrochemical sensor platforms. Furthermore, alteration of the ligands makes possible the creation of inorganic complexes with alternate redox potentials. As such, the capability for parallel sensing also exists - a situation where one aptamer is conjugated to one complex and another aptamer is conjugated to another; the system would be able to detect multiple targets simultaneously. Finally, in its current state, this platform may be used as a single aptamer sensor platform for the detection of a given analyte. 


\section{Chapter 3}

\section{Label-free Biosensing with a Surface Plasmon Resonance Fiber Grating Aptasensor}

Shevchenko, Y.; Francis, T. J.; Blair, D. A. D.; Walsh, R.; De Rosa, M. C.; Albert, J. In situ Biosensing With a Surface Plasmon Resonance Fiber Grating Aptasensor. Anal.

Chem. 2011, accepted.

Statement of Contributions: DNA synthesis and sample preparation was conducted by Tariq Francis. DNA deposition experiments, thrombin detection experiments, and Kd experiments were conducted by Tariq Francis and Yanina Shevchenko. AFM and Confocal Microscopy work was conducted by David Blair and Yanina Shevchenko. Fabrication of the Tilted Fibre Bragg Grating-SPR sensor was conducted by Yanina Shevchenko. Analysis of experimental data was conducted by Yanina Shevchenko. Kd data fitting was conducted by Yanina Shevchenko and Ryan Walsh. 


\subsection{Introduction}

The use of optical fibres with SPR and aptamers is a relatively new field. The desire to utilize optical fibres as a basis for sensor development arises due to their cost effectiveness and compact design. As a result of these factors they can be utilized for both in situ and remote measurements. This project describes a study where a fibre-based biosensor platform is coupled with the thrombin aptamer to detect thrombin protein in both buffer solution and serum solution.

As described in Chapter 1.4, surface plasmon resonance is a unique electromagnetic phenomenon that involves the measurement of changes in refractive index due to a perturbation of an electrical field created by incident light ${ }^{39}$. The dielectric component can consist of either glass or plastic. As such, an optical fibre can be utilized as the dielectric in SPR excitation by depositing a metal layer on the surface of the fibres. ${ }^{80}$ The excitation of the SPR occurs when the wave vector of the light is parallel to the interface and matches the surface plasma wave. ${ }^{80}$

\subsubsection{Optical Fibres}

An optical fibre is an extremely thin strand of glass designed to transmit light from a source to a receiver. ${ }^{81}$ An optical fibre consists of three regions - the core, cladding, and the coating (illustrated in Figure 3.1). 


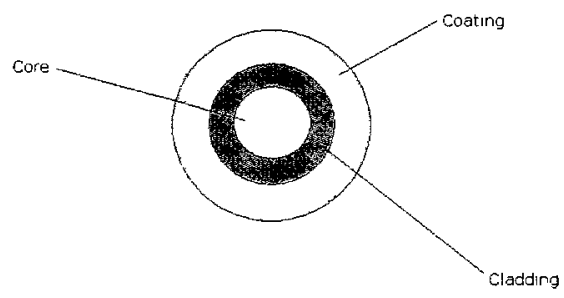

Figure 3.1: Cross sectional representation of an optical fibre.

The core is the region where the light is carried. It typically ranges from 9 to 100 microns in diameter. ${ }^{81}$ The cladding is a region that ensures the light remains confined to the core. To achieve this end, optical fibres are designed such that the core has a higher refractive index than the cladding region. ${ }^{81}$ The cladding region typically has a diameter of 125 microns. ${ }^{81}$ The coating is the outer region of the fibre and is typically made from a plastic material designed to protect the core and cladding regions, as well as to reinforce the strength of the glass fibre. ${ }^{81}$

As light is passed from a medium of higher refractive index to one of lower refractive index the light bends away from the normal. ${ }^{81}$ Snell's Law can be used to determine how large a bend the incident light takes away from the normal. ${ }^{81}$ This is given in Equation 3.1. ${ }^{81}$

$$
n_{1} \sin \theta_{1}=n_{2} \sin \theta_{2}
$$

Equation 3.1: Snell's Law. In terms of fibres $n_{1}$ is the refractive index of the core and $n_{2}$ is the refractive index of the cladding ${ }^{81}$

The critical angle is achieved when the angle of incidence produces an angle of refraction of $90^{\circ}$. As the angle of incidence passes the critical angle, total internal 
reflection occurs. It is at this point that the angle of incidence is equal to the angle of reflection. $^{81}$

$$
\theta_{c}=\sin ^{-1}\left(\frac{n_{2}}{n_{1}}\right)
$$

Equation 3.2: Equation to calculate the critical angle where $\mathrm{n}_{l}$ is the refractive index of the core and $\mathrm{n}_{2}$ is the refractive index of the cladding ${ }^{81}$

Light that travels along the core at the critical angle will progress along the fibre. Light that is at less than the critical angle is refracted into the cladding layer and lost. ${ }^{81}$

\subsubsection{Optical Fibres in Biosensing}

Chapter 1.4 describes a metallic layer on a prism as a requirement when exciting a surface plasmon. This requirement is true for optical waveguides as well. A waveguide propagates light in the form of guided modes.$^{80}$ The core of an optical fibre is the waveguiding layer..$^{80}$ The bulk of the electromagnetic field is concentrated in this layer. ${ }^{80}$ A fraction of the optical energy propagates as an evanescent wave in the material surrounding the core; this material is of a lower refractive index. ${ }^{80}$ 
a)

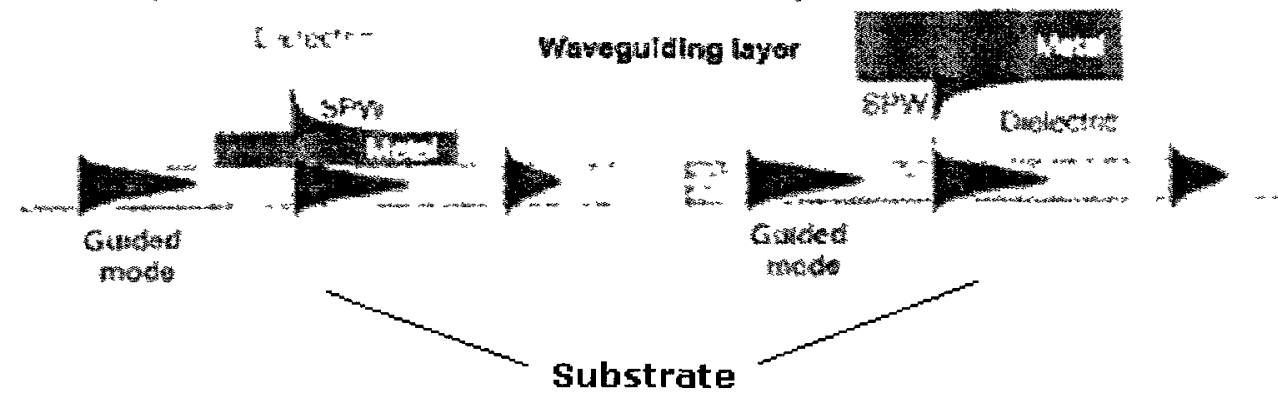

Figure 3.2: Excitation of surface plasma waves using optical waveguides; a) excitation of the surface plasma wave at the boundary of a metallic thin film and a dielectric layer, b) excitation of a surface plasma wave on a metallic thin film through a dielectric buffer

$$
\text { layer [adapted from }{ }^{80} \text { ] }
$$

The metallic thin film can have a surface plasma wave excited on either the outer (Figure 3.2 a) or inner (Figure $3.2 \mathrm{~b}$ ) surface of the film. ${ }^{80}$ The field of a surface plasma wave penetrates into the dielectric layer as it propagates along the interface. ${ }^{80}$ This is essentially probing the dielectric medium. Any changes in the optical properties of the dielectric, such as those incurred from addition of analyte molecules or adhesion of molecular recognition agents to the surface, results in a change of the surface plasma wave ${ }^{80}$ In the context of biosensing, the addition of molecular recognition agents such as aptamers, or the addition of target molecules, results in a change in refractive index of the dielectric layer. A small change of refractive index produces a large change in the propagation constant of the surface plasma wave. ${ }^{80}$ Typically, the molecular recognition element is immobilized on the sensor surface. After immobilization, the analyte solution is added to the surface and the refractive index at the sensor surface increases. This changes the propagation constant of the surface plasma wave. 
Sensors based on surface plasmon resonance are exploiting the sensitivity of the propagation constant of a surface plasma wave.$^{80}$ The changes incurred by the propagation constant result in a change in the properties of the light wave interacting with the surface plasma wave. ${ }^{80}$ There are several types of SPR sensors and these are classified based on their modulation; either angular, wavelength, intensity, phase, or polarization modulation. Angular-based sensors are those that measure the coupling strength at multiple angles of incidence of light waves. ${ }^{80}$ Wavelength-modulation-based sensors are similar, but measure the coupling at multiple wavelengths and use the wavelength that yields the strongest coupling. ${ }^{80}$ Intensity modulation involves a changing intensity of the incident light, while keeping the angle and wavelength constant; likewise, phase modulation monitors the shift in phase of the light wave while interacting with the surface plasma wave, again keeping angle and wavelength constant. ${ }^{80}$ Polarization modulation involves monitoring the changes in the amplitude and phase of transversemagnetic (TM) polarized light. The amplitude and phase of TM-polarized light interacting with a surface plasma wave will change, if the propagation constant changes. ${ }^{80}$

There are several advantages to using optical fibres as a sensor platform. They are immune to electromagnetic interference, are light-weight, flexible and, as a result, stable. ${ }^{82}$ Furthermore, they have a high temperature tolerance. ${ }^{82}$ In the case of the fibre used in this thesis the temperature tolerance ranges from $-60^{\circ} \mathrm{C}$ to $+85^{\circ} \mathrm{C}$ in accordance with the manufacturer's product information sheet for a Corning SMF-28 optical fibre. As a result of their durability, reproducible results are possible. 


\subsubsection{Fibre Bragg Gratings}

Fibre Bragg Gratings were originally developed by Ken Hill of the Canadian Communication Research Centre in 1978 as a telecommunications tool. ${ }^{83,84}$ Since then, however, they have been used as a sensor for a wide variety of applications such as monitoring load, strain, and refractive index changes. ${ }^{84}$ A Bragg grating is essentially a periodic modulation of the refractive index in the core of a single mode fibre. ${ }^{82}$ These gratings contain a phase front perpendicular to the longitudinal axis. ${ }^{82}$

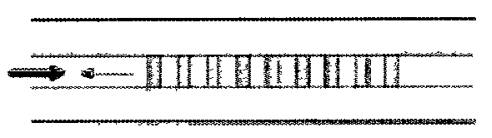

Figure 3.3: Example of a Fibre Bragg grating [adapted from ${ }^{85}$ ]

Figure 3.3 illustrates the constant periodicity of a Bragg grating. Light passing along the core will be scattered by each grating plane. ${ }^{82}$ The Bragg condition states that the frequency of the incident light equals the frequency of the reflected light; furthermore the sum of the incident wavevector and grating wavevector equals the wavevector of the scattered radiation. ${ }^{82}$ This results in the reflections from the surface layers being of the same phase - or phase matched, leading to constructive interference. These two requirements are an extension of the laws of conservation of energy and momentum. ${ }^{82}$ If the Bragg condition is not satisfied, the result is that the reflected light becomes out of phase and eventually cancels out. ${ }^{82}$ When the Bragg condition is satisfied, however, the reflected light from each grating adds in a constructive fashion. ${ }^{82}$ 


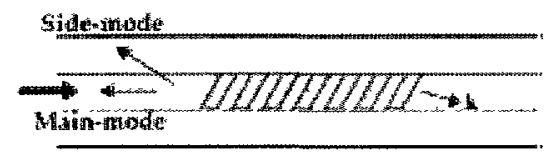

Figure 3.4: Example of a Tilted Fibre Bragg Grating [adapted from ${ }^{85}$ ]

A tilted fibre Bragg grating is a fibre which contains gratings at angles to the fibre axis as shown in Figure 3.4. ${ }^{82}$ This tilt results in light being coupled into the cladding mode. $^{82}$

Fibre Bragg gratings have long been considered excellent sensor elements. ${ }^{82}$ The principal advantage is that information gathered is independent of fluctuating light intensities, as it is dependent on wavelength. ${ }^{82}$ This gives rise to the possibility of an interrupt-immune sensor system since the information being measured is based on wavelength and is thus immune to fluctuating light levels, or power fluctuations. ${ }^{82}$ The use of Bragg gratings as sensors also offers advantages in that a fibre optic cable modified with a Bragg grating shows a linearity in response over several orders of magnitude from parts per billion to several percent. ${ }^{82}$ The use of tilted gratings gives further advantages as they have a higher refractive index sensitivity to that of fibre Bragg gratings. ${ }^{86}$ Tilted fibre Bragg gratings, coupled with fibre optics, gives rise to a highly advantageous sensor platform. Further to this, the tilted geometry means that the cladding layer does not have to be altered. 


\subsubsection{Sensor Platform and Project Goals}

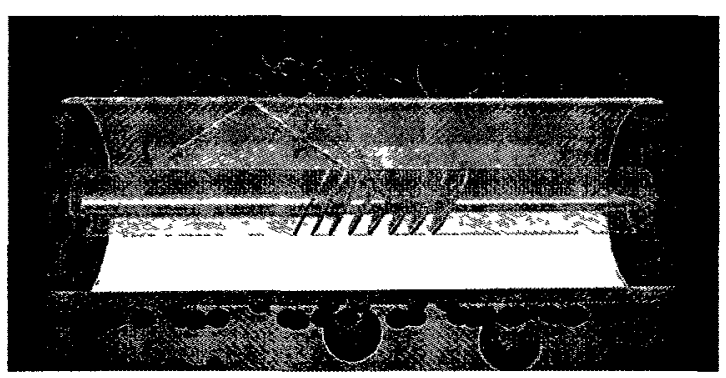

Figure 3.5: Schematic diagram of the tilted fibre Bragg grating sensor system. In this illustration the blue represents the target molecules (thrombin), the red represents the molecular recognition elements (15-mer DNA thrombin aptamer) on a gold coated fibre. Reprinted with permission from Shevchenko, Y.; Francis, T. J.; Blair, D. A. D.; Walsh, R.; DeRosa, M. C.; Albert, J. In Situ Biosensing with a Surface Plasmon Resonance Fiber Grating Aptasensor. Anal. Chem. 2011, ASAP. Copyright 2011 American Chemical Society

Figure 3.5 illustrates this project in its entirety. The incident light is reflected by the tilted fibre Bragg grating (TFBG). This creates evanescent waves in the cladding mode which are used to excite surface plasma waves in the gold coated optical fibres. The use of the TFBG allows for a coupling to occur between the core mode and several cladding modes. Each of these cladding modes strikes the gold-cladding boundary at different angles of incidence. ${ }^{87}$ Coupling to the surface plasma wave occurs if the Bragg conditions are met and there is phase matching. 
As Figure 3.5 shows the optical fibre has a tilted fibre Bragg grating written into its core. To this fibre a $20-25 \mathrm{~nm}$ layer of gold was deposited.$^{87}$ The Bragg gratings were tilted at $10^{\circ}$. This results in the propagating cladding modes reaching a range of $100 \mathrm{~nm}$ on the measured optical spectra ${ }^{69}$ During an experiment, changes in the surface plasma wave are expected during the immobilization of the aptamer on the gold surface, and when the aptamer binds to its target. This arises due to changes in the refractive index at the surface during each step of an experiment. ${ }^{69}$

Immobilization of the aptamer is conducted through the gold thiol interaction $-\mathbf{a}$ commonly used type of immobilization that takes advantage of the soft-soft acid base interaction between gold and sulfur. The desired target was added to the system. At each step, the surface plasma wave is monitored and compared to the original spectra before addition of either DNA aptamer or aptamer target. ${ }^{69}$

This, essentially, creates a portable and lightweight biosensor that can be used in aqueous media. Further to this, there is versatility in the design as the tilt angles of the Bragg gratings can be changed. This results in a sensor system that can be tuned for use in differing media with differing refractive indices. ${ }^{69}$ This is advantageous as the possibility exists for more complex types of solutions to be used when taking measurements - a practical example of such a complex solution could be human blood. 
Finally, verification of the experimental results was conducted using various physical methods such as AFM and Confocal Microscopy. These experiments have been reported previously, ${ }^{69}$ but the results will be reported herein for completeness.

This platform for thrombin detection is used for several reasons. Firstly, thrombin is a well-studied protein and as such the results described herein are comparable to those already described using more conventional techniques. Second, thrombin is the last enzyme protease involved in the coagulant cascade. This cascade creates an insoluble fibrin gel from fibrinogen. The concentration of thrombin can reach low micromolar concentrations during this process and even low nanomolar levels can be generated during the early haemostatic process. As a result, aptamer-based sensors for thrombin detection are valuable tools for monitoring thrombin levels in the plasma or blood. ${ }^{88}$ The novelty of this work stems from applying a tilted fibre Bragg grating-SPR sensor for protein detection.

\subsection{Experimental section}

\subsubsection{Fabrication of the TFBG-SPR sensor}

Synthesis of the sensor system was conducted by Yanina Shevchenko as reported earlier $^{87,89}$. The SPR-TFBG sensor was manufactured using a standard single-mode fibre (Corning SMF-28) with a TFBG inscribed in the fibre's core. Gold was deposited on the surface of the fibre's cladding. 


\subsubsection{Experimental setup, optical configuration}

The experimental setup required the sensor to operate in the transmission regime. During the experiments, the sensors had to be fixed in a $7.5 \mathrm{~cm}$ by $2 \mathrm{~cm}$ plastic cell designed specifically for the biosensing tests. While each individual sensor was fixed in the platform with help of UV-sensitive adhesive, the sensing element $(0.5 \mathrm{~cm}$ in length) was immersed in a carved out indentation ( $45 \mathrm{~mm}$ by $5 \mathrm{~mm}$ ), which was then covered by a glass slide to avoid evaporation of solutions during the experiments. Immersion of the sensor was conducted at the beginning of each test using a pipette; on average $600 \mu \mathrm{L}$ of solution was added.

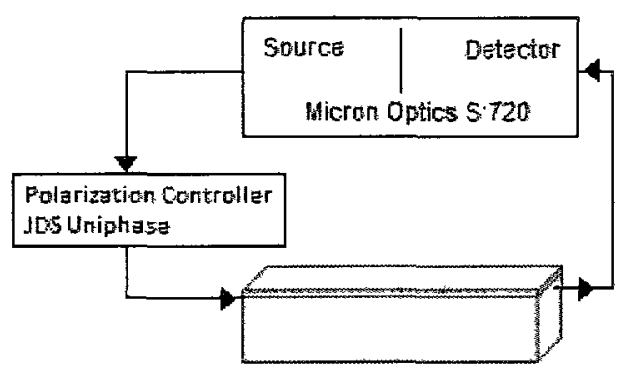

Figure 3.6: Schematic diagram of the sensor setup. Reprinted with permission from Shevchenko, Y.; Francis, T. J.; Blair, D. A. D.; Walsh, R.; DeRosa, M. C.; Albert, J. In Situ Biosensing with a Surface Plasmon Resonance Fiber Grating Aptasensor. Anal. Chem. 2011, ASAP. Copyright 2011 American Chemical Society

Sensors were interrogated using an Optical Sensing Analyzer (model Si720 from Micron Optics). Light over $1520-1570 \mathrm{~nm}$ range was linearly polarized using Polarization Controller from JDS Uniphase. Before each experiment the orientation of the polarization was adjusted to maximize coupling of the cladding modes to the SPR to ensure the 
strongest contrast between SPR-coupled and non-SPR modes. The measurement resolution was set at $0.0025 \mathrm{~nm}$ and measurements were recorded each 0.8 seconds. A schematic of the used optical setup can be found in Figure 3.6.

3.2.3 Analysis of the experimental data

Analysis of the data was conducted by Yanina Shevchenko. Figure 3.7 provides an example of the typical transmission spectrum obtained with the SPR-TFBG sensor while being immersed in the aptamer solution. The red bracket in Figure 3.7 denotes the portion of the SPR-modified spectrum. The analysis presented in this paper is based on tracking the changes in the SPR-modified portion of the spectrum; more particularly tracking of the most sensitive SPR coupled cladding resonance. This resonance occurs on the left from the narrowest part of the SPR-coupled region, as indicated by the red arrow in Figure 3.7. Experiments were conducted a minimum of three times, error bars are the standard deviation between the filtered signal and a linear fit where the signal became saturated and levelled off. 


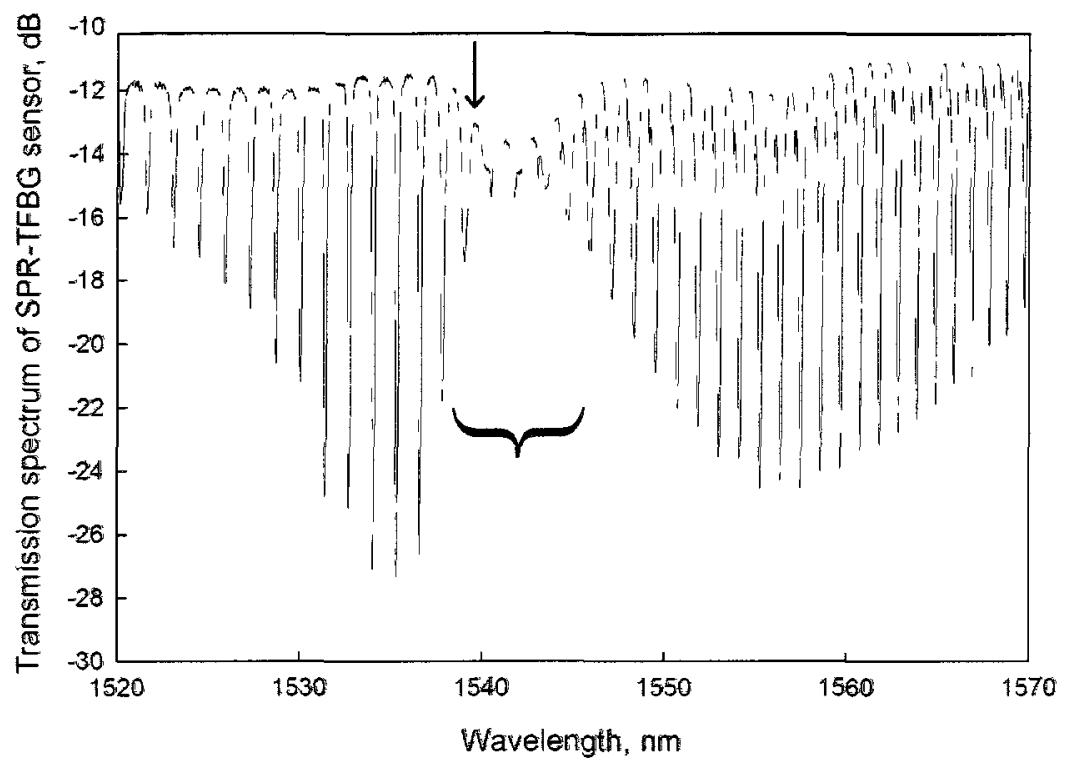

Figure 3.7: Transmission spectrum obtained with the SPR-TFBF sensor while immersed in a solution of thiolated thrombin aptamers. The red bracket indicate the SPR-coupled component of the spectra while the red arrow indicates the most sensitive SPR-coupled cladding resonance. Reprinted with permission from Shevchenko, Y.; Francis, T. J.; Blair, D. A. D.; Walsh, R.; DeRosa, M. C.; Albert, J. In Situ Biosensing with a Surface Plasmon Resonance Fiber Grating Aptasensor. Anal. Chem. 2011, ASAP. Copyright 2011 American Chemical Society

3.2.4 Aptamer sequences, buffers, serum, thrombin protein and water

All buffer solutions were prepared using doubly deionized water from a Milli-Q water system (ThermoFisher). All DNA phosphoramidites and modifiers were purchased from Glen Research. Bovine Serum and Bovine Serum Albumin were purchased from Sigma Aldrich. Bovine serum solution for testing was prepared as a solution of $50 \%$ 
Serum: $50 \%$ Tris Buffer (50 mM Tris, $\left.1 \mathrm{mM} \mathrm{MgCl}_{2}, 140 \mathrm{mM} \mathrm{NaCl}, 5 \mathrm{mM} \mathrm{KCl}\right)$. The thiolated thrombin aptamer, DNA sequence HS- $\left(\mathrm{CH}_{2}\right)_{6}-5^{\prime}$-GGT TGG TGT GGT TGG $3^{\prime}$ (herein called thrombin aptamer), was synthesized on a MerMADE 6 DNA synthesizer (Bioautomation Corporation). The sequence purification was conducted using Clarity QSP Cartridges (Phenomenex). The DNA was dissolved in "DNA buffer" (5 mM phosphate, $100 \mathrm{mM} \mathrm{MgCl} 2,50 \mathrm{mM} \mathrm{NaCl}$ ). DNA sequences were confirmed by ESI-MS and the Ellman's test ${ }^{90}$ was conducted to test for presence of the $5^{\prime}$ Thiol group prior to binding.

Human alpha-thrombin protein was purchased from Haematologic Technologies Inc. The protein was aliquoted as needed and dissolved in "Protein Buffer" (50 mM Tris, $1 \mathrm{mM} \mathrm{MgCl} 2,140 \mathrm{mM} \mathrm{NaCl}, 5 \mathrm{mM} \mathrm{KCl})$.

The sequences used for the confocal microscopy experiments were purchased from Alpha DNA (Montreal). The thrombin aptamer sequences possessed the 5'-thiol C6 modifier, as well as a Cyanine $3\left(\mathrm{Cy} 3^{\mathrm{TM}}\right)$ dye modifier at the $3^{\prime}$ end, making the overall sequence 5'-HS-( $\left(\mathrm{CH}_{2}\right)_{6}$-GGT TGG TGT GGT TGG-Cy3-3' (herein called Cy3 DNA).

\subsubsection{Immobilization of the thrombin aptamer}

Prior to the immobilization of the thrombin aptamer on the surface of the sensor, the sensors were washed with ethanol and then with Milli-Q water. After the cleaning step, DNA functionalization was conducted by filling out the carved indentation with the 
aptamer solution of the desired concentration. Transmission spectra were collected automatically every 0.8 seconds during the entire experiment. Aptamer deposition times and concentrations varied between tests. After the aptamer adsorption step was complete, the sensor was rinsed with DNA buffer several times before the protein solution was added.

3.2.6 Binding of the thrombin protein to the thrombin aptamer

Thrombin solutions were prepared to a desired concentration using human $\alpha$-thrombin and Protein Buffer. The solutions were used to fill the cut out indentation of the platform. The duration of soaking in the thrombin solution varied between 20 min and 2 hours, depending on the experiment. After immersion in the protein solution, the sensor was washed with Protein Buffer for several minutes to prepare for the next step.

\subsubsection{Confocal microscope imaging}

Confocal imaging was conducted by David Blair and has previously been reported. ${ }^{69}$ Confocal microscope imaging combined with fluorescent labelling was used to evaluate and confirm the self-assembly of the aptamer on the surface of the gold coating of the sensors. All confocal microscopy images were collected on a Zeiss LSM510 with a PlanApochromat 63x/1.4 Oil Dic objective with LP950 filter, with an excitation wavelength of $550 \mathrm{~nm}$ and an emission wavelength of $570 \mathrm{~nm}$. Before running the experiment, the sensors were prepared by rinsing them with anhydrous ethanol and then with DNA 
Buffer. Cy3 DNA was dissolved in DNA Buffer to make a $45 \mu$ M solution. Sensors were then immersed in the aptamer solution for 20 hours, rinsed thoroughly, and later imaged while mounted on microscope slides in a solution of $50 \%$ glycerol in water, and covered with $1.7 \mu \mathrm{m}$ thick cover slides.

\subsubsection{Atomic Force Microscope (AFM) Imaging}

AFM imaging was conducted by David Blair and has previously been reported. ${ }^{69}$ AFM imaging was conducted in order to evaluate the surface of the sensor after binding to thrombin protein. All AFM images were collected on an Ntegra system using a SFC050LNTF AFM Head on an inverted microscope (Olympus IX71). Before imaging, gold-coated fibres were immersed in a $25 \mu \mathrm{M}$ solution of thiolated thrombin aptamer for a period of 4 hours. The fibre was then rinsed with DNA buffer and immersed in a $30 \mu \mathrm{M}$ solution of $\alpha$-thrombin in Protein Buffer for approximately 12 hours. After immersion, the fibres were rinsed with Milli-Q water and dried in air before imaging. All samples were collected in air on the dry samples.

3.3 Results and Discussion

3.3.1 Monitoring of thrombin aptamer attachment to the surface

As discussed in Chapter 3.1.4, self assembly of the thrombin aptamer on the surface was carried out using the gold-thiol interaction. The result of immobilized 
aptamer on the surface of the gold coated fibre is a change in refractive index. As a result this change could be monitored via the relative change in SPR signal.

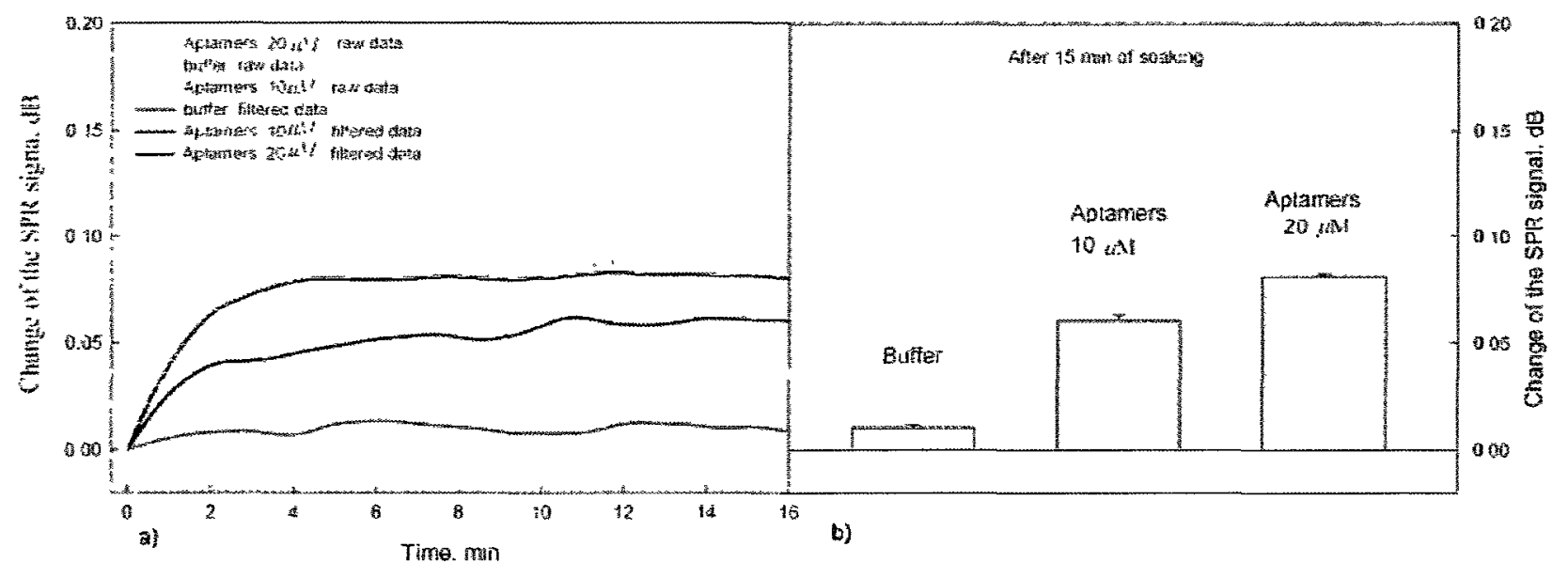

Figure 3.8: a) Change in SPR signal over the first 15 minutes of aptamer immobilization: purple trace - DNA buffer; blue trace - thrombin aptamer at $10 \mu \mathrm{M}$; black trace thrombin aptamer at $20 \mu \mathrm{M}$. b) relative change in SPR after 15 minutes of immobilization expressed as a bar graph for clarity. Reprinted with permission from Shevchenko, Y.; Francis, T. J.; Blair, D. A. D.; Walsh, R.; DeRosa, M. C.; Albert, J. In Situ Biosensing with a Surface Plasmon Resonance Fiber Grating Aptasensor. Anal. Chem. 2011, ASAP. Copyright 2011 American Chemical Society

Figure 3.8 illustrates the change in SPR that occurs upon aptamer deposition. As can be observed, the signal increases with increasing aptamer concentration over the first 6 minutes. The highest concentration, $20 \mu \mathrm{M}$ aptamer, resulted in the largest change followed by the $10 \mu \mathrm{M}$ sample and finally the blank (DNA buffer only) showing the least change in SPR. Furthermore, a doubling of the aptamer concentration did not lead to a 
doubling of the signal change. This indicates that concentrations of $10-20 \mu \mathrm{M}$ are enough to saturate the surface and are thus sufficient for further experiments.

3.3.2 Confocal Microscopy: Verification of aptamer immobilization on the surface

The verification of the aptamer deposition on the fibre has been previously reported. ${ }^{69}$ The thrombin aptamer was modified with both the fluorescent dye Cyanine 3 (Cy3) and a thiol modifier to facilitate immobilization on the gold surface. Imaging was conducted after unbound aptamers were removed via rinsing.
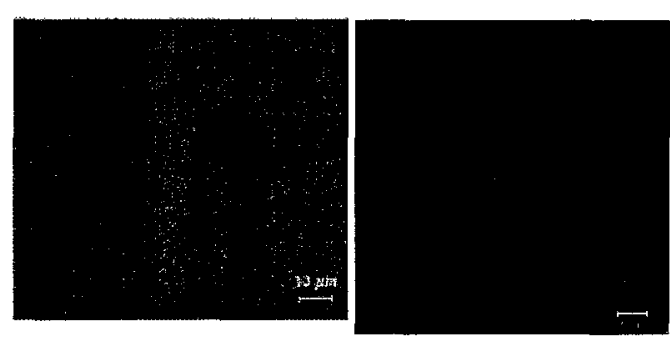

Figure 3.9: Confocal microscope image of an optical fibre immersed in a $45 \mu \mathrm{M}$ solution of $\mathrm{Cy} 3$ and thiol modified DNA for 20 hours. $11 \%$ laser strength, detector pinhole width $55 \mu \mathrm{m}, 63 \mathrm{X}$ magnification was applied (Left) and a confocal microscope image of a bare sensor immersed in a solution of free $\mathrm{Cy} 3$ dye (Right). Reprinted with permission from Shevchenko, Y.; Francis, T. J.; Blair, D. A. D.; Walsh, R.; DeRosa, M. C.; Albert, J. In Situ Biosensing with a Surface Plasmon Resonance Fiber Grating Aptasensor. Anal. Chem. 2011, ASAP. Copyright 2011 American Chemical Society

Figure 3.9 left shows a fluorescent signal from the fibre surface. Figure 3.9 right shows the result of a bare sensor undergoing the same post dye exposure rinsing. As can be seen there is no signal. This verified immobilization of the thiolated DNA. 


\subsubsection{Detection of thrombin}

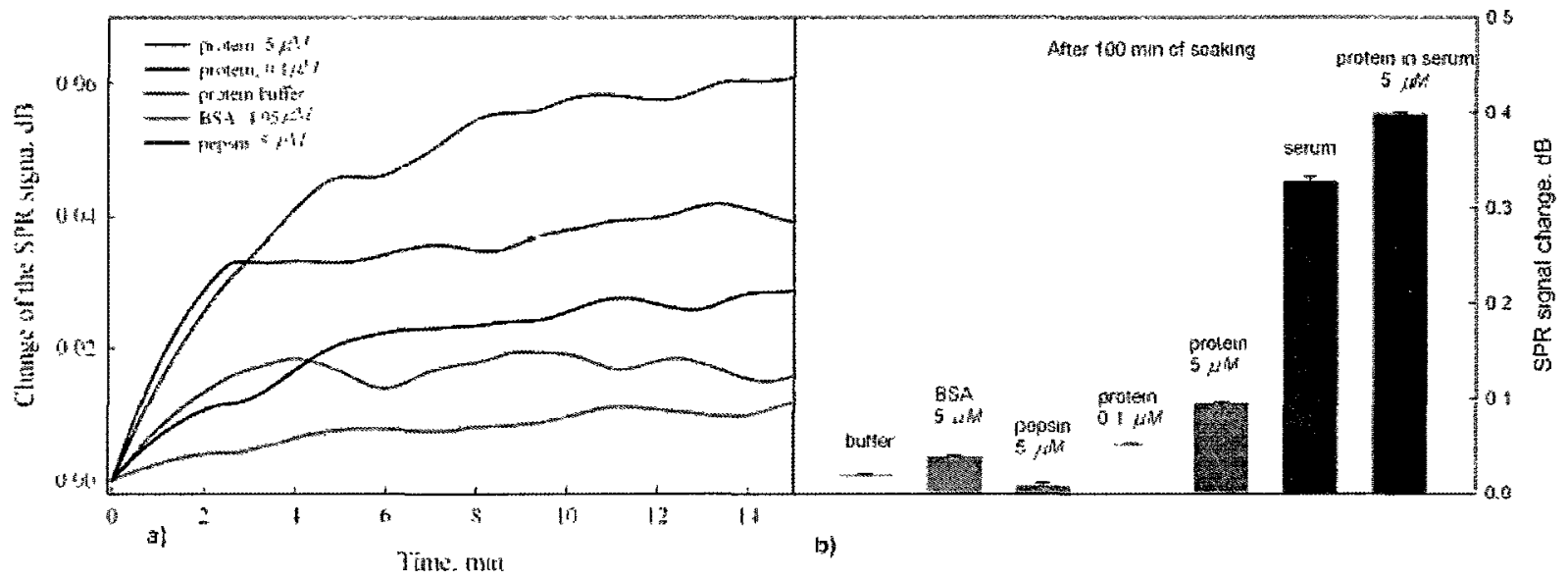

Figure 3.10: a) Change in SPR signal over the first 15 minutes of soaking in a variety of solutions: Protein Buffer (Light Blue); $5 \mu \mathrm{M}$ Bovine Serum Albumin (Green); $5 \mu \mathrm{M}$ Pepsin (Purple); $0.1 \mu \mathrm{M}$ thrombin (Red); $5 \mu \mathrm{M}$ thrombin (Black) b) Bar diagram comparing the results in SPR change over 100 minutes; included are the results of conducting the test in serum (blue bold bars). Reprinted with permission from Shevchenko, Y.; Francis, T. J.; Blair, D. A. D.; Walsh, R.; DeRosa, M. C.; Albert, J. In Situ Biosensing with a Surface Plasmon Resonance Fiber Grating Aptasensor. Anal. Chem. 2011, ASAP. Copyright 2011 American Chemical Society

The results of immersion of the aptamer-functionalized sensor into a variety of thrombin and control solutions are shown in Figure $3.10 \mathrm{a}$ ) and b). In a similar fashion to the DNA immobilization step, the thrombin detection showed a rapid change in SPR signal over the first 10 minutes of immersion, at which time it began to stabilize. 
In order to validate that the signal is generated due to a specific interaction, several controls were used to see if a similar signal change would occur in their presence. Bovine Serum Albumin and Pepsin were chosen as controls. The choice of BSA arose from the fact that BSA is typically used as a control for thrombin aptamer studies. ${ }^{91}$ It is much larger than thrombin (67 $\mathrm{kDa}$ compared to $37 \mathrm{kDa}$ for thrombin). As a result there is a greater possibility of nonspecific interactions occurring. Pepsin is comparable in size to thrombin $(35 \mathrm{kDa})$. This test was conducted to gain a better perspective regarding nonspecific binding. The data in Figure 3.10 reveals that detection of target molecules at concentrations as low as $0.1 \mu \mathrm{M}$ are possible. There is a difference between the signals of $0.1 \mu \mathrm{M}$ thrombin protein, of $5 \mu \mathrm{M} \mathrm{BSA}$, and of $5 \mu \mathrm{M}$ Pepsin in as little as 10 minutes. After 100 minutes the difference between the control signals and target signal reaches a plateau.

Upon validation of the detection results in buffer, a more complex solution was desired in order to evaluate the sensor's versatility and potential applicability in a realworld setting. As a result, bovine serum was chosen, as it contains a high concentration $(60 \mathrm{mg} / \mathrm{mL})$ of nonspecific protein. Furthermore, conducting the test in serum adds to the applicability of this sensor platform in a real world setting. The results from this test are shown in Figure $3.10 \mathrm{~b}$ ). There is a strong non-specific signal increase in the presence of serum as can be seen from the large change in SPR signal. This arises because the serum solution had a vastly different refractive index due to the high concentration of protein. It was observed during preparation that it was highly viscous in nature. Despite this, however, a serum solution containing thrombin such that the thrombin concentration was 
$5 \mu \mathrm{M}$ resulted in a significant change in signal compared to the blank serum sample. The signal difference between the serum-protein/serum solution and buffer-protein/buffer solution was shown to be almost identical. This, in effect, shows that this sensor platform can be used in complex media such as serum just as effectively as simple media such as buffer.

\subsubsection{Verification of thrombin detection}

The verification of thrombin detection has been previously reported. ${ }^{69}$
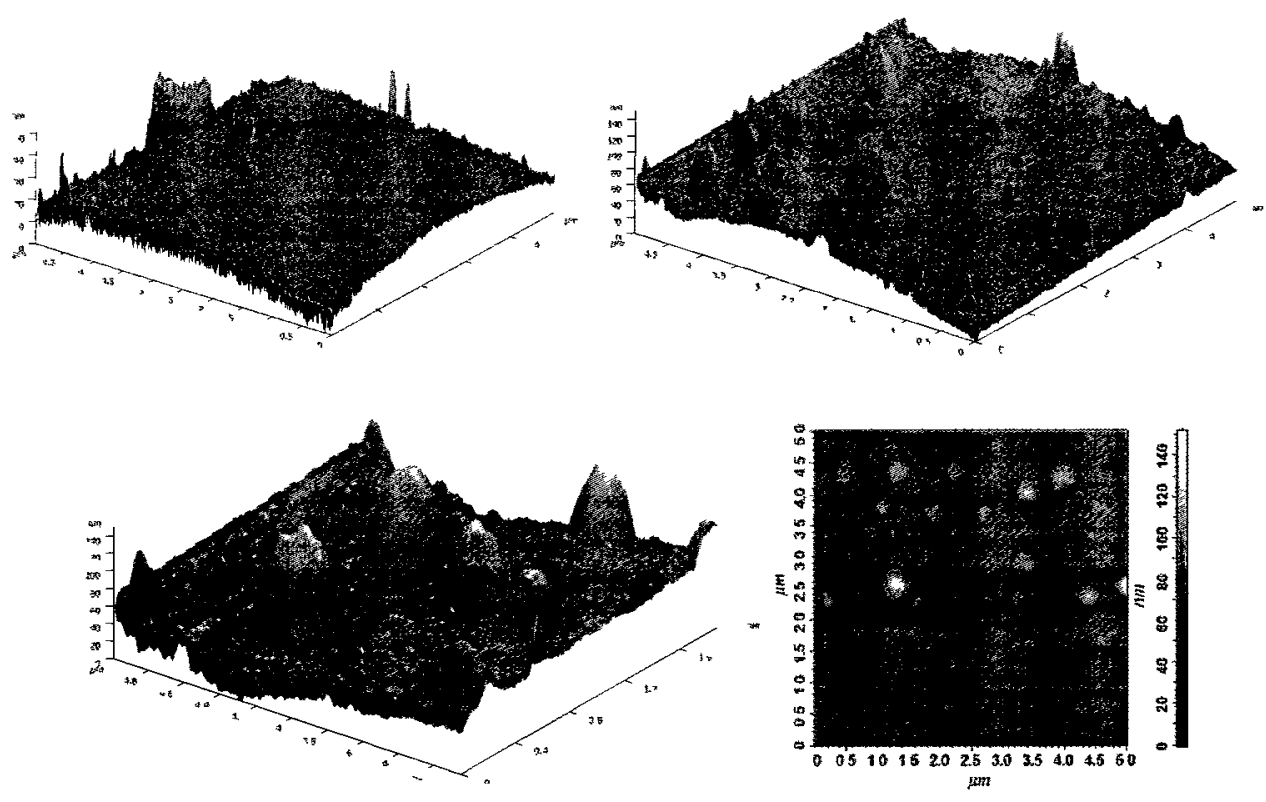

Figure 3.11: 3D AFM image of the sensor's surface after soaking in the thiolated thrombin aptamer solution (Top left); 3D AFM images of the sensor's surface after attachment of thrombin (shown at different scales) (Top right, Bottom left and right). All measurements were conducted in tapping mode and measured in air on a dry sample.

Reprinted with permission from Shevchenko, Y.; Francis, T. J.; Blair, D. A. D.; Walsh, 
R.; DeRosa, M. C.; Albert, J. In Situ Biosensing with a Surface Plasmon Resonance Fiber Grating Aptasensor. Anal. Chem. 2011, ASAP. Copyright 2011 American Chemical Society

The attachment of protein was confirmed using atomic force microscopy. AFM reveals that the sensor surface has many new structural features after target exposure that is not present on the aptamer modified surface alone. It has been reported that the thrombin protein has dimensions of $4.5 \times 4.5 \times 5 \mathrm{~nm} .{ }^{92}$ This is considerably smaller than the observed structural features, which are on the $\mu \mathrm{m}$ and sub- $\mu \mathrm{m}$ scale. A possible explanation for this is that the protein molecules formed clusters in the solution before or during the interaction with the aptamer layer on the surface. In the latter case, formation of protein clusters on the sensor surface could be a result of the uneven distribution of aptamer molecules on the surface of the sensor - a finding that has been previously reported. ${ }^{93}$ Despite this, the SPR changes are valid since they are proportional to the overall protein amount adsorbed to the aptamer surface. The length of the grating is $1 \mathrm{~cm}$, and, as the SPR is excited over the full length, it can be concluded that the observed SPR response is an average of the response over the length of the tilted fibre Bragg grating.

\subsubsection{Limit of Detection, Discussion of Errors and Signal to Noise ratio}

Calculations of error, signal to noise ratio, and the limit of detection was conducted by Yanina Shevchenko. It was found that the signal-to-noise ratio (SNR) varied from 0.5 to 3.97 for the results involving the immobilization of thrombin aptamers, 
shown in Figure $3.8 \mathrm{~b}$ ). For the experiments involving detection of thrombin, the signal to noise ratio varied from 0.36 to 19.83 depending on the experiment. Errors were found as a standard deviation between the data points of the same SPR data set when the signal was saturated. There is a relatively high noise level due to intrinsic noise of the interrogation system. The SNR could be improved by selecting a more stable light source with a lower level of noise. The limit of detection of thrombin (LOD) was calculated as 3 times the noise level ${ }^{94}$ and was found to be $22.6 \mathrm{nM}$. This compares well to the $2 \mathrm{nM}$ LOD reported by Pollet et $\mathrm{al}^{95}$, for another fibre SPR sensor.

\subsection{6 $\mathrm{K}_{\mathrm{d}}$ analysis}

The dissociation constant, $\mathrm{Kd}$, is a parameter used to describe the binding affinity between two interacting molecules. The desire to study the dissociation constant stems from the need to fully characterize the fibre biosensor platform as to increase its applicability for in situ measurements.

The dissociation constant for the thrombin aptamer has been reported in several studies and has been shown to be between $20-200 \mathrm{nM}^{96,97}$ It has also been reported that aptamers functionalized by either chemical modifications or through surface immobilization may have altered binding characteristics. ${ }^{98}$ As a result of these factors, the dissociation constant of the thrombin aptamer immobilized on the fibre sensor was assessed. 
A "Ladder" test was used to evaluate the dissociation constant. This is illustrated in Figure 3.12. Upon functionalizing the surface with thrombin aptamer, the sensor was immersed in a series of solutions with gradually increasing concentrations of thrombin protein. Figure 3.12 shows the results of one of the ladder experiments that utilizing a set of thrombin solutions ranging from $0.1 \mu \mathrm{M}$ to $5 \mu \mathrm{M}$. The SPR signal was obtained by normalizing the amplitude of the most sensitive SPR-coupled resonance. Step 3 of Figure 3.12 illustrates the correlation between SPR signal increase and deposition of the aptamer. Following this, steps 4-7 illustrate soaking of the sensor in thrombin solutions of increasing concentration. Washing with protein buffer in step 8 did not yield a dramatic loss of signal, thus confirming the specific interaction between the protein and the sensor. Removal of the aptamer layer was achieved via soaking in sodium carbonate as shown in step 9. 


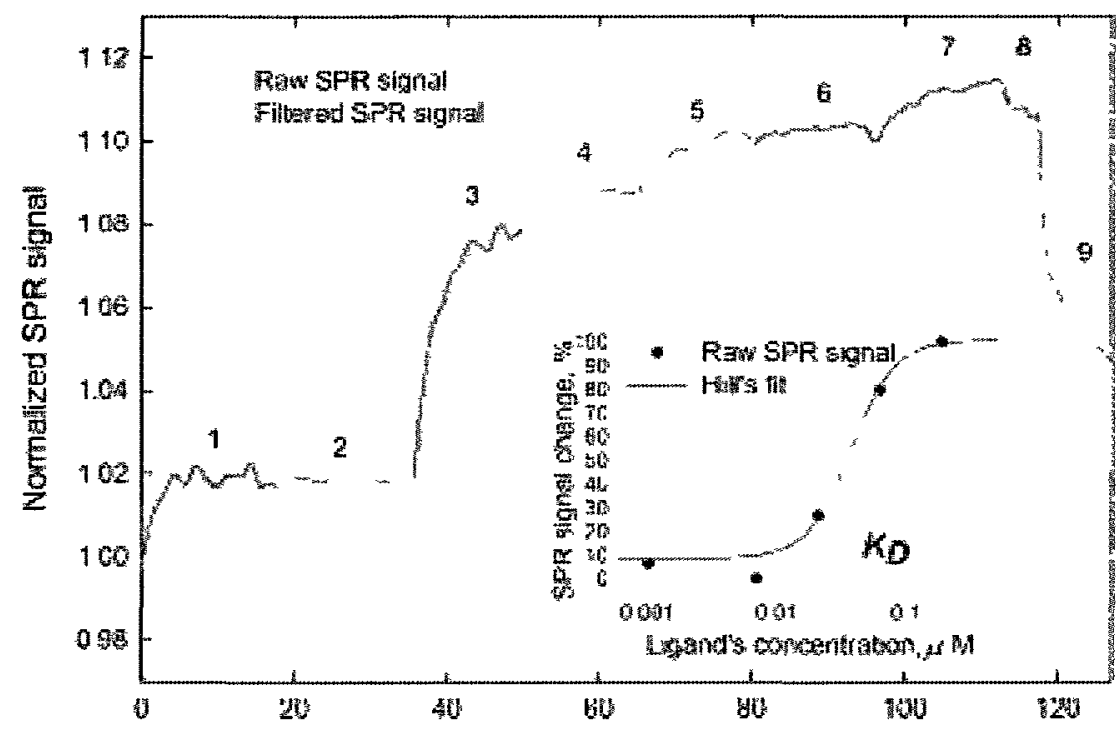

Figure 3.12: SPR signal change during the "Ladder" test. Steps were as follows: 1. MilliQ water; 2. DNA buffer; 3. Thrombin Aptamer, concentration $20 \mu \mathrm{M} ; 4$. Thrombin, concentration $0.1 \mu \mathrm{M} ; 5$. Thrombin, concentration $0.5 \mu \mathrm{M} ; 6$. Thrombin, concentration 1 $\mu \mathrm{M}$; 7. Thrombin, concentration $5 \mu \mathrm{M}$; 8. Protein buffer; 9. Regeneration in $0.2 \mathrm{M}$ $\mathrm{Na}_{2} \mathrm{CO}_{3}$. The data was normalized to the maximum of the SPR signal and was fitted using Hill's equation by Yanina Shevchenko. ${ }^{99}$ Reprinted with permission from Shevchenko, Y.; Francis, T. J.; Blair, D. A. D.; Walsh, R.; DeRosa, M. C.; Albert, J. In Situ Biosensing with a Surface Plasmon Resonance Fiber Grating Aptasensor. Anal. Chem. 2011, ASAP. Copyright 2011 American Chemical Society

The inset in Figure 3.12 illustrates the $K_{d}$ determination. The $K_{d}$ for the thrombin aptamer immobilized on the sensor surface was found to be $40 \pm 1 \mathrm{nM}$. As such, it can be concluded that attachment of the aptamer to the gold surface did not significantly affect the binding affinity between the aptamer and thrombin. Appendix 3.0 contains further $\mathrm{Kd}$ information. 


\subsection{Conclusions}

This study is the first of its kind to utilize a tilted fibre Bragg grating-SPR sensor. The results show that this sensor platform could be successfully applied to biosensing studies. As such it makes this platform an attractive alternative to existing biosensor platforms that rely on optical and non-optical transducing elements. Furthermore, this platform can be used for real-time quality control of sensor manufacturing, since the self assembly of the aptamer layer can be monitored. This system provided a robust detection scheme of thrombin in both buffer and more complex solutions such as serum. The signal difference between the specific and non-specific interactions remained the same regardless of the solution, which suggests several possibilities for future work in complex environments. Furthermore, the ability to detect the desired analyte in serum gives this platform an added practicality, as real-world samples will require the ability to detect targets in complex solutions. Also, the findings confirm that the biosensor can be applied for real time characterization of biorecognition element-target interactions, as well as multistep analysis such as dissociation constant determination. The $\mathrm{K}_{\mathrm{d}}$ constant was found to be $40 \pm 1 \mathrm{nM}$ which is well within the range of values already reported in the literature.

The findings found herein suggest that this sensor platform could be used for the in situ monitoring of biochemical interactions. As a result it can be concluded that this tilted fibre Bragg grating surface Plasmon resonance sensor is a viable alternative to current biosensor platforms. 


\section{Appendix 1.0: DNA analysis via ESI-Mass Spectrometry}

\section{A1.1 Introduction}

MS analysis plays a vital role in DNA analysis for the determination of confirmation, size, and purity of a given oligonucleotide. Electrospray Ionization Mass Spectrometry (ESI-MS) and matrix assisted laser desorption ionization time of flight mass spectrometry (MALDI-TOF-MS) are the cornerstone of DNA-MS analysis. This stems from the fact that ESI-MS and MALDI-TOF-MS are soft ionization techniques. As a consequence of this noncovalent complexes can now be investigated.

A1.1.1 Brief overview of the principles of ESI-MS

Electrospray Ionization mass spectrometry involves an aqueous sample solution, typically $1-10 \mu \mathrm{M}$ in concentration. ${ }^{100}$ The sample is then introduced to the ESI source via a syringe pump or liquid chromatograph. ${ }^{100}$ Following this, the first of three major steps takes place: the formation of charged droplets at the electrospray capillary. This capillary places a voltage across the sample solution. This electric field causes electrophoretic movement of the ions (in this case negatively charged nucleic acid strands) inside the liquid. ${ }^{100}$ The result is the emission of charged droplets at the end of the capillary. Following this the droplets travel to the mass spectrometer. As they travel they collide with ambient gas and begin to evaporate. ${ }^{100}$ As the solvent evaporates the ions become 
more concentrated. ${ }^{100}$ This concentration of charge eventually overcomes the cohesive forces holding the droplet together. The point at which this is reached is called the critical radius or Rayleigh limit. At this point the droplets explode (a process called Rayleigh Fission). ${ }^{100}$ This results in the production of smaller droplets which in turn evaporate and undergo a similar process forming smaller and smaller ion containing droplets. Following the charge residue model, this continues until a final droplet containing only the analyte ion (in this case a nucleic acid) and no residual solvent or counterions remains. ${ }^{100}$ Another factor to consider before beginning the ESI-MS analysis process is the polarity of the ions being formed. The spectrum may be collected in either negative or positive ion mode. Since it is known that the pKa of the phosphodiester backbone of DNA is less than 1.0 it can be said that the DNA is completely deprotonated in solution. ${ }^{100}$ As a result negative ion mode is utilized to conduct ESI-MS.

\section{A1.1.2 Purpose of this investigation}

The desire to develop an in-house oligonucleotide MS analysis method arises as a result of the costs of shipping and analyzing a sample out of house. Given that the principles behind the technique have been thoroughly reported it was considered possible to use an in house ESI-MS for the analysis for oligonucleotides. Described herein are the experimental protocol and the results of test strands used in proof-of-concept analysis. 


\section{A1.3 Experimental}

\section{A1.3.1 Sample Preparation}

The DNA sample was prepared using a Pepclean C18 Spin Column (Fisher Scientific). Two solutions were prepared: Solution A which was deionized water and solution B which was $70 \%$ acetonitrile in deionized water. A sample of DNA was dissolved in $\mathrm{H}_{2} \mathrm{O}$ such that the concentration was $\sim 10 \mu \mathrm{M}$ and volume was $150 \mu \mathrm{L}$. The spin column was loaded into an Eppendorf tube and the resin was activated by washing with $2 \times 200 \mu \mathrm{L}$ of solution $\mathrm{B}$ at $1500 \mathrm{~g}$ for 1 minute. Equilibration was conducted using $2 \times 200 \mu \mathrm{L}$ of solution A at $1500 \mathrm{~g}$ for 1 minute. After equilibration the DNA was loaded onto the resin by transferring the $150 \mu \mathrm{L}$ DNA sample onto the resin and spinning at $1500 \mathrm{~g}$ for 1 minute. The flow-through was collected and loaded onto the resin again to ensure complete loading of the DNA. The DNA was washed in two steps. First $300 \mu \mathrm{L}$ of concentrated EDTA was loaded onto the column and spun through at $1500 \mathrm{~g}$ for 1 minute. Second, $225 \mu \mathrm{L}$ of deionized water was used to wash the column. This was conducted at $1500 \mathrm{~g}$ for 1 minute. The sample was eluted using $3 \times 100 \mu \mathrm{L}$ acetonitrile at $1500 \mathrm{~g}$ for 1 minute. The sample was dried down, dissolved in deionized water $(\sim 200 \mu \mathrm{L})$, and quantified. 


\section{A1.3.2 Sample Analysis}

The DNA sample was either loaded onto a C18 resin in a fused silica column or loaded into a syringe. The column was attached to an HP $1090 \mathrm{LC}$ and eluted into the electrospray source using acetonitrile pumped in from the $\mathrm{LC}_{\mathrm{S}} \mathrm{SF}_{6}$ was used as the curtain gas to act as a proton scavenger. In the case where the syringe was used, it was loaded onto the syringe pump for injection into the QSTAR XL hybrid quadrupole time of flight mass spectrometer (AB Sciex, Foster City, CA). The ESI-MS spectra were collected and analyzed. 
A1.4 Results and Discussion of Test Samples

A series of test sequences were collected and used in the ESI-MS experiments.

-TOF MS 130 MCA scans fiom Sample 1 (neg fullscan 500 to 1800) of Regdouble 1 untf $t=356728898583341040$ e 004 to $=1$ 465267905211078 $10 e+001$

M3x 52280 counts

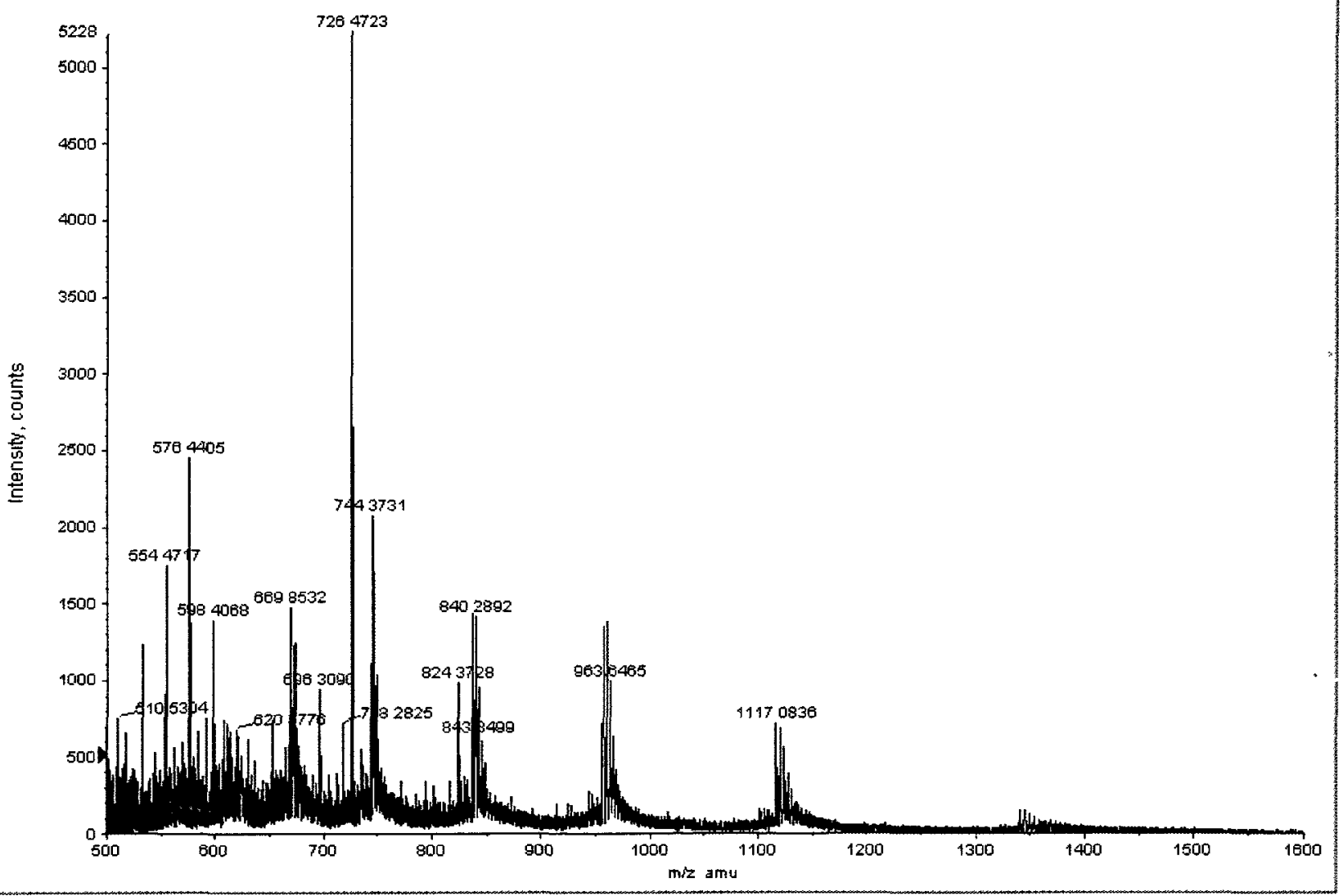

Figure A1.1: ESI-MS spectrum of the sequence TATAATTCGTTTTCGAATTATA collected using the syringe pump injection method

Figure A1.1 illustrates the mass spectrum collected. As can be seen from the figure, DNA was successfully observed over a series of charge states. 
OF MS 515 MCA scans from Sample 2 (DNA NHZ crude2) of ONA NH2 grude Mar 22010 wiff

$a=356728888583341040$ e 004 to $=14652 B 780521107010 e+001$

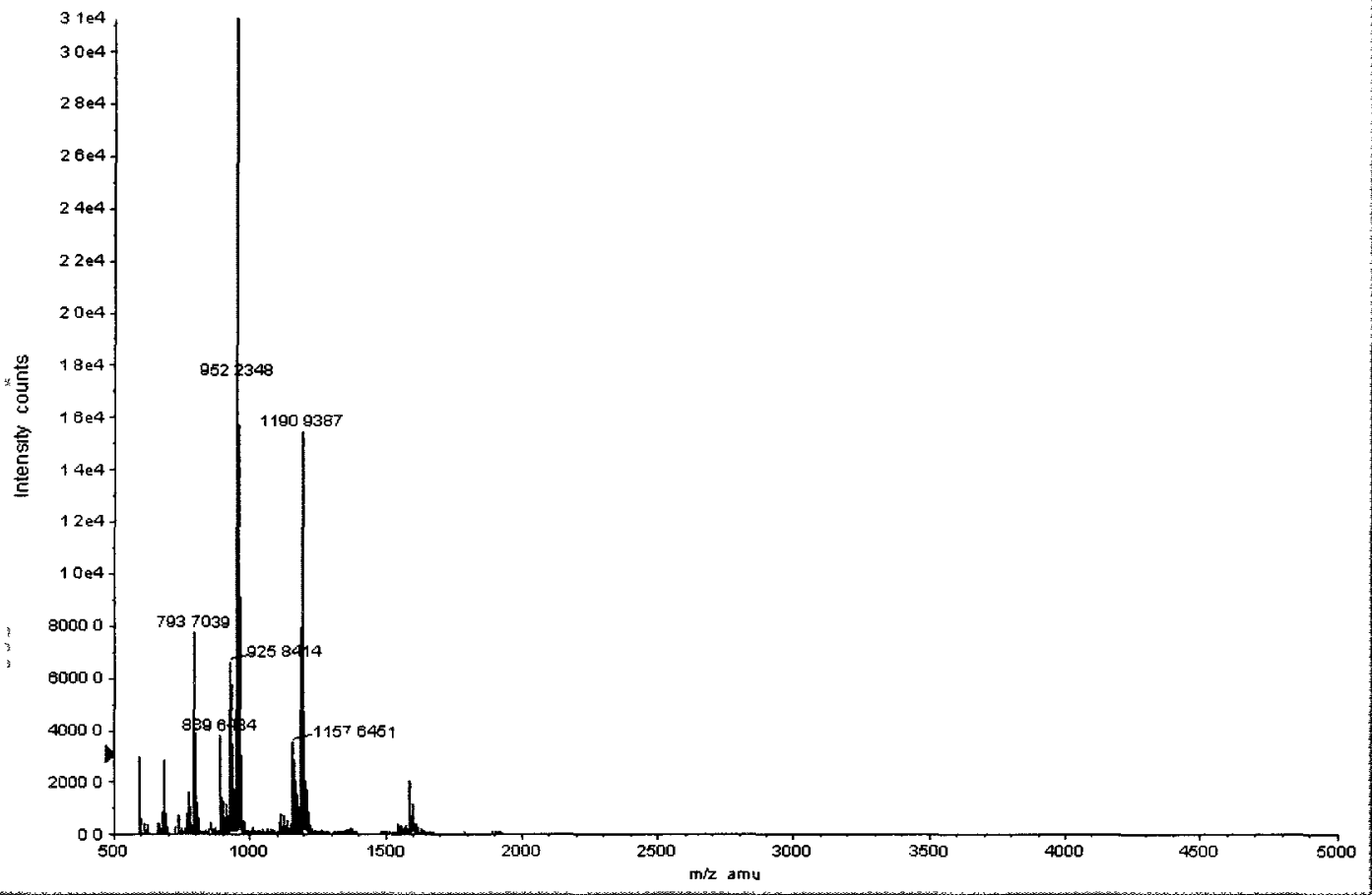

Figure A1.2: ESI-MS spectrum of the sequence $\mathrm{H}_{2} \mathrm{~N}-\left(\mathrm{CH}_{2}\right)_{6}-5^{\prime}$-ATG ATA GCA TCG GTC-3' collected using the C-18-fused silica column injection method

Figure A1.2 illustrates the results of using a C-18-fused silica column for injection. DNA can be observed with this method as with the method presented in Figure A1.1. The major difference between the two is the intensity of the spectrum. There is a better signal to noise ratio using the $\mathrm{C}-18$ column than using the syringe pump. It is believed that this is a result of having the DNA elute from the $\mathrm{C}-18$ column in a concentrated packet versus having it slowly enter the mass spectrometer in a more dilute fashion that the syringe pump provides. Deconvolution of both ESI-MS spectra were conducted in a similar fashion. 


$$
\begin{aligned}
& \text { Equation(1): } n=\frac{\left(m_{n-1}+1.008\right)}{\left(m_{n}-m_{n-1}\right)} \\
& \text { Equation(2): } M_{w}=n\left(m_{n}+1.008\right)
\end{aligned}
$$

First the charge state of a given peak was calculated using two adjacent peaks in the mass spectrum. Once a charge state was solved, the molecular weight of the ion was calculated using Equation 2. In the case of Figure A1.1 the expected mass was 6710Da. Using the method reported here, and the deconvolution formulas, a mass of 6707Da was determined. Figure A1.2 had an expected molecular weight of 4770 Da. What was found was $4767 \mathrm{Da}$. As can be seen, there is an error present in this approach either from the mass spectrometer or in the data analysis that is resulting in molecular weights that are 3 Da too light.

\section{A1.5 Conclusion}

Despite the error present on the mass calculation it can be concluded that this approach was successful. In order for this to be a practical in house method two criteria must be met. First, an ESI-MS dedicated to DNA analysis should be acquired. Second, the 'three Dalton' error has to be resolved. 
Appendix 2.0

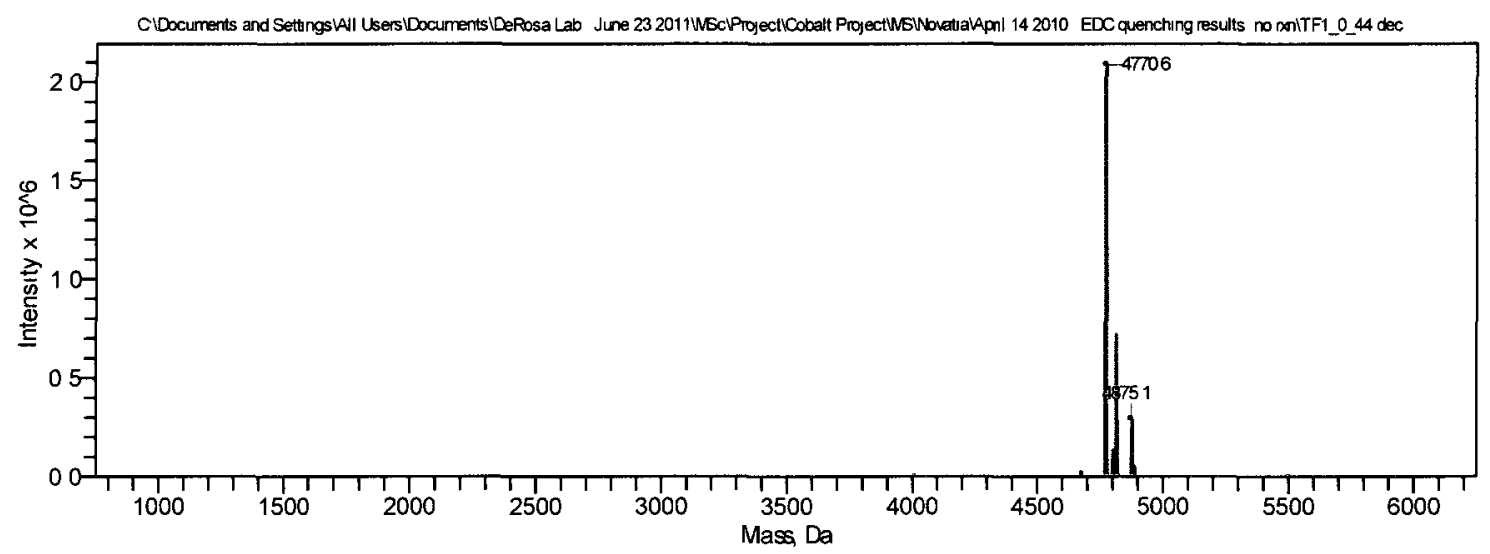

Figure A2.1: ESI-MS spectrum of the product of the EDC-NHS quenching reaction

As discussed briefly in section 2.3.2 an attempt was made to follow a protocol that called for the use of quenchers - specifically 2-Mercaptoethanol to quench the EDC step of the conjugation and Hydroxylamine to quench the NHS step of the conjugation reaction. Figure A2.1 is an ESI-MS with a predominate peak at $4770.6 \mathrm{Da}$ - this is unreacted sequence 1 DNA. As a result it was concluded that this method did not facilitate a successful conjugation between bpy' and $5 \mathrm{NH}_{2}$-DNA.

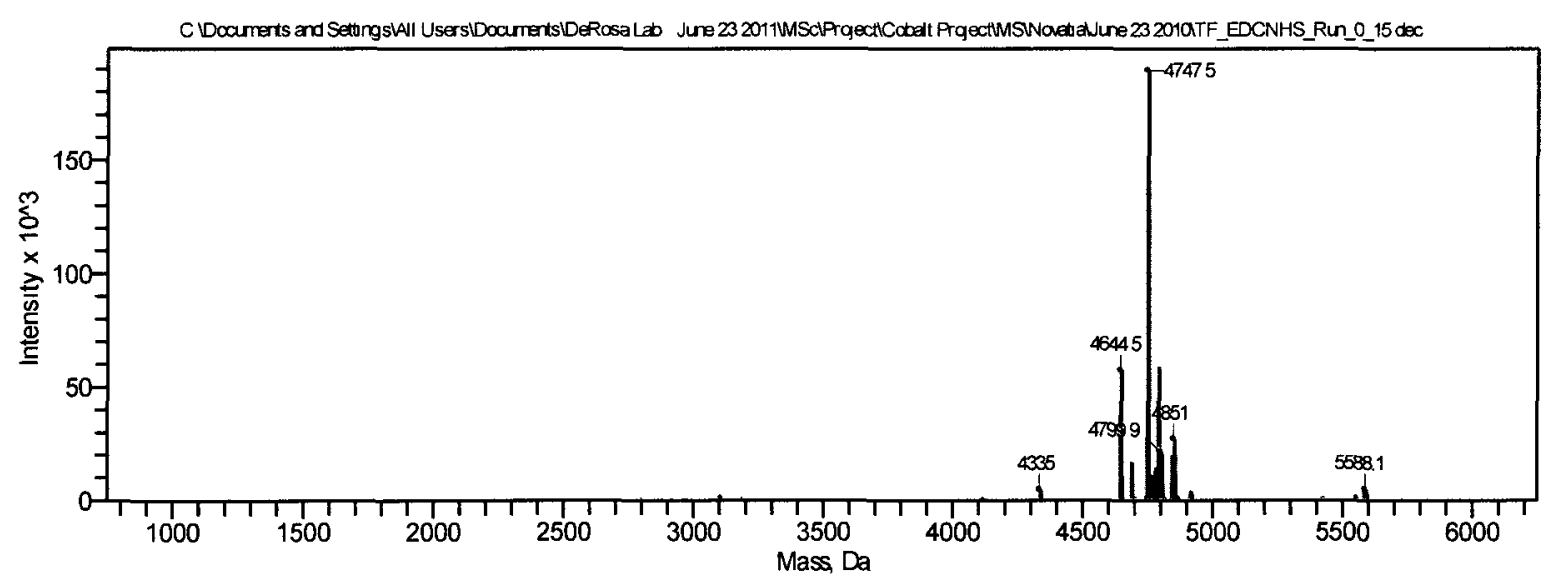

Figure A2.2: ESI-MS spectrum of the product of EDC-NHS reaction using TSTU-DIPEA conditions 
As mentioned in section 2.3.2, a conjugation attempt was made utilizing the same solvent system and conditions as the TSTU-DIPEA except with EDC-NHS in place of TSTU-DIPEA. Figure A2.2 shows the result of the reaction - unreacted sequence 2 DNA. The major product $-4747.5 \mathrm{Da}$ - corresponds to $5 \mathrm{NH}_{2}$-DNA. As a result it was concluded that this approach was unsuccessful.

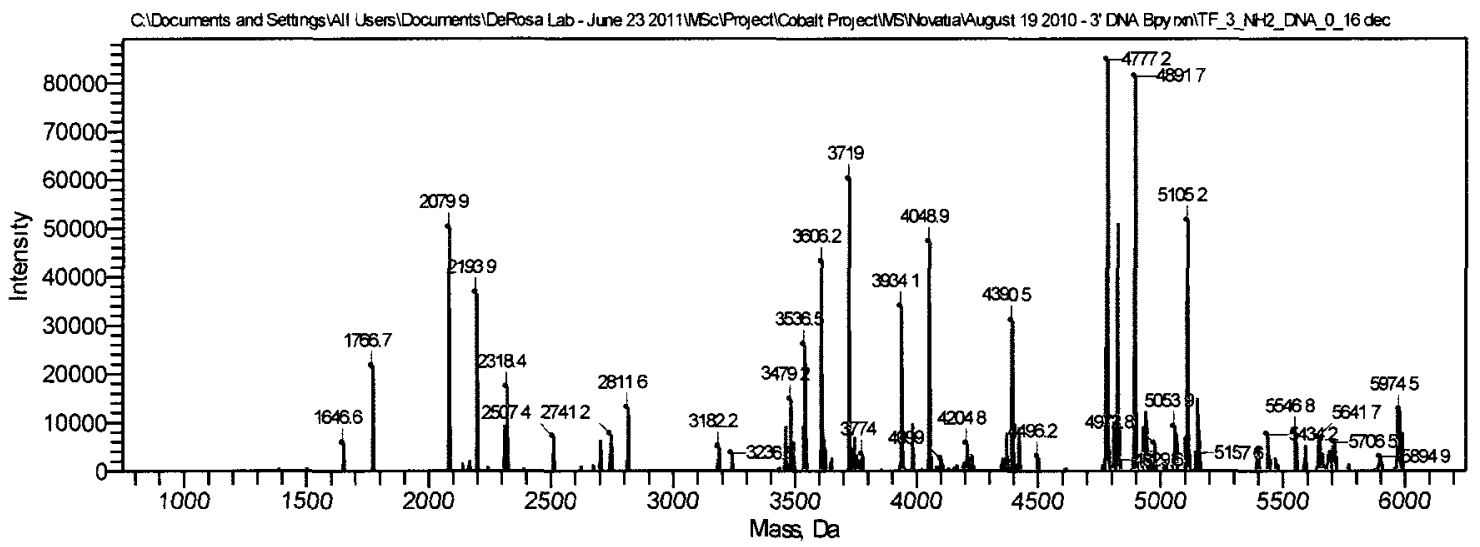

Figure A2.3: ESI-MS of the product of TSTU-DIPEA reaction using $3 \mathrm{NH}_{2}$-DNA (sequence 4)

As briefly discussed in section 2.3 .4 , a conjugation between $3{ }^{\prime} \mathrm{NH}_{2}-\mathrm{DNA}$ and bpy' was unsuccessful. Figure A2.3 illustrates the ESI-MS of such a reaction product. The expected molecular weights of conjugated product could not be discerned. 


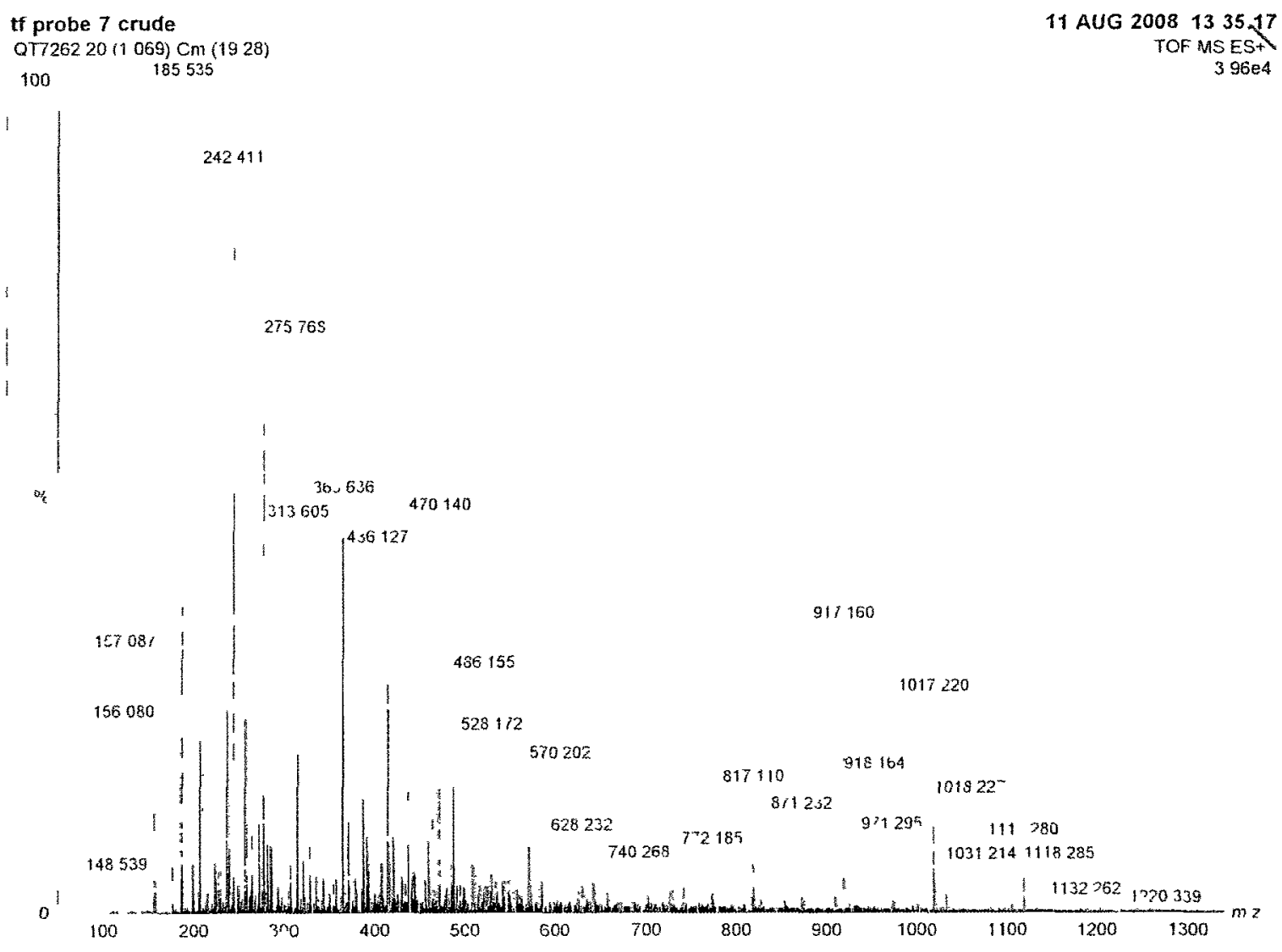

Figure A2.4: ESI-MS Spectrum of crude $\left[\mathrm{Co}(\mathrm{bpy})_{2} \mathrm{bpy}^{\prime}\right]\left(\mathrm{PF}_{6}\right)_{3}$

Figure A2.4 illustrates the ESI-MS discussed in Chapter 2.3.1. The peaks noted in Chapter 2.3.1 can be seen at 628.232Da, 772.185Da and 917.160Da. 


\section{Appendix 3.0}

A3.1 Additional Dissociation constant data

In order to ensure validity of the $K_{d}$ result, the $K_{d}$ study was reproduced several times. Figure A3.1 illustrates another ladder-type dissociation constant test.

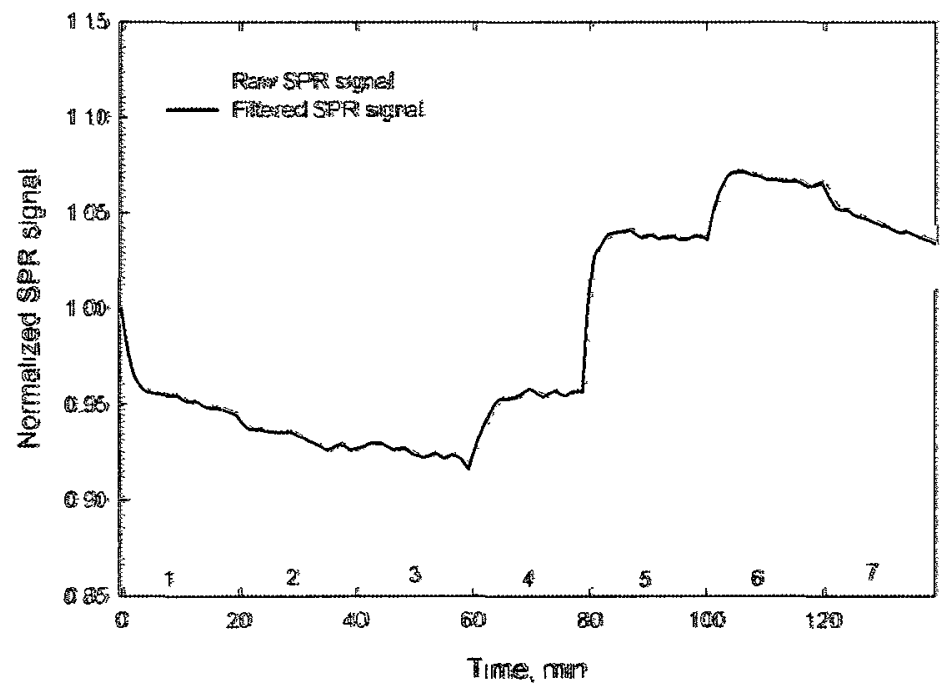

Figure A3.1: $K_{d}$ signal, raw data is shown along with smoothed data. Description of each step: 1. Protein Buffer; 2. Thrombin, concentration $0.00685 \mu \mathrm{M} ; 3$. Thrombin, concentration $0.0205 \mu \mathrm{M} ; 4$. Thrombin, concentration $0.0616 \mu \mathrm{M}$; 5. Thrombin, concentration $0.185 \mu \mathrm{M} ; 6$. Thrombin, concentration $0.55 \mu \mathrm{M} ; 7$. Thrombin, concentration $1.66 \mu \mathrm{M}$. Reprinted with permission from Shevchenko, Y.; Francis, T. J.; Blair, D. A. D.; Walsh, R.; DeRosa, M. C.; Albert, J. In Situ Biosensing with a Surface Plasmon Resonance Fiber Grating Aptasensor. Anal. Chem. 2011, ASAP. Copyright 2011 American Chemical Society 
A3.2 Information about fitting model used to calculate $K_{d}$ constant

Hill's equation has extensively been employed in pharmacology to study drug-receptor interaction. ${ }^{99}$ It has been applied to fit our experimental data presented in the Figure A3.1 and Figure 3.12 (Inset) to evaluate $K_{d}$ constant:

$$
y=y_{b}+\frac{a x^{b}}{c^{3}+x^{b}}
$$




\section{References}

(1) Mairal, T.; Cengiz Özalp, V.; Lozano Sánchez, P.; Mir, M.; Katakis, I.; O’Sullivan, C. K. Aptamers: molecular tools for analytical applications. Anal Bioanal Chem $\mathbf{2 0 0 8}$, 390, 989-1007.

(2) Hermann, T.; Patel, D. J. Adaptive Recognition by Nucleic Acid Aptamers. Science 2000, 287, 820-825.

(3) Tuerk, C.; Gold, L. Systematic Evolution of Ligands by Exponential Enrichment: RNA Ligands to Bacteriophage T4 DNA Polymerase. Science 1990, 249, 505-510.

(4) Ellington, A. D.; Szostak, J. W. In vitro selection of RNA molecules that bind specific ligands. Nature 1990, 346, 818-822.

(5) Keefe, A. D.; Pai, S.; Ellington, A. Aptamers as therapeutics. Nat Rev Drug Discov 2010, 9, 537-550.

(6) Bouchard, P. R.; Hutabarat, R. M.; Thompson, K. M. Discovery and Development of Therapeutic Aptamers. Annu. Rev. Pharmacol. Toxicol. 2010, 50, 237-257.

(7) Mayer, G. The Chemical Biology of Aptamers. Angewandte Chemie International Edition 2009, 48, 2672-2689.

(8) Keefe, A. D.; Schaub, R. G. Aptamers as candidate therapeutics for cardiovascular indications. Current Opinion in Pharmacology 2008, 8, 147-152.

(9) Lee, J. F.; Stovall, G. M.; Ellington, A. D. Aptamer therapeutics advance. Curr. Opin. Chem. Biol. 2006, 10, 282-289.

(10) Borisov, S. M.; Wolfbeis, O. S. Optical Biosensors. Chem. Rev. 2008, 108, 423-461.

(11) Sassolas, A.; Leca-Bouvier, B.; Blum, L. J. DNA Biosensors and Microarrays. Chem. Rev. 2008, 108, 109-139.

(12) Rimmele, M. Nucleic Acid Aptamers as Tools and Drugs: Recent Developments. ChemBioChem 2003, 4, 963-971.

(13) Li, Y.; Guo, L.; Zhang, Z.; Tang, J.; Xie, J. Recent advances of aptamer sensors. Science in China Series B: Chemistry 2008, 51, 193-204.

(14) Cole, J. R.; Dick, , Lawrence W.; Morgan, E. J.; McGown, L. B. Affinity Capture and Detection of Immunoglobulin E in Human Serum Using an Aptamer-Modified Surface in Matrix-Assisted Laser Desorption/Ionization Mass Spectrometry. Anal. Chem. 2007, 79, 273-279. 
(15) Null, E. L.; Lu, Y. Rapid determination of enantiomeric ratio using fluorescent DNA or RNA aptamers. Analyst 2010, 135, 419-422.

(16) Tuleuova, N.; Revzin, A. Micropatterning of Aptamer Beacons to Create CytokineSensing Surfaces. Cellular and Molecular Bioengineering 2010, 3, 337-344.

(17) Wu, C.; Yan, L.; Wang, C.; Lin, H.; Wang, C.; Chen, X.; Yang, C. J. A general excimer signaling approach for aptamer sensors. Biosensors and Bioelectronics 2010 , 25, 2232-2237.

(18) Carrasquilla, C.; Li, Y.; Brennan, J. D. Surface Immobilization of StructureSwitching DNA Aptamers on Macroporous Sol-Gel-Derived Films for Solid-Phase Biosensing Applications. Anal. Chem. 2011, 83, 957-965.

(19) He, J.; Wu, Z.; Zhou, H.; Wang, H.; Jiang, J.; Shen, G.; Yu, R. Fluorescence Aptameric Sensor for Strand Displacement Amplification Detection of Cocaine. Anal. Chem. 2010, 82, 1358-1364.

(20) Ouyang, X.; Yu, R.; Jin, J.; Li, J.; Yang, R.; Tan, W.; Yuan, J. New Strategy for Label-Free and Time-Resolved Luminescent Assay of Protein: Conjugate Eu3+ Complex and Aptamer-Wrapped Carbon Nanotubes. Anal. Chem. 2011, 83, 782-789.

(21) Huang, D.; Niu, C.; Qin, P.; Ruan, M.; Zeng, G. Time-resolved fluorescence aptamer-based sandwich assay for thrombin detection. Talanta 2010, 83, 185-189.

(22) Yang, C.; Wang, Y.; Marty, J.; Yang, X. Aptamer-based colorimetric biosensing of Ochratoxin A using unmodified gold nanoparticles indicator. Biosensors and Bioelectronics 2011, 26, 2724-2727.

(23) Stojanovic, M. N.; Landry, D. W. Aptamer-Based Colorimetric Probe for Cocaine. J. Am. Chem. Soc. 2002, 124, 9678-9679.

(24) Wang, W.; Wu, W.; Zhong, X.; Wang, W.; Miao, Q.; Zhu, J. Aptamer-based PDMSgold nanoparticle composite as a platform for visual detection of biomolecules with silver enhancement. Biosensors and Bioelectronics 2011, 26, 3110-3114.

(25) Gronewold, T. M. A.; Baumgartner, A.; Hierer, J.; Sierra, S.; Blind, M.; Schal’ fer, F.; Bluİ^mer, J.; Tillmann, T.; Kiwitz, A.; Kaiser, R.; Zabe-Kuì`hn, M.; Quandt, E.; Famulok, M. Kinetic Binding Analysis of Aptamers Targeting HIV-1 Proteins by a Combination of a Microbalance Array and Mass Spectrometry (MAMS). Journal of Proteome Research 2009, 8, 3568-3577.

(26) Guo, X.; Liu, Z.; Liu, S.; Bentzley, C. M.; Bruist, M. F. Structural Features of the 1Argininamide-Binding DNA Aptamer Studied with ESI-FTMS. Anal. Chem. 2006, $78,7259-7266$. 
(27) Dick, L. W.; McGown, L. B. Aptamer-Enhanced Laser Desorption/Ionization for Affinity Mass Spectrometry. Anal. Chem. 2004, 76, 3037-3041.

(28) Hianik, T.; Wang, J. Electrochemical Aptasensors - Recent Achievements and Perspectives. Electroanalysis 2009, 21, 1223-1235.

(29) Garcia, D. E.; Chen, T.; Wei, F.; Ho, C. A Parametric Design Study of an Electrochemical Sensor. JALA 2010, 15, 179-188.

(30) Ahmed, M. U.; Hossain, M. M.; Tamiya, E. Electrochemical Biosensors for Medical and Food Applications. Electroanalysis 2008, 20, 616-626.

(31) Stradiotto, N. R.; Yamanaka, H.; Zanoni, M. V. B. Electrochemical Sensors: A Powerful Tool in Analytical Chemistry. J. Braz. Chem. Soc. 2003, 14, 159-173.

(32) Sassolas, A.; Blum, L. J.; Leca-Bouvier, B. Electrochemical Aptasensors. Electroanalysis 2009, 21, 1237-1250.

(33) White, R. J.; Plaxco, K. W. Exploiting Binding-Induced Changes in Probe Flexibility for the Optimization of Electrochemical Biosensors. Anal. Chem. 2010, 82, 73-76.

(34) Rodríguez, M. C.; Rivas, G. A. Label-free electrochemical aptasensor for the detection of lysozyme. Talanta 2009, 78, 212-216.

(35) Kim, Y.; Kim, Y.; Niazi, J.; Gu, M. Electrochemical aptasensor for tetracycline detection. Bioprocess and Biosystems Engineering 2010, 33, 31-37.

(36) Wu, Z.; Zheng, F.; Shen, G.; Yu, R. A hairpin aptamer-based electrochemical biosensing platform for the sensitive detection of proteins. Biomaterials 2009, 30, 2950-2955.

(37) Chen, J.; Zhang, J.; Li, J.; Yang, H.; Fu, F.; Chen, G. An ultrasensitive signal-on electrochemical aptasensor via target-induced conjunction of split aptamer fragments. Biosensors and Bioelectronics 2010, 25, 996-1000.

(38) Xiao, Y.; Piorek, B. D.; Plaxco, K. W.; Heeger, A. J. A Reagentless Signal-On Architecture for Electronic, Aptamer-Based Sensors via Target-Induced Strand Displacement. J. Am. Chem. Soc. 2005, 127, 17990-17991.

(39) D'Orazio, P. Biosensors in clinical chemistry. Clinica Chimica Acta 2003, 334, 4169.

(40) Leung, A.; Shankar, P. M.; Mutharasan, R. A review of fiber-optic biosensors. Sensors Actuators B: Chem. 2007, 125, 688-703. 
(41) Gopinath, S. C. B. Biosensing applications of surface plasmon resonance-based Biacore technology. Sensors Actuators B: Chem. 2010, 150, 722-733.

(42) Polonschii, C.; David, S.; Tombelli, S.; Mascini, M.; Gheorghiu, M. A novel lowcost and easy to develop functionalization platform. Case study: Aptamer-based detection of thrombin by surface plasmon resonance. Talanta 2010, 80, 2157-2164.

(43) Lautner, G.; Balogh, Z.; Bardoczy, V.; Meszaros, T.; Gyurcsanyi, R. E. Aptamerbased biochips for label-free detection of plant virus coat proteins by SPR imaging. Analyst 2010, 135, 918-926.

(44) Blackburn, G. M. In Nucleic acids in chemistry and biology; RSC Pub: Cambridge, UK, 2006; .

(45) Beaucage, S. L.; Caruthers, M. H. Deoxynucleoside phosphoramidites--A new class of key intermediates for deoxypolynucleotide synthesis. Tetrahedron Lett. 1981, 22, $1859-1862$.

(46) Bard, A. J.; Faulkner, L. R. In Electrochemical methods : fundamentals and applications; Wiley: New York, 2001; .

(47) Sawyer, D. T.; Sobkowiak, A.; Roberts, J. L.; Sawyer, D. T. In Electrochemistry for chemists; Wiley: New York, 1995; .

(48) Brett, C. M. A.; Brett, A. M. O. In Electrochemistry : principles, methods, and applications; Oxford science publications. Oxford University Press: Oxford ; New York, 1993; .

(49) Bagotsky, V. S. In Fundamentals of electrochemistry; The Electrochemical Society series. Wiley-Interscience: Hoboken, N.J, 2006; .

(50) Wang, J. In Analytical electrochemistry; Wiley-VCH: New York, 2000; .

(51) Scholz, F. B.,A.M. In Electroanalytical methods guide to experiments and applications /; Fritz Scholz, e., with contributions by A.M.Bond ...[et al.]., Eds.; Heidelberg ;New York : Springer, c2010: 2010; .

(52) Hill, M. G.; Kelley, S. O. In Chapter 5 Electrochemistry at the DNA/Electrode Interface: New Approaches to Nucleic Acids Biosensing; Hammerich, O., Ulstrup, J., Eds.; Bioinorganic Electrochemistry; Springer Netherlands: Dordrecht, The Netherlands, 2008; pp 129-160.

(53) Ferapontova, E.,E. Electrochemical Indicators for DNA Electroanalysis. Current Analytical Chemistry 2011, 7, 51-62. 
(54) Ferapontova, E. E.; Olsen, E. M.; Gothelf, K. V. An RNA Aptamer-Based Electrochemical Biosensor for Detection of Theophylline in Serum. J. Am. Chem. Soc. 2008, 130, 4256-4258.

(55) Doménech-Carbó, A.; Torres, F. J.; Alarcón, J. Electrochemical characterization of cobalt cordierites attached to paraffin-impregnated graphite electrodes. J Solid State Electrochem 2004, 8, 127-137.

(56) Medina, R. M.; Moreno, C.; Marcos, M. L.; Castro, J. A.; Benito, F.; Arnanz, A.; Delgado, S.; Gonzalez-Velasco, J.; Macazaga, M. J. Syntheses, structures and electrochemical study of $\pi$-acetylene complexes of cobalt. Inorg. Chim. Acta 2004, 357, 2069-2080.

(57) Jiang, X.; Guo, L.; Du, X. Electrochemistry and electrocatalysis of binuclear cobalt phthalocyaninehexasulfonate-surfactant film modified electrode. Talanta 2003, 61, 247-256.

(58) Ceres, D. M.; Barton, J. K. In Situ Scanning Tunneling Microscopy of DNAModified Gold Surfaces: Bias and Mismatch Dependence. J. Am. Chem. Soc. 2003, $125,14964-14965$.

(59) Yang, D.; Morin, M. Chronoamperometric study of the reduction of chemisorbed thiols on $\mathrm{Au}(111)$. J Electroanal Chem 1997, 429, 1-5.

(60) Shin-ichiro Imabayashi; Iida, M.; Hobara, D.; Zhi, Q. F.; Niki, K.; Kakiuchi, T. Reductive desorption of carboxylic-acid-terminated alkanethiol monolayers from $\mathrm{Au}(111)$ surfaces. J Electroanal Chem 1997, 428, 33-38.

(61) Love, J. C.; Estroff, L. A.; Kriebel, J. K.; Nuzzo, R. G.; Whitesides, G. M. SelfAssembled Monolayers of Thiolates on Metals as a Form of Nanotechnology. Chem. Rev. 2005, 105, 1103-1170.

(62) Miessler, G. L.; Tarr, D. A. In Inorganic chemistry; Pearson/Prentice Hall: Upper Saddle River, N.J, 2004; .

(63) Davis, F.; Higson, S. P. J. Structured thin films as functional components within biosensors. Biosensors and Bioelectronics 2005, 21, 1-20.

(64) Poe, D. P. Relationship between reduction potentials and mixing constants of mixedligand complexes. Inorg. Chem. 1988, 27, 1280-1283.

(65) Della Ciana, L.; Hamachi, I.; Meyer, T. J. Synthesis of side-chain derivatives of 2,2'bipyridine. J. Org. Chem. 1989, 54, 1731-1735.

(66) Francis, T. Development of a Cobalt Reporter Probe Complex for Use in Electrochemical Aptasensing, BSc. Thesis. Carleton University, Ottawa, 2008. 
(67) Ghosh, S.; Barve, A. C.; Kumbhar, A. A.; Kumbhar, A. S.; Puranik, V. G.; Datar, P. A.; Sonawane, U. B.; Joshi, R. R. Synthesis, characterization, X-ray structure and DNA photocleavage by cis-dichloro bis(diimine) Co(III) complexes. J. Inorg. Biochem. 2006, 100,331-343.

(68) Vlcek, A. A. Preparation of Co(dipy) $2 X 2+$ complexes (X- = chloride, bromide, iodide, nitrite) by controlled oxidative processes. Inorg. Chem. 1967, 6, 1425-1427.

(69) Blair, D. A. D. Aptamer-based Sensors: Developing Electrochemical and Surface Plasmon Resonance Sensors Using Aptamers as Target Recognition Elements, MSc. Thesis, Carleton University, Ottawa, 2008.

(70) Ge, B.; Huang, Y.; Sen, D.; Yu, H. Electrochemical investigation of DNA-modified surfaces: From quantitation methods to experimental conditions. J Electroanal Chem 2007, 602, 156-162.

(71) Yu, H.; Luo, C.; Sankar, C. G.; Sen, D. Voltammetric Procedure for Examining DNA-Modified Surfaces: Quantitation, Cationic Binding Activity, and ElectronTransfer Kinetics. Anal. Chem. 2003, 75, 3902-3907.

(72) Wei, K.; Wu, C.; Huang, W.; Lin, J.; Dai, S. A. N-Aryl Acylureas as Intermediates in Sequential Self-Repetitive Reactions To Form Poly(amide-imide)s. Macromolecules 2006, 39, 12-14.

(73) Pottorf, R. S.; Szeto, P. In 1-Ethyl-3-(3ф-dimethylaminopropyl)carbodiimide Hydrochloride; e-EROS Encyclopedia of Reagents for Organic Synthesis; John Wiley and Sons Ltd.: 2001; .

(74) Narendra, N.; Chennakrishnareddy, G.; Sureshbabu, V. V. Application of carbodiimide mediated Lossen rearrangement for the synthesis of [small alpha]ureidopeptides and peptidyl ureas employing $\mathrm{N}$-urethane [small alpha]amino/peptidyl hydroxamic acids. Org. Biomol. Chem. 2009, 7, 3520-3526.

(75) Isidro-Llobet, A.; Just-Baringo, X.; Ewenson, A.; Alvarez, M.; Albericio, F. Fmoc2-mercaptobenzothiazole, for the introduction of the Fmoc moiety free of sidereactions. Biopolymers 2007, 88, 733-737.

(76) Posthumus, W.; Derksen, A. J.; van, d. G.; Hesselmans, L. C. J. Crosslinking by polycarbodiimides. Progress in Organic Coatings 2007, 58, 231-236.

(77) Wilchek, M.; Knudsen, K. L.; Miron, T. Improved Method for Preparing NHydroxysuccinimide Ester-Containing Polymers for Affinity Chromatography. Bioconjug. Chem. 1994, 5, 491-492.

(78) Valeur, E.; Bradley, M. Amide bond formation: beyond the myth of coupling reagents. Chem. Soc. Rev. 2009, 38, 606-631. 
(79) Holmlin, R. E.; Dandliker, P. J.; Barton, J. K. Synthesis of Metallointercalator-DNA Conjugates on a Solid Support. Bioconjug. Chem. 1999, 10, 1122-1130.

(80) Homola, J.; Yee, S. S.; Myszka, D. In Surface Plasmon Resonance Biosensors; Frances S. Ligler, Chris A. Rowe Taitt, Eds.; Optical Biosensors; Elsevier Science: Amsterdam, 2002; pp 207-251.

(81) Goff, D. R.; Hansen, K. S. In Fiber optic reference guide : a practical guide to the technology; Focal Press: Boston, 1999; .

(82) Othonos, A.; Kalli, K. In Fiber Bragg gratings : fundamentals and applications in telecommunications and sensing; Artech House optoelectronics library. Artech House: Boston, Mass, 1999; .

(83) Hill, K.; Fujii, Y.; Johnson, D.; Kawasaki, B. Photosensitivity in optical fiber waveguides: Application to reflection filter fabrication. Appl. Phys. Lett. 1978, 32, 647-649.

(84) Fan, X.; White, I. M.; Shopova, S. I.; Zhu, H.; Suter, J. D.; Sun, Y. Sensitive optical biosensors for unlabeled targets: A review. Anal. Chim. Acta 2008, 620, 8-26.

(85) Lee, B. Review of the present status of optical fiber sensors. Optical Fiber Technology 2003, 9, 57-79.

(86) Tuan Guo; Chengkun Chen; Laronche, A.; Albert, J. Power-Referenced and Temperature-Calibrated Optical Fiber Refractometer. Photonics Technology Letters, IEEE 2008, 20, 635-637.

(87) Shevchenko, Y. Y.; Albert, J. Plasmon resonances in gold-coated tilted fiber Bragg gratings. Opt. Lett. 2007, 32, 211-213.

(88) Tennico, Y. H.; Hutanu, D.; Koesdjojo, M. T.; Bartel, C. M.; Remcho, V. T. OnChip Aptamer-Based Sandwich Assay for Thrombin Detection Employing Magnetic Beads and Quantum Dots. Anal. Chem. 2010, 82, 5591-5597.

(89) Shevchenko, Y.; Ahamad, N. U.; Ianoul, A.; Albert, J. In situ monitoring of the formation of nanoscale polyelectrolyte coatings on optical fibers using Surface Plasmon Resonances. Opt. Express 2010, 18, 20409-20421.

(90) Ellman, G. L. Tissue sulfhydryl groups. Arch. Biochem. Biophys. 1959, 82, 70-77.

(91) Rahman, M. A.; Son, J. I.; Won, M.; Shim, Y. Gold Nanoparticles Doped Conducting Polymer Nanorod Electrodes: Ferrocene Catalyzed Aptamer-Based Thrombin Immunosensor. Anal. Chem. 2009, 81, 6604-6611. 
(92) Bode, W.; Turk, D.; Karshikov, A. The refined 1.9-A X-ray crystal structure of DPhe-Pro-Arg chloromethylketone-inhibited human alpha-thrombin: Structure analysis, overall structure, electrostatic properties, detailed active-site geometry, and structure-function relationships. Protein Science 1992, 1, 426-471.

(93) Jeon, S. H.; Kayhan, B.; Ben-Yedidia, T.; Arnon, R. A DNA Aptamer Prevents Influenza Infection by Blocking the Receptor Binding Region of the Viral Hemagglutinin. J. Biol. Chem. 2004, 279, 48410-48419.

(94) Vial, J.; Jardy, A. Experimental Comparison of the Different Approaches To Estimate LOD and LOQ of an HPLC Method. Anal. Chem. 1999, 71, 2672-2677.

(95) Pollet, J.; Delport, F.; Janssen, K. P. F.; Jans, K.; Maes, G.; Pfeiffer, H.; Wevers, M.; Lammertyn, J. Fiber optic SPR biosensing of DNA hybridization and DNA-protein interactions. Biosensors and Bioelectronics 2009, 25, 864-869.

(96) Bock, L. C.; Griffin, L. C.; Latham, J. A.; Vermaas, E. H.; Toole, J. J. Selection of single-stranded DNA molecules that bind and inhibit human thrombin. Nature 1992, $355,564-566$.

(97) Hamaguchi, N.; Ellington, A.; Stanton, M. Aptamer Beacons for the Direct Detection of Proteins. Anal. Biochem. 2001, 294, 126-131.

(98) Jing, M.; Bowser, M. T. Methods for measuring aptamer-protein equilibria: A review. Anal. Chim. Acta 2011, 686, 9-18.

(99) Bode, W.; Mayr, I.; Baumann, U.; Huber, R.; Stone, S. R.; Hofsteenge, J. The refined 1.9 A crystal structure of human alpha-thrombin: interaction with D-Phe-ProArg chloromethylketone and significance of the Tyr-Pro-Pro-Trp insertion segment. The EMBO Journal 1989, 8, 3467-3475.

(100) Rosu, F.; De Pauw, E.; Gabelica, V. Electrospray mass spectrometry to study drugnucleic acids interactions. Biochimie 2008, 90, 1074-1087. 